$L A--9560-M$

DE83 003993
LA-9560-M

Manual

UC-32

Issued: October 1982

\title{
User's Manual for HDR3 Computer Code
}

Connie J. Arundale*

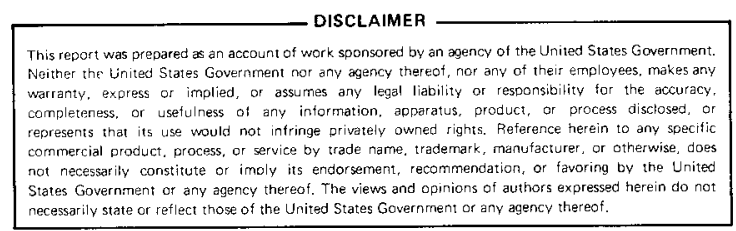

NOTICE

PORTIONS OF THIS REPORT ARE ILLEGIBLE. It has been reproduced from the best available copy to permit the broadest possible availability.

\section{MN ONLY}

*Graduate Research Assistant. Economics Department, University of New Mexico, Albuquerque, New Mexico 87131.

$$
\text { Contract } \omega-7405 \text {-ENG. } 36 \text {. }
$$

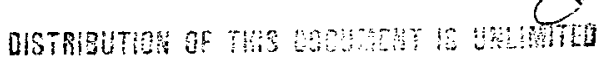




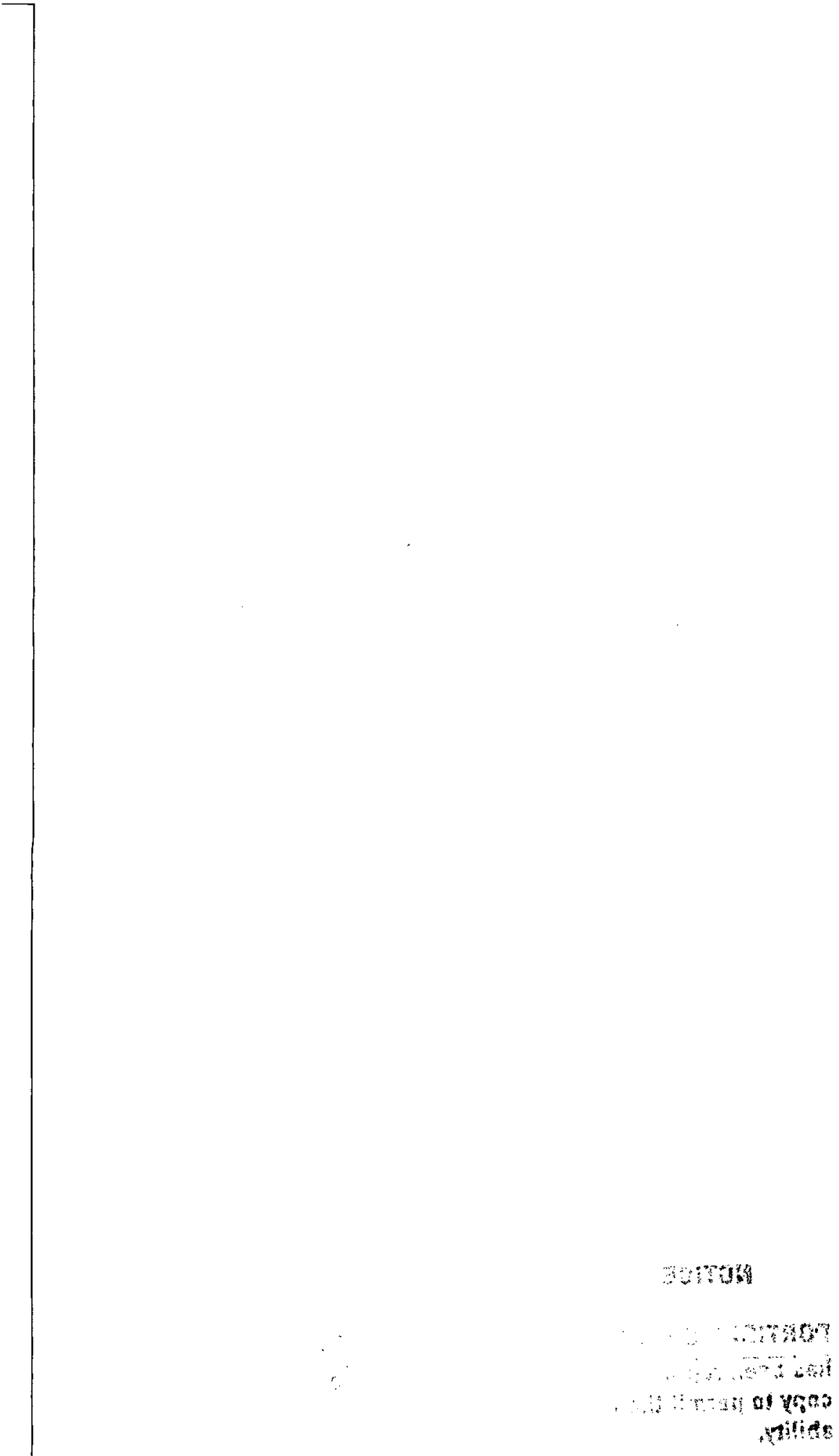

11 


\section{DISCLAIMER}

This report was prepared as an account of work sponsored by an agency of the United States Government. Neither the United States Government nor any agency Thereof, nor any of their employees, makes any warranty, express or implied, or assumes any legal liability or responsibility for the accuracy, completeness, or usefulness of any information, apparatus, product, or process disclosed, or represents that its use would not infringe privately owned rights. Reference herein to any specific commercial product, process, or service by trade name, trademark, manufacturer, or otherwise does not necessarily constitute or imply its endorsement, recommendation, or favoring by the United States Government or any agency thereof. The views and opinions of authors expressed herein do not necessarily state or reflect those of the United States Government or any agency thereof. 


\section{DISCLAIMER}

Portions of this document may be illegible in electronic image products. Images are produced from the best available original document. 
USER'S MANUAL FOR HDR3 COMPUTER CODE

by

Connie J. Arundale

\begin{abstract}
A description of the HDR3 computer code and instructions for its use are provided. HDR3 calculates space heating costs for a hot dry rock (HDR) geothermal space heating system. The code also compares these costs to those of a specific oil heating system in use at the National Aeronautics and Space Administration Flight Center at Wallops Island, Virginia. HDR3 allows many HDR system parameters to be varied so that the user may examine various reservoir management schemes and may optimize reservoir design to suit a particular set of geophysical and economic parameters.
\end{abstract}

\title{
I. INTRODUCTION
}

The HDR3 computer code, given various parametric values, calculates the total reservoir cost of space heating using hot dry rock geothermal resources (HDR) under various assumptions. The code presently contains no considerations for surface distribution system costs, exploration and development costs, or tax considerations, as it was developed for use in a case study of the NASA Wallops Flight Center (WFC) at Wallops Island, Virginia. A steam distribution system already existed at WFC for which alterations and extensions to the hot water system were being made. It was an advantageous choice also because previous exploration work had been done in the area, and as a government installation, tax considerations were irrelevant. Current $\mathrm{plans}$ include extension of the model for situations where it is necessary to consider the factors mentioned above. 
Two drilling cost alternatives are used in HDR3. The first, denoted throughout as RGICOST, is based on a study by Republic Geothermal, Inc., and is best described as a step-type function dependent on the depth of drilling and other technical and geographical variables. RGICOST values are not determined in HDR3, but enter as input provided by a companion program, RGICOST, and translated to proper form by two programs, WRITEPP and FILEIT. Instructions for use of all four programs is given in Sec. III.

GEOCOST, the second drilling cost alternative, is an exponential function based on information obtained from Battelle Memorial Institute.* GEOCOST values are computed in a subroutine of HDR3 where depth of drilling is the only variable. Rock hardness determines the choice of a function, and it was assumed for this study that all permeable rock is of medium hardness and impermeable rock is hard (the choices were soft, medium, medium hard, or hard). Section II details the function and the changes required for different rock hardnesses.

The three drilling strategy options used to determine total costs with both RGICOST and GEOCOST are: (1) redrilling to the same depth, thereby restoring the original reservoir heat content, (2) redrilling to deeper depths, creating a hotter reservoir than that resulting from initial drilling, and (3) a preheat option. The preheat option compares the cost of restoring the reservoir by using (1), when temperatures therein fall below design temperature, with the cost of heating the water to design temperature using conventional fuels. The lesser of the two costs in each period is used to compute total costs for this option.

Given other parameters, HDR3 is designed to loop on various initial drilling depths, real discount rates, drilling cost increase factors, and fuel cost increase factors. The parameters include the number of fractures, required annual Btus, design temperatures, geothermal gradient, time horizon, and the difference between entrance and exit temperatures through the surface system heat exchanger. These values are all contained in the input file LOOPON, which is discussed in greater detail in Sec. III.

Given the parametric values described above, the model computes initial reservoir temperature and drilling costs. Subroutine FLOW then calculates

*This information supplied by Linda Fosbender of Battelle in a telephone conversation on June 18, 1981. 
temperature drawdown in every year and compares yearly temperatures to design temperature. When the latter equals or exceeds the former, present value costs are computed under each of the drilling strategy options and the process repeats. This continues until the end of the time horizon is reached, at which time the present value of each redrilling is summed with initial drilling costs, resulting in total reservoir costs.

HDR3 also calculates benefits resulting from the use of HDR for space heat. Benefits are defined as avoided costs or the cost of using conventional fuels (and existing systems) to provide the same heat. Net benefits, total benefits minus total costs, are computed for each of the three drilling strategy options and are reported with cost results.

The following sections of this report deal with the functions used in the program, instructions for use of HDR3 and its companion programs, and an example of how the program works for a particular set of assumptions. A description of the major functions found in the program is given in Sec. II. Section III deals with the mechanics of running HDR3, RGICOST, FILEIT, and WRITEPP. It also details changes required in various input files to change parametric values. The final section, Sec. IV, includes a sample output from a run of HDR3 and explains the results. The programs and input files are contained in the Appendix.

\section{MAJOR FUNCTIONS USED IN HDR3}

\section{A. Calculation of Surface System Flow Rate}

The flow rate of water through the surface system is a function of the total Btus required per hour and the difference, $\Delta T$, between the temperature that water enters a heat exchanger and the temperature at which it exits. The equation

$$
\text { gal } / \mathrm{min}=(B t u / h) /\left(500 \times \Delta T^{0} F\right)
$$

is used to compute the surface system flow rate (SMDOT). A number of conversions are necessary as SMDOT is expressed in units of kilograms per second, and our parameters include required Btu/year and $\Delta T$ in degrees centigrade. The conversions used are 


$$
\begin{array}{ll}
1 \text { gal } \mathrm{H}_{2} \mathrm{O} & =3.779 \mathrm{~kg} \mathrm{H} \mathrm{H}_{2} \\
\Delta \mathrm{T}^{\mathrm{O}} \mathrm{F} & =1.8 \Delta \mathrm{T}^{\circ} \mathrm{C} \\
1 \text { min } & =60 \mathrm{~s} \\
1 \text { year } & =8760 \mathrm{~h} .
\end{array}
$$

The resulting function is

$$
\text { SMDOT }=(\text { HDRBTU *3.779) } /(\text { DELT } \times 500 \times 8760 \times 60 \times 1.8),
$$

where

$$
\begin{aligned}
& \text { HDRBTU }=\text { required } B \text { tu/year, and } \\
& \text { DELT }=\Delta T^{\circ} \mathrm{C} .
\end{aligned}
$$

B. Rock Temperatures Resulting from Drilling

The temperature of the rock reached by drilling is a function of the depth of drilling (D), the geothermal temperature gradient (GR), and the temperature of the rock at the depth of basement rock (DB). In our case study of WFC, the temperature of the rock (TDB) at $9000 \mathrm{ft}$, the depth of basement, was given as $90^{\circ} \mathrm{C}$. This would change for other depths of basement rock.

The temperature resulting from drilling is given then as

$$
T R O C K=T D B+(D-D B) \times G R .
$$

Should the temperature at depth of basement rock not be known, well temperatures may be approximated using the following equation:

$$
\text { TROCK }=15.0+D \times G R,
$$

where $15^{\circ} \mathrm{C}$ is the rock temperature at the surface (before any depth is accomplished).

\section{Reservoir System Flow Rate}

To obtain the flow rate necessary for the surface system and the heat extraction rate $(\Delta T)$, given a minimum water temperature (design temperature, TD) at which the heating system can operate, it is necessary to mix water from 
the reservoir with water at the surface whenever reservoir temperatures exceed the design temperatures. To determine the rate of flow of water through the reservoir, the importance of which is discussed in a later section on temperature drawdown, several calculations are required. The first is the calculation of the temperature of water reinjected into the reservoir (TINJ), which is simply

$$
\text { TINJ = TD - DELT } .
$$

This results because water flowing through the surface system is maintained at design temperature and is reinjected in the reservoir once heat has been extracted from it (DELT $=\Delta T^{\circ} \mathrm{C}$ ).

To maintain design temperature through the surface system water from the reservoir is mixed with water at reinjection temperature once it reaches the surface. In order to maintain system equilibrium, it is required that

SMDOT $\times$ TD $=($ MDOT $\times T)+($ XMDOT $\times$ TINJ $)$

and

$$
\text { SMDOT }=\text { MDOT }+ \text { XMDOT },
$$

where

$$
\begin{aligned}
\text { MDOT }= & \text { flow rate of water from reservoir at temperature } T, \\
\text { XMDOT }= & \text { flow rate of water mixed at surface at temperature TINJ, and } \\
\text { SMDOT }= & \text { flow rate of water through surface system at design temperature, } \\
& \text { TD. }
\end{aligned}
$$

To calculate the flow rate through the reservoir, the above equation is al tered as follows.

$$
\begin{aligned}
& \text { SMDOT } \times \text { TD }=(\text { MDOT } \times T)+(\text { XMDOT } \times \text { TINJ }) \cdot \\
& \text { SMDOT } \times \text { TD }=(\text { MDOT } \times T)+(\text { SMDOT }- \text { MDOT }) \times T I N J . \\
& M D O T(T-\text { TINJ })=\text { SMDOT }(T D-\text { TINJ }) .
\end{aligned}
$$




$$
\text { MDOT }=\operatorname{SMDOT}(T D-T I N J) /(T-T I N J)
$$

The last equation is the form that is used in HDR3.

\section{Temperature Drawdown}

As water flows through the reservoir system, heat is transferred from the rock to the water. As a result, the rock gradually cools over time. The cooling process was accounted for in our model in the following way.

$$
T_{t+1}=T_{i n j}+\left(T_{\text {rock }}-T_{i n j}\right) \operatorname{erF}\left(Z_{t}\right) \text {, }
$$

where

$$
\begin{aligned}
T_{t+1}= & \text { rock temperature at beginning of year } t+1 \text { (or end of year } t \text { ), } \\
T_{\text {inj }}= & \text { temperature of water reinjected into the reservoir (constant), } \\
& \text { and } \\
T_{\text {rock }}= & \text { rock temperature reached when drilling was completed (before } \\
& \text { any cooling resulted from water flowing through the reservoir). }
\end{aligned}
$$

$$
\operatorname{erF}\left(z_{t}\right)=\text { error function of } z_{t}=\frac{2}{\sqrt{\pi}} \int_{0}^{Z} e^{-x^{2}} d x \text {, }
$$

where

$$
z_{t}=\sqrt{\frac{\lambda \rho C_{r}}{t^{\prime}}}\left(\frac{\pi R^{2} N F}{\pi_{t} C_{w}}\right)
$$

and where

$$
\begin{aligned}
\pi R^{2}= & \text { area of one fracture }\left(\mathrm{m}^{2}\right), \\
N F= & \text { number of fractures, } \\
C_{W}= & \text { heat capacity of water }=4200 \mathrm{~J} / \mathrm{kg} \cdot \mathrm{K}, \\
C_{r}= & \text { heat capacity of granite }=1000 \mathrm{~J} / \mathrm{kg} \cdot \mathrm{K}, \\
\dot{m}_{t}= & \text { water mass flow rate through the reservoir system in year } t \\
& (\mathrm{~kg} / \mathrm{s}),
\end{aligned}
$$




$$
\begin{aligned}
& t^{\prime}=\text { time (seconds) }=t \times 31536000, \\
& \lambda=\text { thermal conductivity of granite }=3.0 \mathrm{~W} / \mathrm{mK} \text {, and } \\
& \rho=\text { rock density } \sim 2500 \mathrm{~kg} / \mathrm{m}^{3} .
\end{aligned}
$$

Several means of obtaining values of the function erf $\left(z_{t}\right)$ were available for use in our model. One method employed the Tables of the Error Function and Its Derivative (US Department of Commerce, National Bureau of Standards Applied Mathematics Series, No. 41, October 22, 1954), which gave values accurate to fifteen decimal places. Using a power series, a second method was to compute values of the function or an asymptotic expansion for large values of $z_{t}$. The second method was used in our analysis, although resulting values in several runs were checked against the tables to guarantee accuracy. The computational algorithms we used are detailed below.

For large values of $z_{t}$, erf $\left(z_{t}\right)$ may be advantageously computed from the following asymptotic expansion:

$1-\operatorname{erf}\left(z_{t}\right) \sim \frac{2}{\sqrt{\pi}} \frac{e^{-z_{t}^{2}}}{2 z_{t}}\left[1-\frac{1}{2 z_{t}^{2}}+\frac{1 \times 3}{\left(2 z_{t}^{2}\right)^{2}}-\frac{1 \times 3 \times 5}{\left(2 z_{t}^{2}\right)^{3}}+\frac{1 \times 3 \times 5 \times 7}{\left(2 z_{t}^{2}\right)^{4}}-\ldots\right]$.

In our model when $z_{t}$ was equal to or greater than two, the following expression was used.

$$
\begin{aligned}
\operatorname{erf}\left(z_{t}\right)=1 & -\left\{\frac { e ^ { - z _ { t } ^ { 2 } } } { z _ { t } \sqrt { \pi } } \left[1-\frac{1}{2 z_{t}^{2}}+\frac{1 \times 3}{\left(2 z_{t}^{2}\right)^{2}}-\frac{1 \times 3 \times 5}{\left(2 z_{t}^{2}\right)^{3}}+\frac{1 \times 3 \times 5 \times 7}{\left(2 z_{t}^{2}\right)^{4}}\right.\right. \\
& \left.\left.-\frac{1 \times 3 \times 5 \times 7 \times 9}{\left(2 z_{t}^{2}\right)^{5}}\right]\right\}
\end{aligned}
$$

The true value of $\operatorname{erf}\left(z_{t}\right)$ lies somewhere between the value calculated above and the value that would result from adding one more term to the series. Therefore, the error in the above calculation must be less than 


$$
\frac{e^{-z_{t}^{2}}}{z_{t} \sqrt{\pi}}\left[\frac{1 \times 3 \times 5 \times 7 \times 9 \times 11}{\left(2 z_{t}^{2}\right)^{6}}\right]
$$

If $z_{t}=2$, the error would not exceed $2 \times 10^{-4}$. For values of $z_{t}$ equat to 3 and 4 , the error would be less than $6.9 \times 10^{-9}$ and $1.5 \times 10^{-13}$, respectively. This meant that all computations of erf $\left(z_{t}\right)$ for values of $Z \geq 2$ were accurate to at least three decimal places, which was appropriate for our analysis.

For values of $Z_{t}$ less than two, the calculations of erf $\left(z_{t}\right)$ were made from the power series

$$
\operatorname{erf}\left(z_{t}\right)=\frac{2}{\sqrt{\pi}}\left(z-\frac{z^{3}}{1.3}+\frac{z^{5}}{2.5}-\frac{z^{7}}{3.7}+\frac{z^{9}}{4 ! 9}-\ldots\right)
$$

This series was carried as far as necessary for each $z_{t}$ in our model to guarantee accuracy to three decimal places.

This method of computing temperature drawdown in the reservoir has a major weakness that tends to overestimate the temperature loss in every year except in years when drilling occurs. This results because $\operatorname{erf}\left(z_{t}\right)$ assumes that the same flow rate through the reservoir (MDOT) occurred in all previous years as in the year in question. As reservoir temperatures decrease, reservoir system flow rates increase each year. Because these flow rates enter in the denominator of the calculation of $Z_{t}$, larger flow rates lead to smaller $Z_{t} s$ and, therefore, smaller erf $\left(z_{t}\right) s$. This relationship would not present any bias if the larger flow rate used in any year had also been used in previous years, but because MDOT increases in every year (when redrilling does not occur) a bias does exist. We are currently attempting to determine a function free of such bias, but until that determination is made, the bias does exist and causes overestimation of temperature drawdown in most years.

\section{E. GEOCOST}

In HDR3 all values for GEOCOST are calculated in a subroutine of the same name. As mentioned previously, we assumed that permeable rock was of medium 
hardness while impermeable rock was hard. The following functions were then used to compute costs.

$$
\begin{aligned}
& \text { Cost (medium) }=116.0894471 \mathrm{e}^{0.951723819 \times \text { Depth }} \\
& \text { Cost }\left(\text { hard) }=121.9627943 \mathrm{e}^{1.130093484 \times \text { Depth }}\right.
\end{aligned}
$$

To determine total costs, using the first equation, one calculates the cost of drilling through the permeable section and adds the cost of drilling through the impermeable section, multiples this sum by two (because the functions are for one well, and we need costs for a well pair) and then adds the cost of fracturing. The cost for the impermeable drilling is computed as follows (using the second equation): Cost to total depth - Cost to a depth which is the boundary between permeable and impermeable. Fracturing costs were given as $\$ 70000$ times the number of fractures.

Should different rock hardnesses be assumed, the following functions may be used in place of the two above:

$$
\begin{array}{ll}
\text { Cost (medium hard) } & =117.7297704 \mathrm{e}^{1.057297303 \times \text { Depth }} \\
\text { Cost }(\text { soft }) & =108.4796579 \mathrm{e}^{0.8729852 \times \text { Depth }}
\end{array}
$$

\section{F. Preheat Calculations}

HDR3 computes the costs resulting from the preheat option in the subroutine HEAT. This subroutine calculates the number of Btus required to heat reservoir water to design temperature and the cost of doing so using conventional fuels (in our case \#6 oil). This is done by first calculating required Btu/s from the following equation:

$$
B t u / s=[\text { MDOT } \times 4200 \times(\text { TD }- \text { TAVG })] / 1054,
$$

where

$$
\begin{aligned}
\text { MDOT } & =\text { SMDOT }=\text { reservoir flow rate as no mixing is done, } \\
4200 & =\text { heat capacity of water, } \\
\text { TD } & =\text { design temperature, } \\
\text { TAVG } & =\text { reservoir temperature at the middle of the year } \\
& =\left(T_{t}+T_{t+1}\right) / 2, \text { and, } \\
1054 & =\text { number of } B t u / J .
\end{aligned}
$$


The resulting value is multiplied by $3.1536 \times 10^{7}$ to convert to Btu/year and by 1.27 to account for boiler and feed water losses. This is the total yearly Btu requirement. The number of barrels of oil required per year is calculated by dividing that requirement by $144000 \times 42$, where 144000 is the Btu content of a gallon of \#6 $0 i 1$, and 42 is the number of gallons per barrel. To obtain present value costs, it is then only necessary to multiply by the cost of a barrel of oil and discount this value using the ratio of the fuel cost increase factor to the real discount rate.

\section{INSTRUCTIONS FOR USE OF HDR3 AND COMPANION PROGRAMS}

To run HDR3* it is first necessary to create a drilling cost file, WICST, where _ denotes the number of fractures in the reservoir, that is, WICST3 is the RGICOST file for three fractures. This involves the use of three companion programs, RGICOST, WRITEPP, and FILEIT. Copies of each are contained in the Appendix, and descriptions and directions for their use are given below.

RGICOST is the program that calculates HDR drilling costs according to Republic Geothermal, Inc.'s (RGI) cost simulation procedure. 1 It performs a series of table look-ups in calculating well programs and cost components. To do this, 12 data files are called while the program is running. The first of these, PP, is a file containing all parameters relevant to the case under study. The remaining 11 files contain tables found in the RGI manual and must be present in the user's library when RGICOST is run. These tables, their allocated unit number within the program, and their relation to tables in the RGI manual are as follows.

(1) TABLES3--opened and allocated to Unit 1 by RGICOST--contains data specified in Tables $3.1,3.2$, and 3.3 of the RGI manual.

(2) Tl1P2--Unit 2, Table 11.2.

(3) T5P3--Unit 4, Tables 5.3A and 5.3B.

(4) T7P1--Unit 5, Table 7.1 .

(5) TGP1--Unit 7, Table G.1.

(6) TGP2--Unit 8, Table G.2.

(7) TGP3--Unit 9, Table G.3.

(8) TGP4--Unit 10, Table G.4.

(9) T4P3--Unit 14, Table 4.3.

Æprogram names are denoted by underscored capital letters, whereas data files are denoted simply by capitals. 
(10) T5P1--Unit 15, Table 5.1.

(11) TGP8--Unit 16, Table G.8.

As mentioned above, the data file PP contains the site- and studyspecific parameters needed for RGI cost runs. It is opened and allocated to Unit 18 by the program and is the only file the user need change to run RGICOST. The data in the file are read in free format, but must be entered on $\mathrm{PP}$ in the following order.

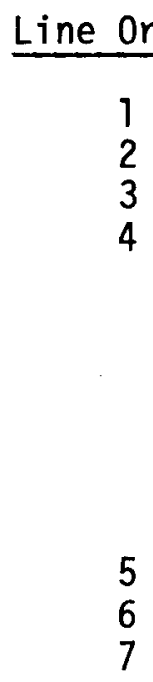

\section{Line Contents}

number of parameter runs.

SD SDM LLP LFP LPT LRE LWS.

NF HF ALPHA BETA TD WWD GRAD.

CLASS STATE REMOTE TECH.

NOTE: lines 2-4 contain parameters relevant for each parameter run. If the number of parameter runs (line 1) is greater than one, values for these parameters must be given for each run following line 1 (that is, if line 1 is 3 , lines $2-10$ would contain this information, where 1 ines 2-4 correspond to the first run, 5-7 to the second, and 8-10 to the third). CF1 CF2.

number of depth tests.

TEMPD P.

NOTE: if the number of depth tests is greater than one, lines must be added after 7 for each depth and permeable-section depth to be tested.

Variable Names on PP

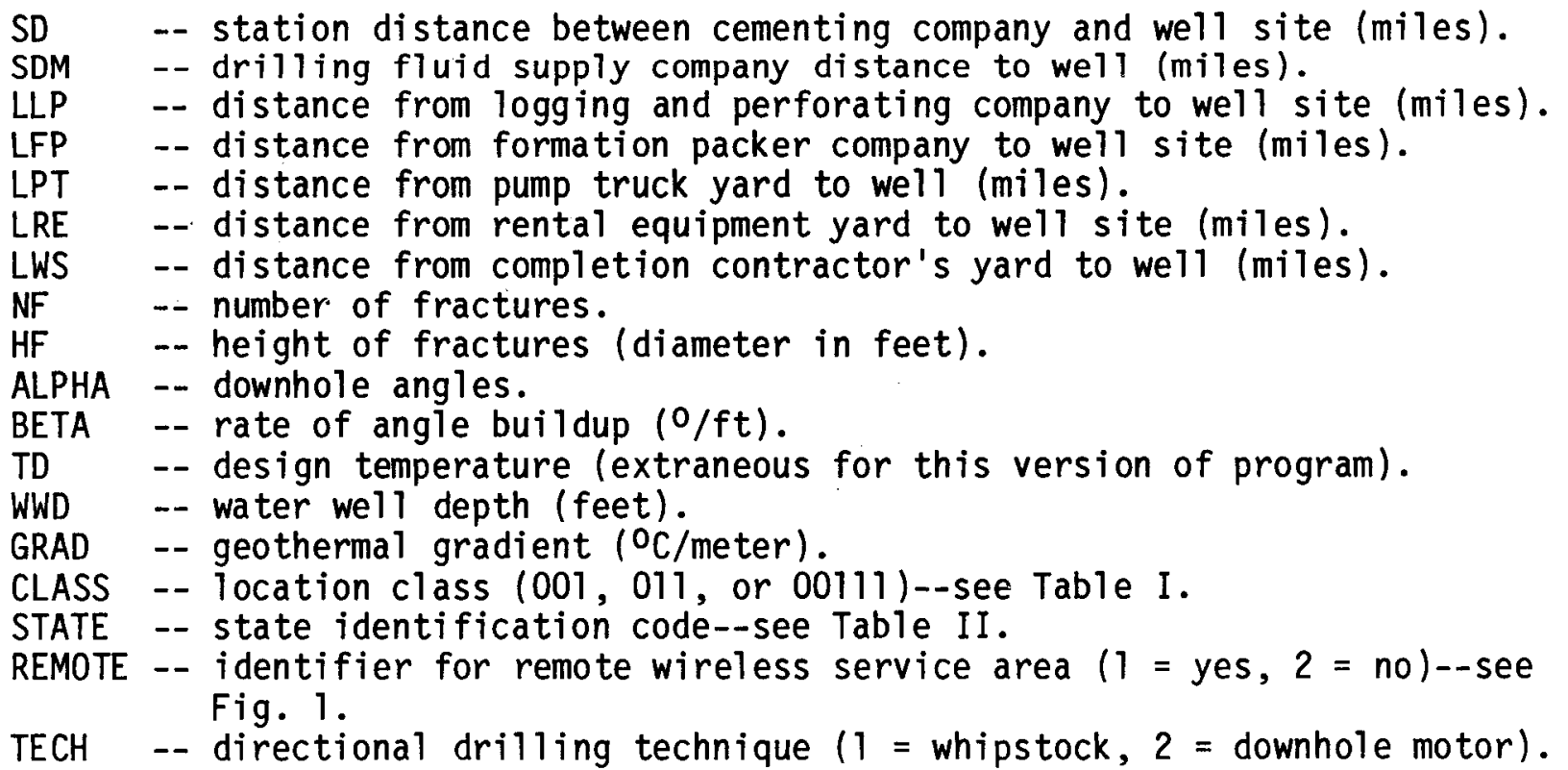


TABLE I

WELL LOCATION CLASSIF ICATIONS

$\frac{\text { Class }}{\text { I }} \frac{\text { Terrain }}{\begin{array}{l}\text { Level to gently } \\ \text { rolling }\end{array}}$

IIa. Foothill and mountain--site selected to minimize cut and fill

b. Level to gently rolling

IIIa. Hillside location requiring extensive cut and fill

b. Foothill and mountain--site selected to minimize cut and fill
Soil
Relatively stable, no blasting or ripping re- quired, road building material, e.g., gravel or clay, available with- in 20 miles
Stable, some blasting or ripping required
OR
Relatively stable, no blasting or ripping re- quired, road building material, e.g., gravel or clay available within 20 miles

Stable, some blasting or ripping required

OR

Stable, some blasting or ripping required
Environmental

Sensitivity

Norma1

Normal
High, requiring lined reserve pit and more stringent compaction provisions

Normal
High, requiring lined reserve pit, more stringent drainage and compaction provisions, and noise abatement

OR

c. Shallow water or
very unstable location requiring built-up or boarded location

Unstable--fill material (if Normal required) available within 20 miles 


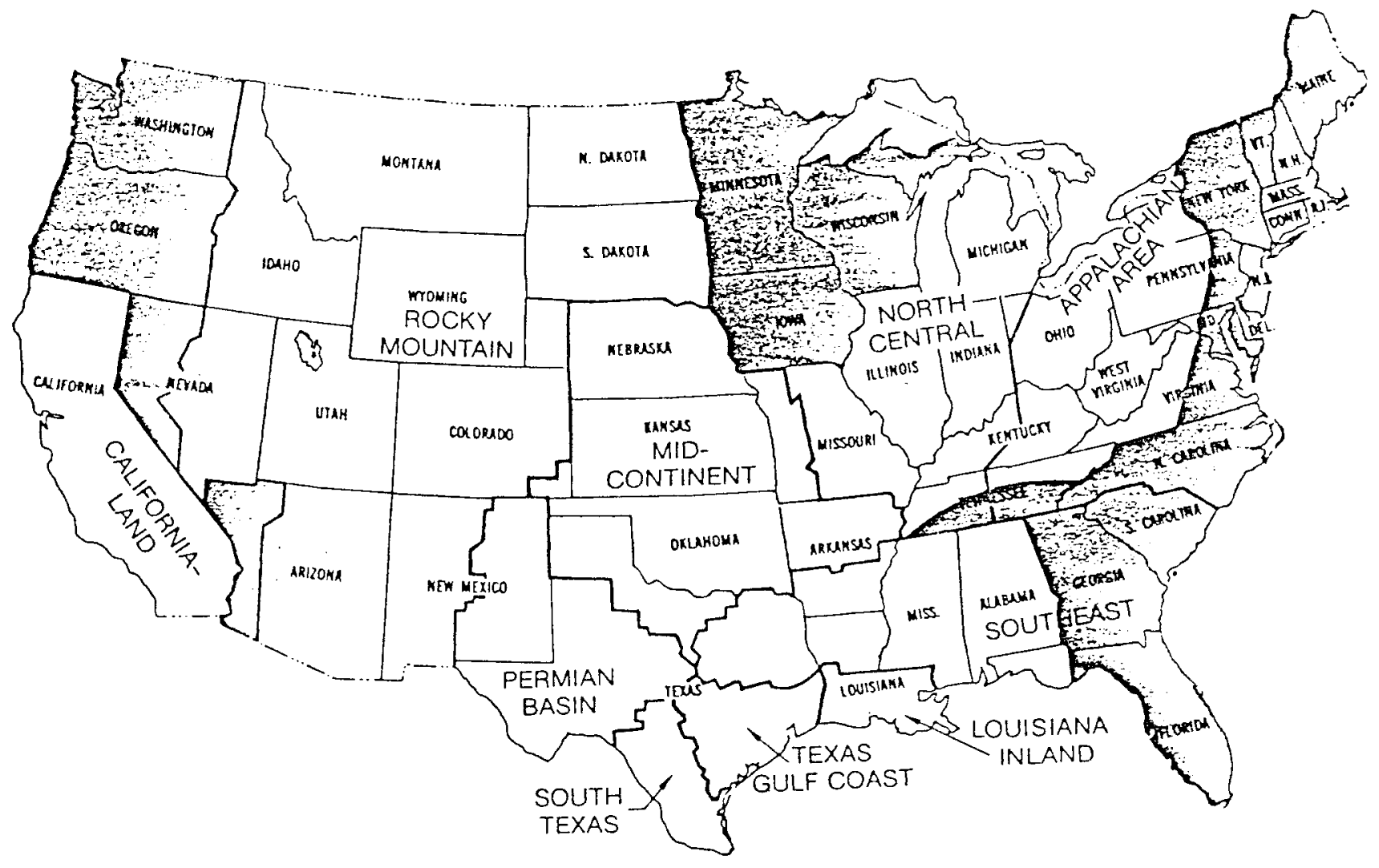

SOURCE: Schlumberger Well Services.

Fig. 1. Remote wireline service areas. Shaded areas are considered remote service areas.

TABLE II

STATE AND STATE IDENTIFICATION CODES
$\mathrm{AL}=1$
$\mathrm{GA}=11$
$M D=21$
$N M=31$
$S D=41$
$A K=2$
$M A=22$
$N Y=32$
$T N=42$
$A Z=3$
$\begin{aligned} H I & =12 \\ I D & =13\end{aligned}$
$M I=23$
$N C=33$
$T X=43$
$A R=4$
$\mathrm{IL}=14$
$\mathrm{ND}=34$
$U T=44$
$C A=5$
IN $=15$
$M S=24$
$\mathrm{OH}=35$
$V T=45$
$\mathrm{CO}=6$
$M O=25$
$O K=36$
$V A=46$
$C T=7$
$N B=27$
$O R=37$
$W A=47$
$\mathrm{DE}=8$
$K S=17$
$P A=38$
$W V=48$
$D C=9$
$N V=28$
$L A=19$
$\mathrm{NH}=29$
$R I=39$
$W I=49$
$F L=10$
$M E=20$
$\mathrm{NJ}=30$
$S C=40$
$W Y=50$ 

CFl -- cost contingency factor on drilling rig time in permeable section (decimal notation).*
CF2 -- cost contingency factor on drilling rig time in impermeable section (decimal notation).*
TEMPD -- temperature depth** (feet).
P -. depth to basement (permeable section) (feet).

Three output files must be created to receive results from RGICOST. These are (1) TOTAL, for final cost results; (2) COST, for intermediate cost results; and (3) WELL, for well specification information. The program is currently set up to print only final costs. If more detailed information is desired, lines 553 (for well specifications) and/or 554 (for intermediate costs) in RGICOST must be changed by deleting the "c" (for comment) in column 1. This change allows the subroutines that print these results to be called. To obtain copies of any results one must then only load and list the pertinent file.

To facilitate the creation of cost files called by HDR3, two other programs were written. The first, WRITEPP, creates the parameter file PP, called by RGICOST, which was discussed above. FILEIT, the second program, takes final cost results from the file TOTAL and transforms them to proper format and location, resulting in RGI drilling cost files, WICST_ (where, again, the _ denotes the number of fractures).

WRITEPP may be used when all parameters besides number and height of fractures, drilling cost contingency factors, and depth of drilling and permeable section depth are held constant. An initial file, PARAMS, which contains the same data (in the same order) as the first four lines of the file

*The cost contingency factor on drilling rig time has been respecified since the time that the cost runs for "The Use of Hot Dry Rock Geothermal Resources for Space Heating: A Case Study," Cumming et al., Los Alamos National Laboratory, October 1981, were made.2 Those runs were made using $50 \%$ for permeable sections and $15 \%$ for impermeable, but resulted in lower cost figures than results in runs using the same cost contingency factors according to the new specification. It was found that previously the factors affected only normal drilling time (then rather indirectly), and no allowance was made for time required for directional drilling.

** The temperature depth should not be equated with either vertical depth or measured depth, as it is the depth to the reservoir temperature center. RGICOST uses this depth and number and height of fractures to calculate vertical and measured depths. This was done to simplify data entry, as the depth with which we are concerned is the temperature depth, that is, the depth required at the center of the reservoir to reach a given temperature at that point, this being the average temperature of the entire reservoir. 
PP must be constructed by the user. Running WRITEPP will then create the file PP by reading PARAMS, duplicating the unchanged portions, and adding any changed parameters and a series of depth tests. It is set up to take an initial depth, calculate the additional depth needed for each of a specified number of redrillings (via the deeper depth strategy), and then repeat the process for a depth equal to the initial depth plus a specified interval. One may request as many initial depths as needed, but the program automatically stops when depths greater than $23000 \mathrm{ft} 122000 \mathrm{ft}$ for more than four fractures) are reached, as RGICOST cannot calculate costs associated with deeper drilling.

To run WRITEPP, one must change lines 5-13 to correspond with one's desired parameters (as shown below).

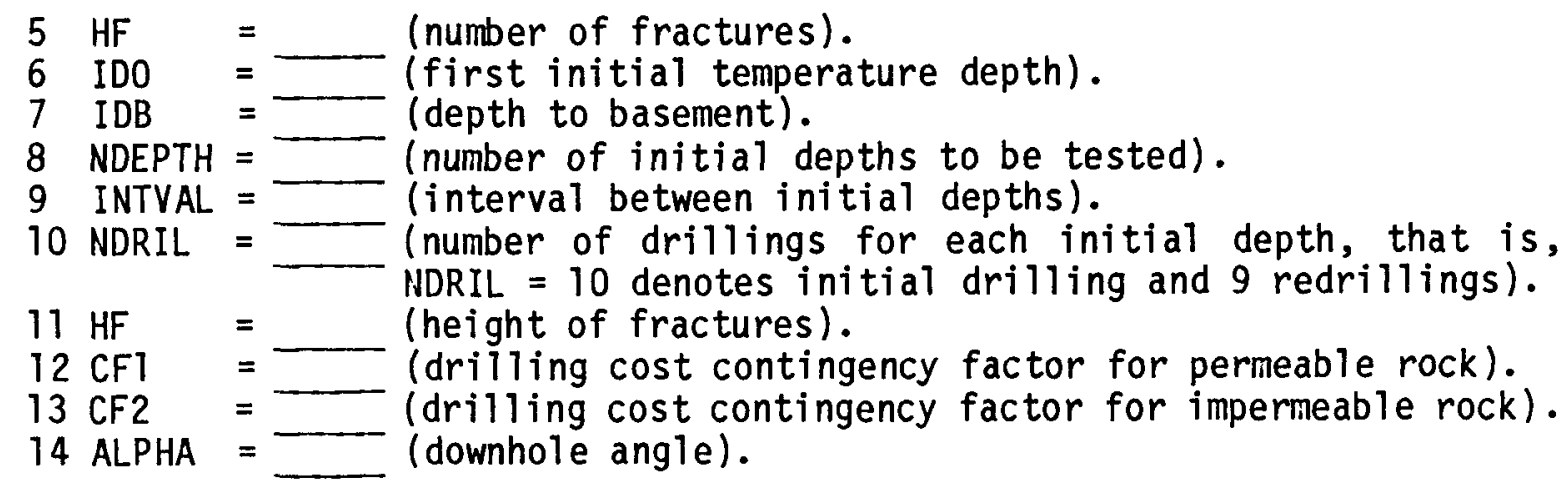

If one wishes the first initial depth to be the minimum depth at which an HDR reservoir can be created, given the number and height of fractures, depth to basement, and downhole angle, one should enter 0 for the first initial depth on 1 ine 6 . The program will then compute the minimum initial depth using the well geometry given in the RGI Manual ${ }^{7}$ and the Los Alamos National Laboratory specification that directional drilling must not begin less than $250 \mathrm{ft}$ into basement rock (Ref. 1, pp. 16-18).*

$\begin{aligned} \text { KOP2 } & =P+250 \text { (from LOS ATamos National Laboratory), } \\ \text { KOP2 } & =\text { KOP1 }+164 \times \cos \alpha-H F(\text { from RGI), } \\ \text { KOP1 } & =\text { TOPI }-(180 / 0.02 \pi) \times \sin \alpha-164 \times \cos \alpha \text { (from RGI), } \\ \therefore \text { KOP2 } & =\text { TOPI }-(180 / 0.02 \pi) \times \sin \alpha-H F, \\ \therefore \text { TOPI } & =\text { KOP2 }+(180 / 0.02 \pi) \times \sin \alpha+H F, \\ \text { TEMPD } & =\text { TOPI }-1 / 2 \mathrm{HF}+\{[(N F-1) \times 164] /(2 \times \tan \alpha)\} \text { (from RGI), }\end{aligned}$ where

KOP2 = kickoff point 2 ,

KOP $1=$ kickoff point 1 ,

TOPI = top of production interval,

TEMPD = depth to temperature center of reservoir. 
The program is then ready to run and the file PP will be created. It is then necessary to load and run RGICOST, resulting in output file TOTAL. This file is not in a form that can be read by HDR3, but is easily converted using the program FILEIT. Parameter changes in this program must correspond with those made for WRITEPP and are made on lines 4-6:

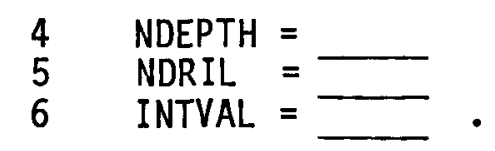

It is also necessary to change line 2 , which calls open the output file WICST_. If $N F=6$, then the output file should be WICST6; if $N F=3$, then the output file is WICST3, etc. Once these changes are made* and the program is run, a cost file WICST_exists that may be read by HDR3.

HDR3 has two input files for each set of runs. The first is the drilling cost file, WICST_, discussed above, and the second is a parameter file, LOOPON. Data from LOOPON are read in a free format by HDR3, but must be entered in the following order

\begin{tabular}{|c|c|c|c|c|}
\hline $\begin{array}{l}\text { Line } \\
\text { Number }\end{array}$ & Content & & & \\
\hline 1 & NR & & & \\
\hline 2 & $R(1) \quad R($ & $\ldots$ & $R(N R)$ & \\
\hline 3 & NDC IF & & & \\
\hline 4 & $\operatorname{DCIF}(1)$ & $\operatorname{DCIF}(2)$ & $\ldots$ & $\operatorname{DCIF}(\mathrm{N})$ \\
\hline 5 & NFCIF & & & \\
\hline 6 & FCIF (1) & FCIF (2) & $\cdots$ & $\operatorname{FCIF}(\mathrm{N})$ \\
\hline $\begin{array}{l}7 \\
8\end{array}$ & $\begin{array}{l}\text { BTUS } \\
\text { TD }\end{array}$ & & & \\
\hline 9 & G & & & \\
\hline 10 & ITH & & & \\
\hline 11 & $\mathrm{DB} \quad \mathrm{TDB}$ & & & \\
\hline 12 & DELT & & & \\
\hline 13 & NFRAC & & & \\
\hline 14 & $\mathrm{HF}$ & & & \\
\hline 15 & $\mathrm{RP}$ & & & \\
\hline
\end{tabular}

*It may be necessary to change dimension sizes should they exceed those given in line 1:

1 DIMENSION RGI $(X, Y), R(Y, Z)$,

where

$X \geq$ NDRIL, $Y \geq$ NDEPTH, and $Z \geq N D R I L+3$. 
Variable Names on LOOPON

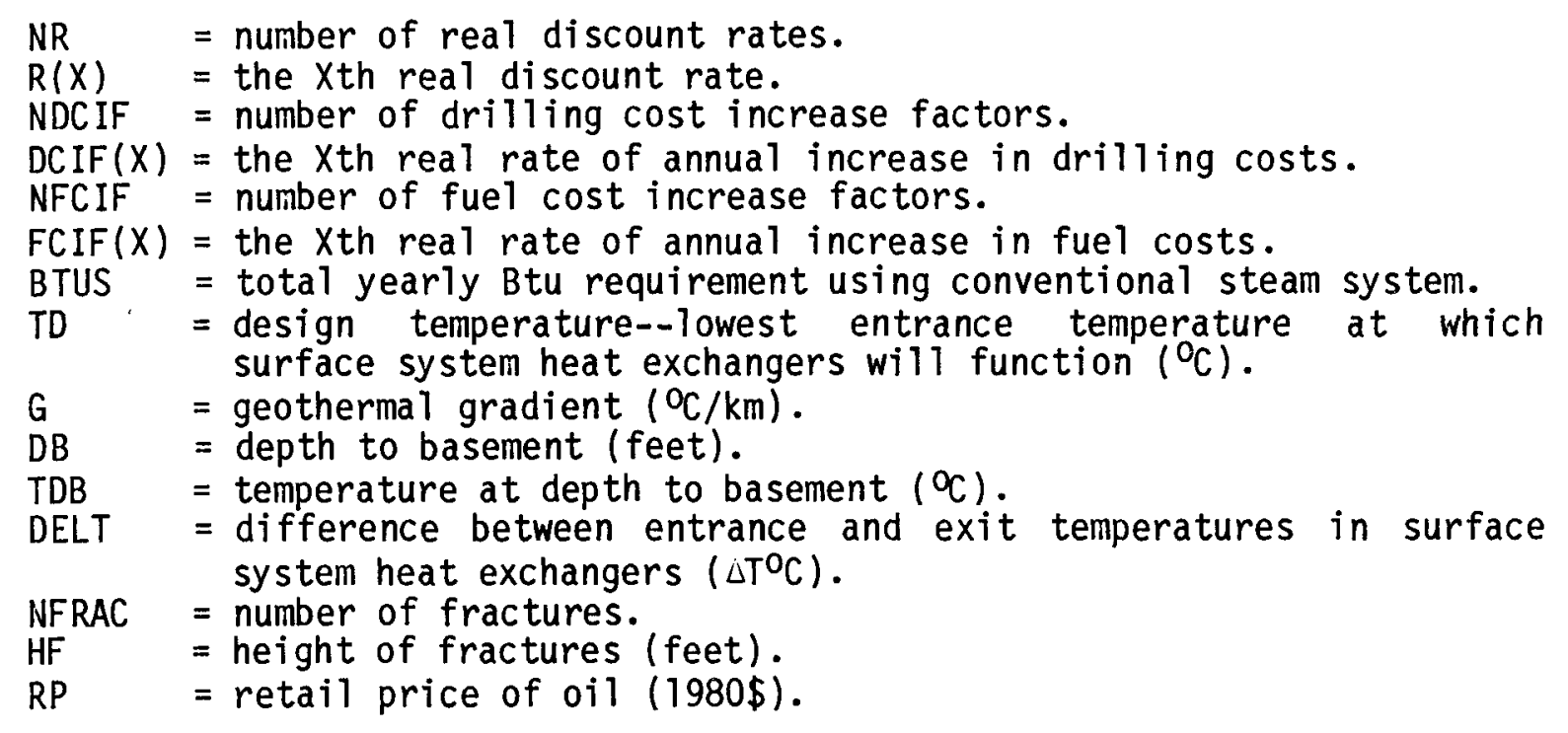

The only change generally required in HDR3 is 1 ine 32 , which calls open the drilling cost file WICST. This must be altered to correspond to the number of fractures entered on the file LOOPON. If more than three discount rates, drilling or fuel cost increase factors, more than ten initial depths, or a time horizon greater than $30 \mathrm{yr}$ are used, it is necessary to change variable dimensions (1ines 24-28 and line 393).

The program is then ready to run and the results are printed directly at the terminal. The general procedure for running the programs is outlined again below.

A. To create RGI drilling cost files, WICST,

1. Type file PARAMS (lines $1-4$ of PP file).

2. Load WRITEPP.

3. Make changes in WRITEPP.
a. Line 5
$\mathrm{NF}=$
(number of fractures).
b. Line 6 IDO=
(1st initial temperature depth. Set equal to 0 if minimum depth is wanted).
c. Line 7 IDB = (depth to basement).
d. Line 8 NDEPTH $=$ (number of initial depths to be tested).
e. Line 9 INTVAL $=$ (interval between initial depths).
f. Line 10 NDRIL = (number of drillings for each initial
g. Line $11 \mathrm{HF}=$ depth). (height of fractures). 

h. Line 12 CFI = (drilling cost contingency factor--per- i. Line 13 CF2 = meable). (drilling cost contingency factor--im- permeable).

4. Run WRITEPP

5. Load RGICOST.

6. Run RGICOST.

7. Load FILEIT.

8. Make changes in FILEIT.

a. Line 2 WICST_ (blank denotes number of fractures--

b. Line 4 NDEPTH $=$

c. Line 5 NDRIL = must correspond to (a) above).

d. Line 6 INTVAL = (same as (d) above).

(same as (e) above).

e. variable dimension sizes (if necessary).

9. Run FILEIT.

B. To get total reservoir costs of space heating using HDR,

1. Create file LOOPON.

2. Load HDR3.

3. Make changes in HDR3.

a. Line 32 WTCST $=$ (blank denotes number of fractures--must correspond to line 13 in LOOPON).

b. variable dimension sizes (if necessary).

4. Run HDR3.

IV. SAMPLE CASE RUNS

To illustrate how the programs work, this section presents a sample case. We assume that none of the files necessary to run HDR3 exist and must therefore be created. Referring to the general procedure outlined in the previous section, one sees that to begin one must create the file PARAMS. The following parameters will be used to create the file.

1. station distance between cementing company and well site (SD) $=250 \mathrm{mi}$.

2. drilling fluid supply company distance to well (SDM) $=250 \mathrm{mi}$.

3. distance from logging and perforating company to well (LLP) $=250 \mathrm{mi}$.

4. distance from formation packer company to we11 (LFP) $=250 \mathrm{mi}$.

5. distance from pump truck yard to well (LPT) $=250 \mathrm{mi}$.

6. distance from rental equipment yard to well (LRE) $=250 \mathrm{mi}$.

7. distance from completion contractor's yard to well (LWS) $=250 \mathrm{mi}$.

8. number of fractures (NF) $=3$.

9. height of fractures $(H F)=1181 \mathrm{ft}(360 \mathrm{~m})$.

10. downhole angle $(A L P H A)=30^{\circ}$.

11. rate of angle buildup $(B E T A)=0.020 / \mathrm{ft}$.

12. design temperature (extraneous for this version of RGICOST) (TD) $=74^{\circ} \mathrm{C}$.

13. water well depth (WWD) $=300 \mathrm{ft}$.

14. geothermal gradient (GRAD) $=0.03^{\circ} \mathrm{C} / \mathrm{m}$.

15. location class $(001,011$, or 111) (CLASS) $=1$. 
16. state identification code $(46=V A)($ STATE $)=46$.

17. identifier for remote wireless service area or not $(1=$ yes, $2=$ no $)$ $($ REMOTE $)=2$.

18. directional drilling technique ( 1 = whipstock, 2 = downhole motor $)$

$(T E C H)=1$.

With this information, the data file PARAMS is constructed as shown (note that only one parameter run is made).

Line

Number

$\begin{array}{cccccccc}1 & 1 & & & & & \\ 2 & 250.0 & 250.0 & 250.0 & 250.0 & 250.0 & 250.0 & 250.0 \\ 3 & 3.0 & 1181 & 30.0 & 0.02 & 74.0 & 300.0 & 0.03 \\ 4 & 1 & 46 & 2 & 1 & & & \end{array}$

Once this file is created and saved as PARAMS, the next step is to load the program WRITEPP and make the necessary changes to conform to our case. These are as follows.

Line

Number

\begin{tabular}{|c|c|c|c|}
\hline 5 & NF & $=3$ & $\begin{array}{l}\text { (whatever is entered here will replace that entered } \\
\text { in PARAMS). }\end{array}$ \\
\hline 6 & IDO & $=0$ & $\begin{array}{l}\text { (denotes that one wishes to start with the minimum } \\
\text { allowable depth). }\end{array}$ \\
\hline 7 & IDB & $=9000$ & (depth to basement $=9000 \mathrm{ft})$. \\
\hline 8 & NDEP TH & $=10$ & (will test 10 initial depths). \\
\hline 9 & I NT VAL & $=1000$ & $\begin{array}{l}\text { (each initial depth will be } 1000 \mathrm{ft} \text { deeper than the } \\
\text { previous one). }\end{array}$ \\
\hline 10 & NDRIL & $=10$ & $\begin{array}{l}\text { (number of drillings at each initial depth } a 10,1 \\
\text { for initial drilling and } 9 \text { redrillings). }\end{array}$ \\
\hline 1 & HF & $=1181$ & $\begin{array}{l}\text { (height of fracture }=1181 \mathrm{ft} \text { ) (whatever is entered } \\
\text { here will replace that entered in PARAMS). }\end{array}$ \\
\hline 12 & $\begin{array}{l}\text { CF } 1 \\
\text { CF2 }\end{array}$ & $\left.\begin{array}{l}=0.0 \\
=0.0\end{array}\right\}$ & $\begin{array}{l}\text { (we assume no case contingencies for our sample cas } \\
\text { if one assumed } 50 \% \text {, it would be entered as } 0.5 \text { ). }\end{array}$ \\
\hline
\end{tabular}

(Many of these lines will remain the same for subsequent runs so fewer changes will usually be required.)

After making the changes noted above, one is ready to run WRITEPP. (Warning: an output file PP must exist in user's workspace for the program to run.) The resulting file PP (shown below) consists of five lines (1-5) of general site parameters, number of depth tests (1ine 6) and 63 depth tests (lines 7-69). One should note that the number of depth tests on line 6 does 
not agree with the actual number of such tests. This disagreement results (as mentioned above) because the program WRITEPP deletes any tests for depths greater than those for which costs $c a n$ be computed by RGICOST. Because of this disagreement, running RGICOST may result in a statement indicating that the end of input file PP was reached and computation therefore terminated. This will not alter results and should not be a source of concern should it happen.

\section{FILE PP}

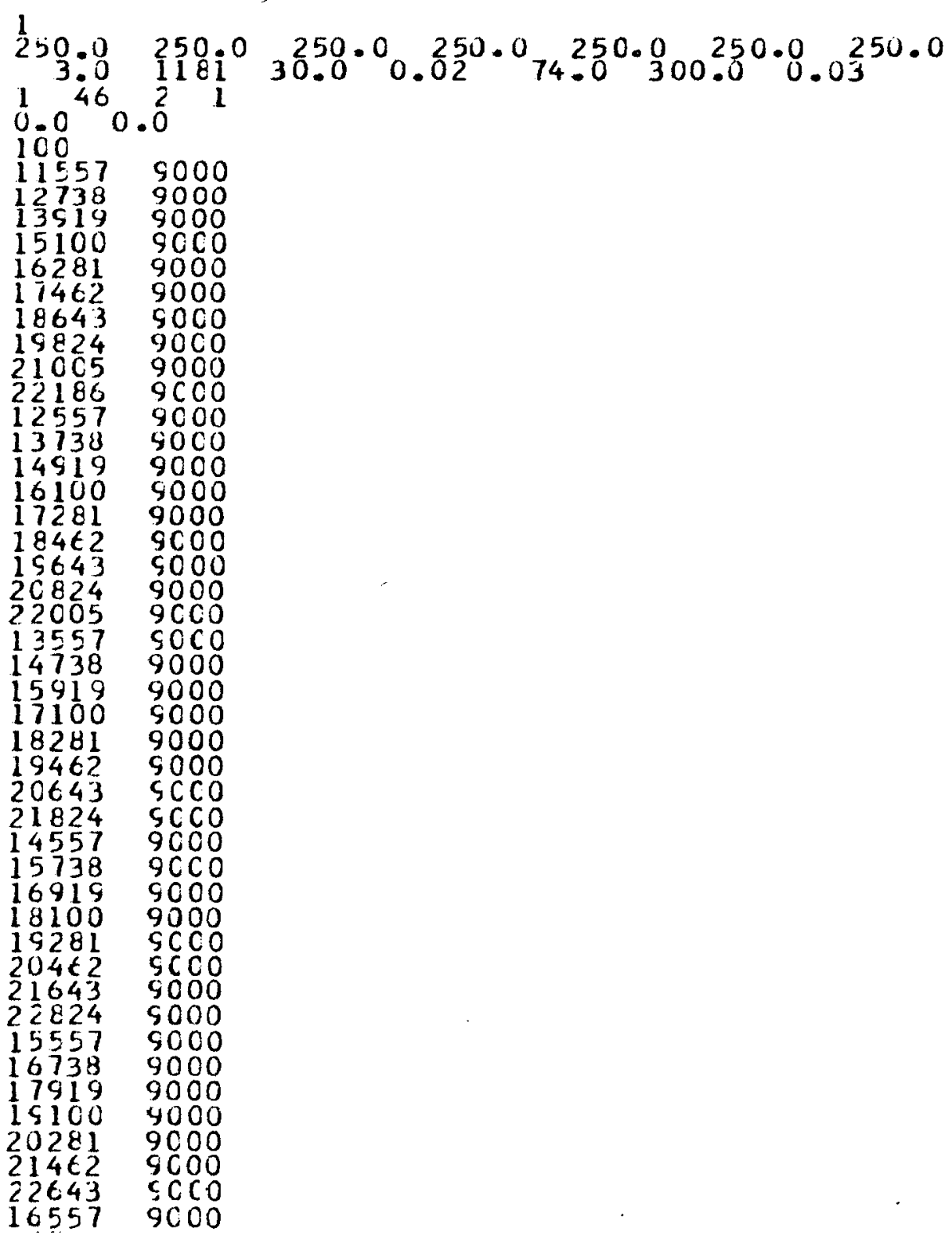


FILE PP (cont)

$\begin{array}{ll}17338 & 9000 \\ 18919 & 9000 \\ 20100 & 5 C 00 \\ 21281 & 9000 \\ 22462 & 9000 \\ 17557 & 9000 \\ 18738 & 9000 \\ 19919 & 9000 \\ 21100 & 9000 \\ 22281 & 9000 \\ 18557 & 9000 \\ 1673 & 9 C C 0 \\ 2 C 19 & 9 C 00 \\ 22100 & 9000 \\ 19557 & 9000 \\ 20738 & 9600 \\ 21919 & 9000 \\ 20557 & 9000 \\ 21738 & 5 C C 0 \\ 22919 & 9000\end{array}$

Again, referring to the general procedure for using the programs (Sec. III), one sees that the next step is to load and run RGICOST. Results for total costs calculated by the program are stored in the output file TOTAL, which is included here.

FILE TOTAL

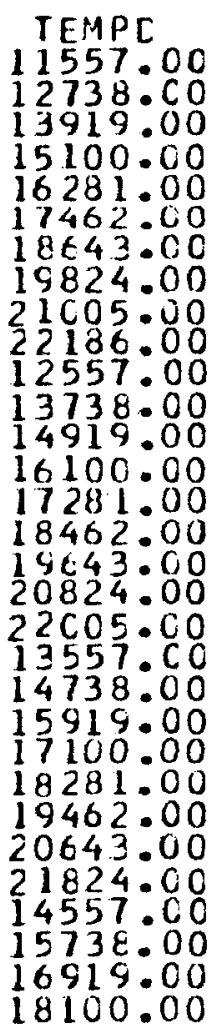

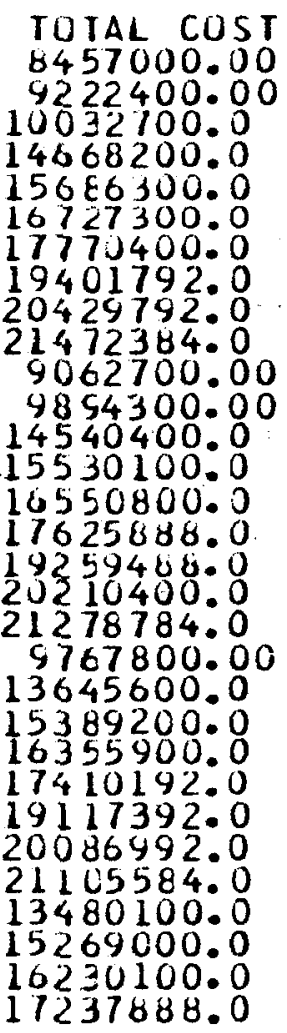

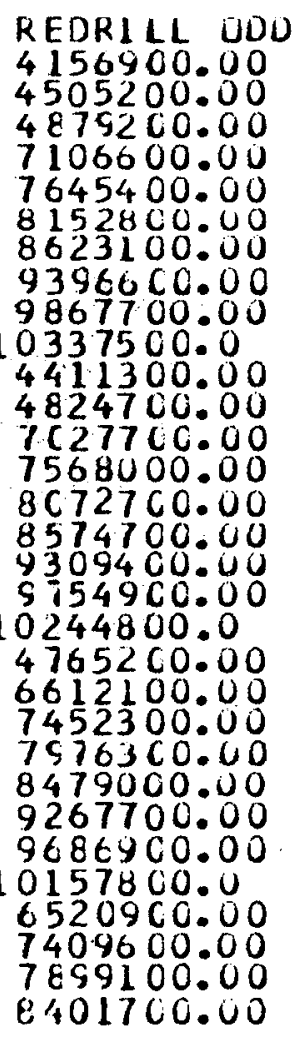


FILE TOTAL (cont)

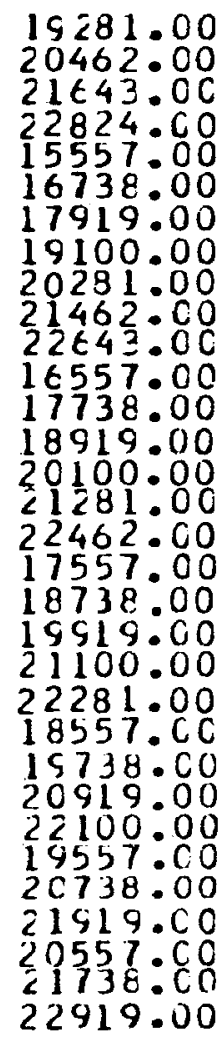

18943688.0

19944592.0

$209 \notin 3488.0$

21976080.0

15074700.0

$16 C 57400.0$

17108192.0

16775680.0

19756480.0

20841392.0

21813184.0

15922900.0

16970000.0

$186 \in 2800.0$

19606992.0

20052192.0

21690880.0

16755600.0

17850400.0

19480576.0

20483280.0

21522080.0

$176,6688.0$

19354080.0

20316490.0

21322880.0

19166096.0

20163088.0

21205376.0

19993584.0

22157584.0

9199300.00
9644400.00
10090800.0
10576000.0
7331600.00
7846000.00
8322400.00
9132300.00
9576300.00
10048900.0
10468900.0
7749500.00
8273700.00
9670400.00
9489100.00
9560400.00
10426700.00
8196300.00
8676300.00
9417700.00
9893500.00
10358500.0
8598900.00
9375700.00
9782100.00
10271200.00
9288600.00
9754200.00
10158800.00
9665900.00
10156900.00
10658700.0

9965200.00

10510660.0

11085000.0

I 1606900.0

7896400.00

$83927 \mathrm{CO} .00$

$85283 \mathrm{CO} . \mathrm{CO}$

$98642 \mathrm{CO} .00$

$104316 \mathrm{CO} .0$
$110055 \mathrm{CO} .0$

$115522 C 0.0$

$83156 \mathrm{CO} .00$

8838600.00

$98098 \mathrm{C0.00}$

10330400.0

$109058 \mathrm{CO} .0$

$114725 \mathrm{CC}$. C

8742700.00

$93128 \mathrm{CO} .00$

$102760 \mathrm{C0} .0$

$108048 \mathrm{CO} .0$

$113730 \mathrm{CO} . \mathrm{C}$

9217400.00

$101920 \mathrm{C0} 0$

$107504 \mathrm{CO} .0$

11272000.0

$100922 \mathrm{CO} 0$

$206396 \mathrm{CO} 0$

11217700.0

$105387 \mathrm{C0} 00$

11132400.0

11766960.0

Should more detailed results be desired, one must load RGICOST and change lines 553 and 554 by deleting the "c" in column 1. This will allow two subroutines to be called that determine and store well specifications in output file WELL and intermediate cost data in output file COST. Because of space limitations, when complete breakdowns are required, it is recommended that no more than twelve depth tests are made at one time. For purposes of illustration, such a run was made for only one depth test, $11557 \mathrm{ft}$ (the minimum initial depth possible for 3 fractures with $9000 \mathrm{ft}$ of permeable section). The resulting files, TOTAL, WELL and COST, are shown below.

FILE TOTAL

TEMPD

11557.00
TOTAL CUST

8457000.00
REDRILL OUD

4156400.00
RECRILL EVEN

$44265 \mathrm{CU} .00$ 


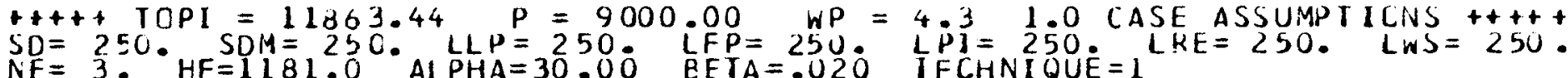

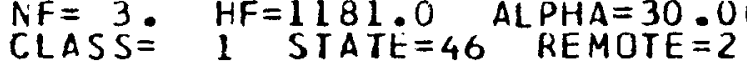

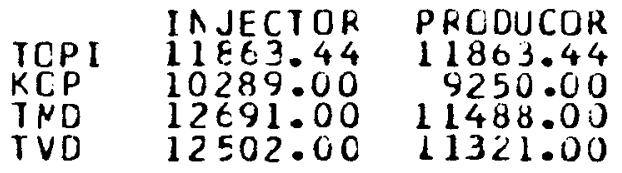

\begin{tabular}{rrrr}
\multicolumn{2}{c}{ PRUOUCUR } & \\
NURT & TRIP & BIT \\
43.5 & 271.4 & 1 & 2 \\
40.6 & 279.3 & 6 & 7 \\
76.5 & 822.3 & 12 & 13 \\
53.7 & 29.8 & 1 & 2 \\
& 1418.3 & 18 & 7 \\
& 216.2 & 3 & 4
\end{tabular}

$V T=2184.00 \quad V V T=666.47$

130 
$+t+t+t+t$ TOPI $=11863.44$ P $=9$ COO OOO

LCCAT ICN COST

NCVE COST

RIG MOEILIZATICN COST

RIG FLEL CCST

WATER SUPPLY SETUP CHARGES

WATER WELL COST

PACKER, EOP, \& SCRAPER

CCNPLETICN RIG CCST

PUMP TKUCK SERVICE

PORIAELE DERR ICK

REATAL EOUIP. ¿ TRANS.

CASING TRANSPORTAIIUN

DRILLING FLUID TRANSPORT ATION

ACDITICNAL TRANSPCR TAIION

SUPERVISION E CO. LABOR

INCIDENIAL COSIS

$G \varepsilon A$ CESTS

WELLHEAD \& LINER HANGERS

TOTAL TANGIBLE COSTS

TAX GN TANGIBLES

BIT CST

STABILI ZER COST

NCN-MAGNETIC COLLAR RENTAL

ANGLE BUILDUP FIXED CUST

DRILLING FLUID COST

CEMENTING COST

LCGG IAG COST

מATER IN JECTICN TEST

FLCWMETER E TEMP SURVEY

MISCELLANEOUS COS IS

SHARE CF COMACN CCSTS

TCIALS

ICTAL COST TO ESTABLISH A HDR RESERVOIR

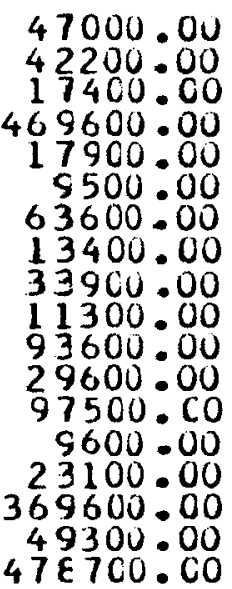

INJECTCR

48600.00 459500.00 18400.00 400700.00

20300.00

900.00

75800.00

105300.00

151500 . C 0

$45 \mathrm{C00} 000$

31700.00

1055400.00

4445000.00
PROCUCOR

$6210 \mathrm{C} .0 \mathrm{C}$ 519000.00 20800.00 1738900.00 381800.00

1880.00

3400.00

105300.00

176600.00

42400.00

$970 \mathrm{C} .00$

16500.00

$8204 \mathrm{CC} . \mathrm{CC}$

4011000.00

8457000.00 
Because the file TOTAL is not in a form that can be read by the program HDR3, it is necessary to change this form. This is done simply by loading and running (after making necessary changes) the program FILEIT. The required changes are

\section{Line}

Number

$\begin{array}{lll}2 & \ldots \text { WICST3 } \ldots & \text { (must correspond to number of fractures, in our } \\ & \text { Case }-3 \text { ) } & \text { (same as line } 8 \text { in WRITEPP) } \\ 4 & \text { NDEPTH }=10 & \text { (same as 1ine } 10 \text { in WRITEPP) } \\ 5 & \text { NDRIL }=10 & \text { (same as line } 9 \text { in WRITEPP) }\end{array}$

Running FILEIT results in the RGI drilling cost file, WICST3, shown below. Looking back at the file TOTAL one can see what the program FILEIT does. It takes the information for the first initial depth test (1ine 2), including depth, total cost, and the costs for redrilling to the same depth via samedepth drilling. Redrilling cost is given for "odd" and "even" when same-depth drilling is used. This is because the first (third, fifth, etc.) time redrilling is undertaken, a new injection well is created to replace the original one, which is closed down, while the second (fourth, sixth, etc.) time redrilling occurs, a new production well is created and the old production well is closed. These four values become the first four values (line 1) of the cost file WICST3. The rest of the values found on line 1 (WICST3) are the cost of redrilling to increasingly deeper depths. These values are taken from lines 2-10 of TOTAL. The value for "redrill even," that for creating a new production well at a deeper depth, is used for each redrilling to deeper depths. FILEIT proceeds to create one line of data in WICST3 for each initial drilling depth and all deeper drilling corresponding to that initial depth. If 10 initial depths are tested, the RGICOST file WICST3 will have 10 lines containing this information.

\section{FILE WICST3}

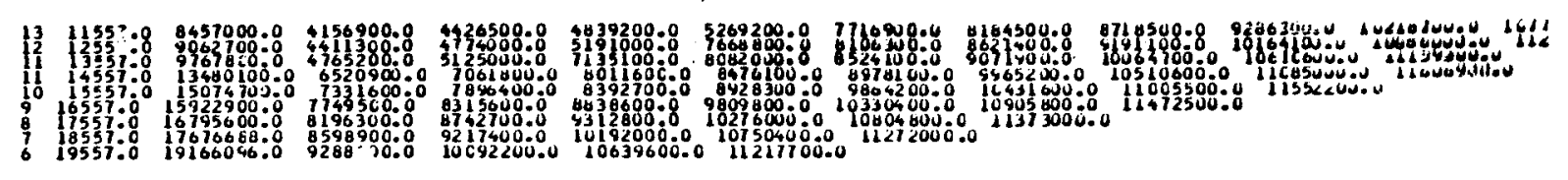


Once the cost file WICST3 exists, one is ready to run the program HDR3, which determines present value costs of producing heat using HDR over a given time horizon. Again, referring to the general procedure for using the programs one sees that the file LOOPON must be created (or changed) to correspond with the parameters that one wishes to use. We assume here that no such file exists and will therefore need to make one using the following parameters.

1. number of discount rates to be used $=3$

2. discount rates $=4 \%, 7.25 \%, 10 \%$

3. number of drilling cost increase factors $=3$

4. drilling cost increase factors $=3 \%, 4.34 \%, 6 \%$

5. number of fuel cost increase factors $=3$

6. fuel cost increase factors $=2 \%, 3 \%, 4 \%$

7. yearly Btu requirement using conventional system $=161.28 \times 10^{9}$

8. design temperature $=74^{\circ} \mathrm{C}$

9. geothermal gradient $=30^{\circ} \mathrm{C} / \mathrm{km}$

10. time horizon $=30 \mathrm{yr}$

11. depth to basement $=9000 \mathrm{ft}$

12. temperature at depth to basement $=90^{\circ} \mathrm{C}$

13. heat extraction rate for heat exchangers $(\Delta T)=11.1111^{\circ} \mathrm{C}$

14. number of fractures $=3$

15. height of fractures $=1181 \mathrm{ft}$

16. retail price of $\# 6$ oil $=1980 \$=31.13$

Using these parameters, the file LOOPON will be:

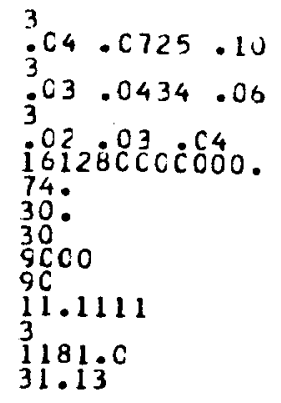

To facilitate understanding of the final results printed out by the program and the program (HDR3) itself, it will be helpful to examine intermediate results and the methods by which they were reached. In the following section, we take the values given as parameters in the file LOOPON and perform the same calculations as the program does. Each statement is given in the form found in the program, and program line numbers are given in parentheses. A list of all variable names follows the calculations. File results as printed by the program at the terminal, are presented here before the intermediate results are examined. 
Program reads data from file LOOPON and file WICST3

2 The following calculations are made.

a. HDRBTU $=[$ Btu $\times(0.32+0.11)] \times 1.05$

$=\left(1.6128 \times 10^{11} \times 0.43\right) \times 1.05$

$=7.2818 \times 10^{10}$

converts total yearly Btu requirements using conventional system to total yearly Btu requirements using HDR.

b. $\quad$ BARREL $=$ BTUS/ $(144000 \times 42)$

$$
\begin{aligned}
& =1.6128 \times 10^{11 / 6048000} \\
& =26666.67
\end{aligned}
$$

calculates barrels of oil required to meet Btu requirement using conventional system.

c. $G R=G /(1000 \times 3.28084)$

$$
\begin{aligned}
& =30 / 3280.84 \\
& =0.009744
\end{aligned}
$$

translates geothermal gradient $\left({ }^{\circ} \mathrm{C} / \mathrm{km}\right)$ to ${ }^{\circ} \mathrm{C} / \mathrm{ft}$.

d. $\quad$ SMDOT $=($ HDRBTU $\times 3.779) /($ DELT $\times 500 \times 8760 \times 60 \times 1.8)$

$=\left(7.1818 \times 10^{10} \times 3.779\right) /(11.1111 \times 500 \times 8760$

$\times 60 \times 1.8)$

$=52.36$

determines surface system flow rate requirement.

e. $\quad$ TINJ $=$ TD - DELT

$$
\begin{aligned}
& =74=11.1111 \\
& =62.8889
\end{aligned}
$$

calculates reinjection temperature. 
PROGRAM RESULT

*** 3 FRACIURES ***

*** INIIIAL CEPTH $=11557.0 \mathrm{CFET} * *$

\author{
INIT IAL DR ILLING CQSTS \\ RGI $=9.457$ GEC $=11.020$
}

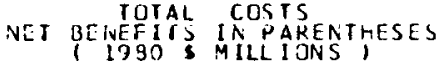

\begin{tabular}{|c|c|c|}
\hline $\mathbf{R}$ & DCIF & FCIF \\
\hline .0400 & .0300 & .0200 \\
\hline .0400 & .0300 & .0300 \\
\hline .0400 & .0300 & .0400 \\
\hline .0400 & .0434 & .0200 \\
\hline .0400 & .0434 & .0300 \\
\hline .0400 & .0434 & .0400 \\
\hline .0400 & .0600 & .0200 \\
\hline .0400 & .0600 & .0300 \\
\hline .0400 & .0600 & .0400 \\
\hline .0725 & .0300 & .0200 \\
\hline .0725 & .0300 & .0300 \\
\hline .0725 & .0300 & .0400 \\
\hline .0725 & .0434 & .0200 \\
\hline .0725 & .0434 & .0300 \\
\hline .0725 & .0434 & .0400 \\
\hline .0725 & .0600 & .0200 \\
\hline .0725 & .0600 & .0300 \\
\hline .0725 & .0600 & .0400 \\
\hline .1000 & .0300 & .0200 \\
\hline .1000 & .0300 & .0300 \\
\hline .1000 & .0300 & .0400 \\
\hline .1000 & .0434 & .0200 \\
\hline .1000 & .0434 & .0300 \\
\hline .1000 & .0434 & .0400 \\
\hline .1000 & .0600 & .0200 \\
\hline .1000 & .0600 & .0300 \\
\hline .1000 & .0600 & .0400 \\
\hline
\end{tabular}
RGI SAME DEPTH GEO

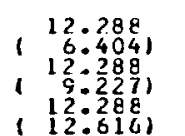

16.068
2.6041
16.088

$\left(\begin{array}{l}12.288 \\ (12.816)\end{array}\right.$

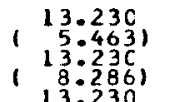

13.230
$(11.674)$

14.699
$3.994)$
14.695
16.8171
14.695
110.2051

16.083
5.4271
16.088

(17.334

17.334
$(4.181)$

17.334
1.5701

10.728
1.8221
10.728
$(3.41 C)$
10.728

$\left(\begin{array}{r}19.277 \\ -0.584\end{array}\right)$

( 19.277

19.277
$(5.627)$

10.728
5.2841

$\left(\begin{array}{l}14.024 \\ -1.474)\end{array}\right.$

14.424
$1,0.024$
$0.114 !$
14.024

11.286
$1.264)$
11.286
2.8521
11.286

14.762

$(4.726)$

$\left(\begin{array}{l}14.762 \\ 14.762\end{array}\right.$

14.762
-0.6251
14.762

12.156
0.3941
12.156
1.9811
12.156
1351

(1.2491

9.933

$\left(\begin{array}{l}15.914 \\ -3.3641\end{array}\right.$

( 15.914 )

9.933
-0.4481
9.933

0.098

( 0.5821

$\left(\begin{array}{c}12.973 \\ (3.488 \\ 12.973\end{array}\right.$

12.973
-2.4571

$(1.781)(-1.259)$

10.296

13.453
-3.968

$\left(\begin{array}{ll}-0.8111 & -3.968 \\ 10.296 & 13.453\end{array}\right.$

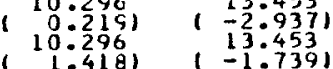

$(10.862)$

10.862
10.867
-0.3471

14.202
-4.717
14.202

-0.3471
10.862

( -3.686

$\left(\begin{array}{r}14.202 \\ -2.488)\end{array}\right.$

$$
\begin{aligned}
& \text { UEEPER DEPIHS } \\
& \text { RGI }
\end{aligned}
$$

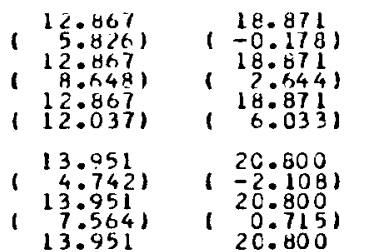

$\begin{array}{ll}1 & 13.951 \\ (10.953) & 20.800 \\ 4.104)\end{array}$

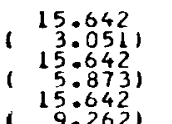

$\left(\begin{array}{c}23.810 \\ -5.1181\end{array}\right.$

$\left(\begin{array}{r}23.820 \\ -2.2951\end{array}\right.$

$\left(\begin{array}{r}15.642 \\ 9.262)(23.820 \\ 1.0941\end{array}\right.$

$\left(\begin{array}{l}11.071 \\ 1.479, \quad 15.073 \\ 11.071 \\ 15.1231\end{array}\right.$

$\begin{array}{ll}1 & 1.479 \\ (1.075) & (15.673 \\ 11.071 & 15.5361\end{array}$

$\left(\begin{array}{r}11.071, \quad 15.673 \\ 4.941), 0.3381\end{array}\right.$

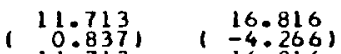

$\begin{array}{lll}(1.837) & (-4.266) \\ 1 & 1.713 & 16.816 \\ 2.424) & (-2.679)\end{array}$

$(4.298),(-0.805)$

$\left(\begin{array}{l}12.715, \quad 18.600 \\ 10.165) \quad(-6.050)\end{array}\right.$

$\begin{array}{cc}(-0.165) & (-6.050) \\ 12.715 & 18.600 \\ 1.422) & (-4.463)\end{array}$

$\begin{array}{rr}12.715 & (-4.463) \\ (3.296) & 1-2.500 \\ 1-581\end{array}$

$\left(\frac{10.157, \quad(14.045}{1}, 0.561\right)$

$\begin{array}{cc}10.157 & 14.045 \\ 10.354) \quad(-3.5301\end{array}$

$\left(\begin{array}{cc}10.151 \\ 1.5581 & (14.045 \\ 1.2 .331)\end{array}\right.$

$\left(\begin{array}{l}10.574,1.0891,1489 \\ -5.304)\end{array}\right.$

10.574
$1-0.0591 \quad 14.785$
$10.733)$

$\begin{array}{rr}-10.574 & 1-7.789 \\ 1.1401 & (-3.075)\end{array}$

(1 1.226$) \quad\left(\frac{15.949}{1}-6.464\right)$

$\begin{array}{ll}11.226 & 15.449\end{array}$

$(-0.710) \quad(-5.433)$

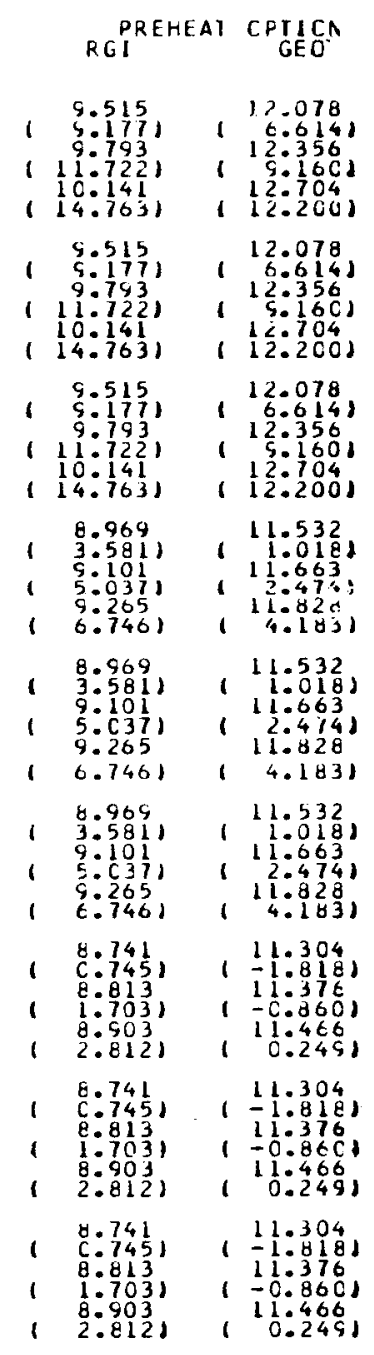

SURFACE SYSTEM TEMPERAIURE DROP $=11.1111$

OES IGN TEMPERATURE $=72.300$

GRADIENT $=30$. 0

DEPTH OF PASEMENT ROCK $=9000.0$

FOR SAME DEPTH ORILLING, REDRILLING OCCURRRED IN YEARS I8,
FOR DEEPER DEPTHS DR ILLING, REDRILLING OCCURRREC IN YEARS 18,
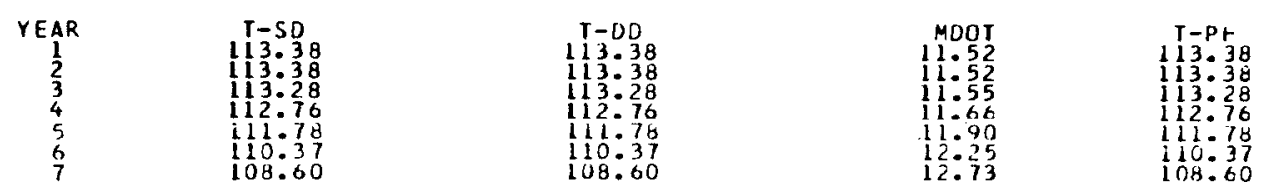


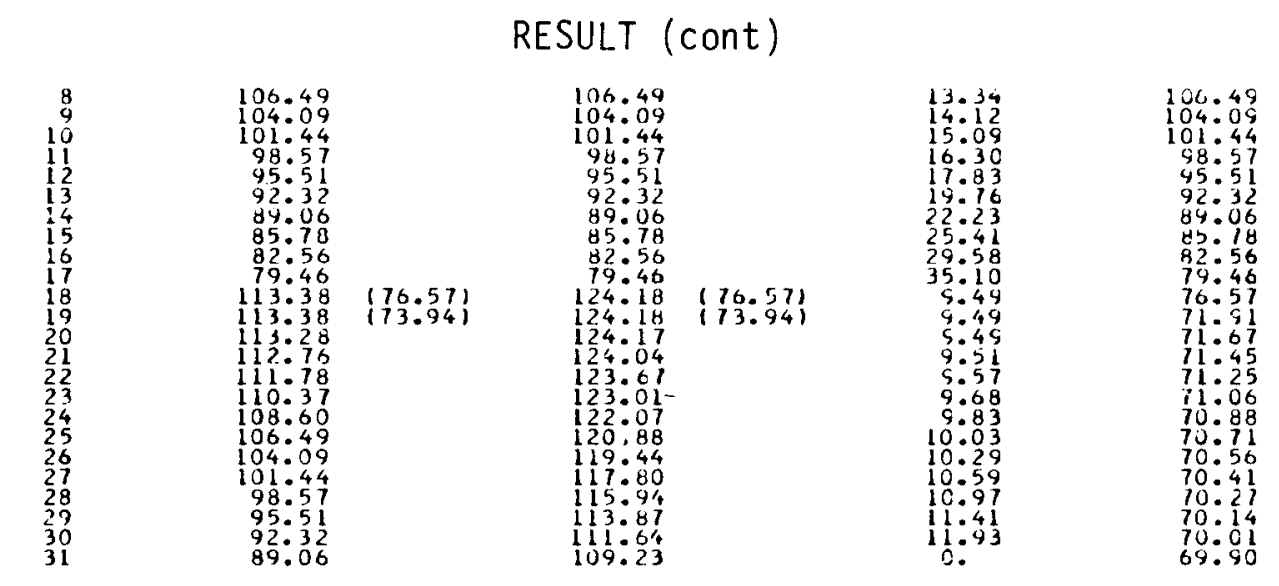

*** 3 FRACTURES ***

** INITIAL DEPIr $=12557.0 \mathrm{CFEET}$ **

INITIAL DRILLLNG COSTS

RGI $=9.063 \quad$ GEO $=16.392$

TOIAL COSTS
NET BENEFIIS IN PARENTHESES

\begin{tabular}{|c|c|c|}
\hline$R$ & DCIF & FCIF \\
\hline .0400 & .0300 & .0200 \\
\hline .0400 & .0300 & .0300 \\
\hline .0400 & .0300 & .0400 \\
\hline .0400 & .0434 & .0200 \\
\hline .0400 & .0434 & .0300 \\
\hline .0400 & .11434 & .0400 \\
\hline .0400 & .0600 & .0200 \\
\hline .0400 & .0600 & .0300 \\
\hline .0400 & .0600 & $.0 \% 00$ \\
\hline .0725 & .0300 & .0200 \\
\hline .0725 & $.0,00$ & .0300 \\
\hline .0725 & .0300 & .0400 \\
\hline .0725 & .0434 & .0200 \\
\hline .0725 & .0434 & .0300 \\
\hline .0725 & .0434 & .0400 \\
\hline .0725 & .0600 & .0200 \\
\hline .0725 & .0600 & .0300 \\
\hline .0725 & .0600 & .0400 \\
\hline .1000 & .0300 & .0200 \\
\hline .1000 & .0300 & .0300 \\
\hline .1000 & .0300 & .0400 \\
\hline 1000 & .0434 & .0200 \\
\hline .1000 & .0434 & .0300 \\
\hline .1000 & .0434 & .0400 \\
\hline .1000 & .0600 & .0200 \\
\hline .1000 & .0600 & .0300 \\
\hline .1000 & .0600 & .0400 \\
\hline
\end{tabular}
RGI SAME DEPTH GEO

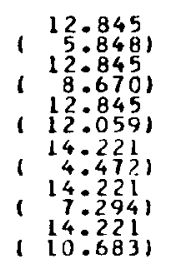

23.260
-4.5671

$\left(\begin{array}{l}23.280 \\ -1.744)\end{array}\right.$

$\left(\begin{array}{l}1.644) \\ (-1.045\end{array}\right.$

$\left(\begin{array}{l}25.757 \\ -7.065)\end{array}\right.$

$\left(\begin{array}{r}25.757 \\ -45.242)\end{array}\right.$

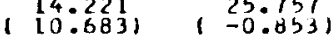

16.596
2.0961
16.596
4.9151
16.596
18.3081

$\left(\begin{array}{r}30.070 \\ (-11.378)\end{array}\right.$

30.070

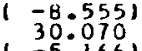

18.3081

10.870
1.6801
10.870
13.2671
1.08701

13.2671
$1 \quad 5.870$
$\quad 5.1411$

$\left(\begin{array}{r}19.674 \\ -7.124)\end{array}\right.$

$\left(\begin{array}{r}19.674 \\ -5.536) \\ 19.674\end{array}\right.$

$\left(\begin{array}{l}1.527,0231,20.867 \\ 11.0527\end{array}\right.$

11.527
12.6101
11.527

20.867

$\left(\begin{array}{l}-6.730) \\ 20.867\end{array}\right.$

$(12.662)(-22.928$

$\left(\begin{array}{rr}-0.112) & (-10.378 \\ 12.662 & 22.928\end{array}\right.$

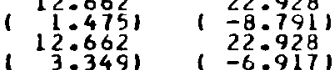

$\left(\begin{array}{l}10.047 \\ -0.562),(-8.180 \\ 10.694)\end{array}\right.$

$10.047,18.180$

$\begin{array}{cc}0.469) & (-7.664) \\ 10.047 & 18.180\end{array}$

$10.405,18.830$

$\left(\begin{array}{cc}10.9201 & (-9.344) \\ 10.405 & -19.330\end{array}\right.$

$\begin{array}{ll}10.4111 & (-8.8314) \\ 10.405 & 18.830 \\ 1.3091 & (-7.1151\end{array}$

( $\begin{array}{cc}11.023 & 19.952 \\ 1 & 1.5381\end{array}$

$\begin{array}{rr}11.023 & 1-10.467) \\ 1-0.5081 & 19.952\end{array}$
RGI DEEPER CEPIHS

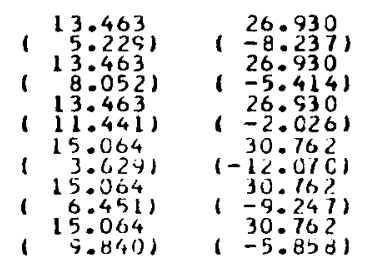

17.329
$0.365)(-17.330 .688)$

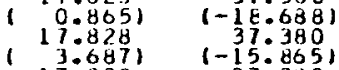

$\begin{array}{cc}17.828 & (-37.380 \\ 7.076) & (-12.476)\end{array}$

(11.165, ( 1.21 .427$,

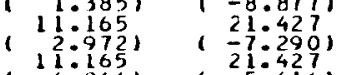

$(4.846)$

11.930
$0.620)$
11.930
$2.207)$

2.2071
$(11.930$
$4.081)$

23.259

13.759
23.259

$\left(\begin{array}{l}-9.1211) \\ 23.259\end{array}\right.$

$\left(\begin{array}{l}13.251 \\ -0.701)(-13.871)\end{array}\right.$

$\begin{array}{rr}13.251 & 26.421 \\ 0.8861 & (-12.2841 \\ 13.251 & 26.421\end{array}$

$\left(\begin{array}{r}3.251 \\ (2.760)\end{array}\right.$

$(-10.410)$

10.208
10.7221
10.208
0.3081
10.208

$\left(\begin{array}{r}29.135 \\ (-5.649)\end{array}\right.$

$\left(\begin{array}{l}10.208 \\ (1.507)\end{array}\right.$

$\begin{array}{r}19.135 \\ -8.619) \\ 19.135 \\ \hline\end{array}$

$\begin{array}{ll}10.625 & 20.132 \\ -1.1391 & 1-10.0471\end{array}$

10.625
-0.1091

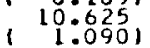

20.132
$(9.616)$
20.132
$(-8.418)$

11.344
11.8588
11.344
-0.8281

21.854
$(-12.369)$
21.854
$(-1) .339)$
21.854
PREHEAT CPI ICA
REI EO

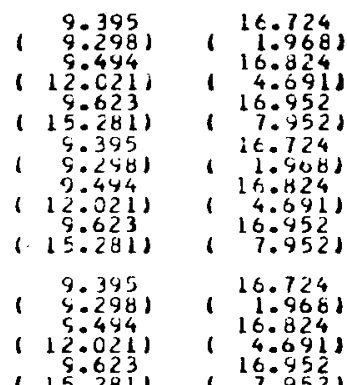

$115.2811(7.952$

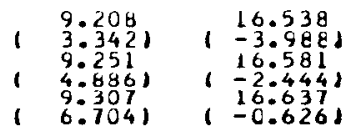

$9.208,16.53 E$
$3.3421,13.98 E$

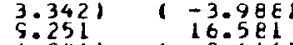

$\begin{array}{ll}4.8861 & (-2.4441 \\ 9.307 & 16.637\end{array}$

$9.307,116.637$
-6.6261

$9.208,15.538$
$3.3421,-3.968)$

$1-3.968$

4.8861

6. 307 ,

( -2.4441

9.136
0.3491

0.1361
91158
$1: 357$

1 $5: 187$

1 16.466

( -5.9721

$9.136,16.406$

$9: 158,16.488$

$1: 3571 \quad 1-5.9721$

$15.5281,1-4.5021$

$19: 136), 16.466$,

$19: 159,16.4861$ 
RESULT (cont)

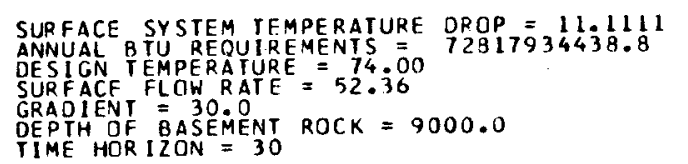

FOR SAME DEPTH DRILLING, REORILLING DCCURRRED IN YEARS 25,
FCR DEEPER DEPTHS DRILLING, REDRILLING OCCURRREC IN YEARS' 25.

\begin{tabular}{|c|c|c|c|c|c|}
\hline $\begin{array}{c}\text { YEAR } \\
1 \\
2 \\
3 \\
4 \\
5 \\
5 \\
6 \\
7 \\
8 \\
9 \\
10 \\
11 \\
12 \\
13 \\
14 \\
15 \\
16 \\
17 \\
18 \\
19 \\
20 \\
21 \\
22 \\
23 \\
24 \\
25 \\
25 \\
26 \\
27 \\
28 \\
29 \\
30 \\
31\end{array}$ & 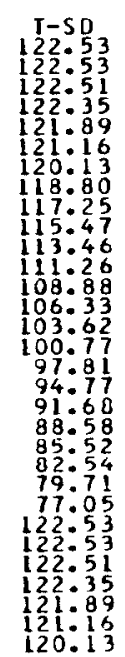 & $\left(\begin{array}{r}74.62 \\
72: 45\}\end{array}\right.$ & 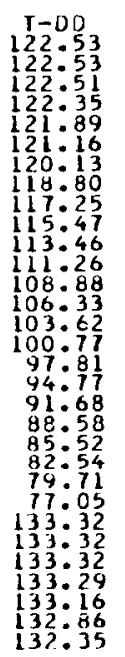 & $\left(\begin{array}{l}74.62) \\
(72: 45)\end{array}\right.$ & 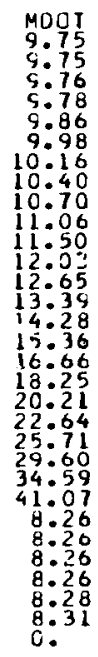 \\
\hline
\end{tabular}

*** 3 FRACTURES ***

* * INITIAL CEPTH $=13557.06$ FEEI*** INITIALLCRILLING ECSIS

RGI $=9.768 \quad$ GEO $=23.974$

*** NeVER Redrill, total cosi = INITIAL CCST***

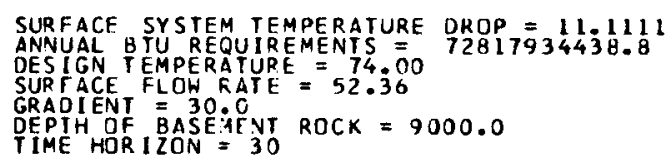


3 Program loops on various interest rates and initial drilling depths for all calculations, but we will use only the following (for this reason, subscripts on variables are not used here).

$R=0.0725$.

$D C I F=0.0434$.

$\mathrm{FCIF}=0.03$

DO $=11557$.

4 Calculates average temperature gained by drilling to initial depth.

$$
\begin{aligned}
\text { TROCK } & =\text { TDB }+(D O-D B) \times G R \\
& =90+(11557-9000) \times 0.009144 \\
& =113.38 .
\end{aligned}
$$

5 Calculates the present value of total benefits (avoided costs) for HDR where annual benefits are given as

$$
\begin{aligned}
\text { BENFIT } & =(\text { BARREL } \times \text { RP }) \times(1+F C I F) t /(1+R)^{t} \\
& =(26666.67 \times 31.13)(1.03)^{t} /(1.0715)^{t} .
\end{aligned}
$$

Annual benefits summed over $30 \mathrm{yr}=\$ 14.14$ million.

6 Determines RGI initial drilling costs (millions)

$$
\text { a. } \quad \begin{aligned}
\operatorname{RGICD} & =\operatorname{RGICST}(2) / 1000000 \\
& =8.457
\end{aligned}
$$

(uses values read from WICST3).

b. Calls subroutine GEOCST to calculate GEO initial drilling costs (millions) using the exponential function

$$
\begin{aligned}
\text { GEOCT }= & 2\left\{1 2 1 . 9 6 2 7 9 4 3 \left[\mathrm{e}^{1.130093434(\mathrm{DO} \times 0.3048 / 1000)}\right.\right. \\
& -\mathrm{e}^{1.130093484(\mathrm{DB} \times 0.3048 / 1000)]} \\
& +116.0894471 \mathrm{e}^{0.951723819(\mathrm{DB} \times 0.3048 / 1000)\} / 1000}
\end{aligned}
$$

$$
\begin{aligned}
= & 2\left[121.9627943\left(\mathrm{e}^{3.9808}-\mathrm{e}^{3.1001}\right)+116.0894471\right. \\
& \left.\mathrm{e}^{2.6108}\right] / 1000 \\
= & 10.810 .
\end{aligned}
$$


6 b. Figures cost of fracturing using

$$
\begin{aligned}
\text { GFRAC } & =0.07 \times \mathrm{NFRAC} \\
& =0.07 \times 3 \\
& =0.21
\end{aligned}
$$

and adds the two together for total cost:

$$
\begin{aligned}
\text { GEOCD } & =\text { GEOCT + GFRAC } \\
& =10.81+0.21 \\
& =11.02 .
\end{aligned}
$$

7 Temperature drawdown is calculated for each year and resulting temperature is checked to see if it has fallen below design temperature. For the purpose of illustration, the required calculations will be made to determine drawdown in year 1 and the temperature at the beginning of year $2[T(1)=$ TROCK, calculated above. $]$

$$
\text { a. } \begin{aligned}
\operatorname{MDOT}(1) & =\operatorname{SMDOT} \times(T D-\operatorname{TINJ}) /[T(1)-T I N J] \\
& =52.36(74-62.8889) /(113.38-62.8889) \\
& =11.5224
\end{aligned}
$$

Calculates flow rate through reservoir.

b. Calls subroutine FLOW, which calculates value for $Z$ and then for $\operatorname{erf}(Z)$ where.

$$
\begin{aligned}
Z & =\sqrt{\frac{\text { LAMDA } \times R O \times C R}{\text { TIME }}} \quad \frac{P I \times R^{2} \times N F R A C}{\text { MDOT } \times C W} \\
& =\sqrt{\frac{3 \times 2500 \times 1000}{3.1536 \times 10^{7} \times t}} \frac{3.1416 \times(180)^{2} \times 3}{11.5224 \times 4200} \\
& =3.077 .
\end{aligned}
$$

Since $z \geq 2$, 
b.

$$
\begin{aligned}
\text { erf } & =1-\frac{e^{-z^{2}}}{z \sqrt{P I}}\left[1-\frac{1}{2 z^{2}}+\frac{1 \times 3}{\left(2 z^{2}\right)^{2}}-\frac{1 \times 3 \times 5}{\left(2 z^{2}\right)^{3}}+\frac{1 \times 3 \times 5 \times 7}{\left(2 z^{2}\right)^{4}}\right. \\
& \left.-\frac{1 \times 3 \times 5 \times 7 \times 9}{\left(2 z^{2}\right)^{5}}\right] \\
& =1-\left\{\frac { e ^ { - 3 . 0 7 7 ^ { 2 } } } { 3 . 0 7 7 \sqrt { 3 . 1 4 1 6 } } \left[1-\frac{1}{2(3.077)^{2}}+\frac{3}{\left(2 \times 3.077^{2}\right)^{2}}\right.\right. \\
& \left.\left.=1-\frac{15}{\left(2 \cdot 3.077^{2}\right)^{3}}+\frac{105}{\left(2 \cdot 3.077^{2}\right)^{4}}-\frac{945}{\left(2 \cdot 3.077^{2}\right)^{5}}\right]\right\} \\
& =1.000 .
\end{aligned}
$$

Temperature in year 2 is thus

$$
\begin{aligned}
T(2) & =T I N J+(T R O C K-T I N J) \times E R F \\
& =62.8889+(113.38-62.8889) \times 1.0 \\
& =113.38 .
\end{aligned}
$$

In this example the rate of temperature drawdown was zero, so the same temperature was obtained in year 2 as in year 1 . In later years, temperature drawdown increases substantially, resulting in temperatures below design temperature after year 17. To illustrate this, the above calculations will be performed for year 17. Temperature at the beginning of the year was $79.48^{\circ} \mathrm{C}$, so

$$
\begin{aligned}
\operatorname{MDOT}(17) & =52.36(74-62.8889) /(79.48-62.8889) \\
& =35.07 . \\
Z(17) & =\sqrt{\frac{3 \times 2500 \times 1000}{17 \times 3.1536 \times 10^{7}}} \quad \frac{3.1416 \times(180)^{2} \times 3}{35.07 \times 4200} \\
& =0.2452 .
\end{aligned}
$$


b. Here, because $Z<2$,

$$
\begin{aligned}
\operatorname{erf}=\frac{2}{\sqrt{\mathrm{PI}}}(z & -\frac{z^{3}}{1 \times 3}+\frac{z^{5}}{1 \times 2 \times 5}-\frac{z^{7}}{1 \times 2 \times 3 \times 7} \\
& \left.+\frac{z^{9}}{1 \times 2 \times 3 \times 4 \times 9}\right) \\
= & \frac{2}{\sqrt{3.1416}}\left(0.2452-\frac{0.2452^{3}}{3}+\frac{0.2452^{5}}{10}-\frac{0.2452^{7}}{42}+\frac{0.2452^{9}}{216}\right) \\
= & 0.2712,
\end{aligned}
$$

and temperature at the beginning of year 18 is

$$
\begin{aligned}
T(18) & =\text { TINJ + (TROCK }- \text { TINJ) } \times \text { ERF } \\
& =62.8889+(113.38-62.8889)(0.2712) \\
& =76.58 .
\end{aligned}
$$

The temperature at the beginning of year 18 is still above design temperature $\left(74^{\circ}\right)$, but falls below design by the end of the year (73.96).

8 Because temperature at the end of year 18 (beginning of year 19) was below design temperature, the program exits from the drawdown loop (line 63 ) and goes on to compute redrilling and preheat costs. A check is also made to ensure that the end of the time horizon has not been reached (1ine 72).

9 Program initializes values to be used in calculating redrilling to same depth using RGI cost data and for the preheat option (lines 78-94). Redrilling takes place in year 18 and preheat also begins in year 18. Number of redrillings equals 1 .

10 Calculates present values of redrilling in year 18 to same depth. Since this is the first redrilling, the value for "odd" redrillings is used.

$$
\begin{aligned}
& \operatorname{RGIODD}(18)=[(\operatorname{RGICST}(3)+358.160)] \\
& x\left[(1+D C I F)^{t-1} /(1+R)^{t-1}\right] / 1000000 \\
& =(4156900+358160)
\end{aligned}
$$


Step

$$
\begin{aligned}
& \times\left[(1.0434)^{\left.17 /(1.0725)^{17}\right] / 1000000}\right. \\
= & 2.829
\end{aligned}
$$

where $\$ 358160$ is a plugging cost to shut down the old injection well when the new one is opened.

11 Determines length of time preheat will be used (1ines 97-101). Normally it would be 18 years, the amount of time before redrilling would again occur, but because that extends past the time horizon, the preheat option will be used only through the end of year 30 .

12 Calls subroutine HEAT, which calculates preheat option costs as follows.

a. Calls subroutine FLOW, which determines temperature drawdown during the year (uses surface flow rate as reservoir flow rate as it is assumed that one flow rate is used for an entire year, and temperature is below design temperature at some point in the year, therefore negating the possibility of mixing at the surface).

b. Calculates temperature at end of year.

c. Determines average yearly temperature

$$
\begin{aligned}
\operatorname{TAVG} & =[\operatorname{TT}(18)+\operatorname{TT}(19)] / 2 \\
& =(76.58+71.91) / 2 \\
& =74.25 .
\end{aligned}
$$

d. Checks to see if average temperature is above design temperature ( 1 ine 402). If so, computes average temperature for second half of year.

$$
\begin{aligned}
\text { TTAVG } & =[\text { TAVG }+ \text { TT(19) }] / 2 \\
& =(74.25+71.91) / 2 \\
& =73.08 .
\end{aligned}
$$

e. Computes Btus required to heat HDR water to design temperature using conventional system. If TAVG < TD

HBTU $=[$ MDOT $\times 4200 \times($ TD - TAVG $) \times 31536000 \times 1.27] / 1054$.

If $T A V G \geq T D$

HBTU $=[$ MDOT $\times 4200 \times($ TD - TTAVG $) \times 31536000$ 
Step

12

e.

$\times 1.27] /(1054 \times 2)$

because preheating is only required for half the year. In our case,

$$
\begin{aligned}
\text { HBTU }= & {[52.36 \times 4200 \times(74-73.08) \times 31536000} \\
& \times 1.27] /(1054 \times 2) \\
= & 3843938910 .
\end{aligned}
$$

f. Computes barrels of $0 i 1$ needed to supply the Btu requirement.

$$
\begin{aligned}
B A R & =H B T U /(144000 \times 42) \\
& =3843938910 /(144000 \times 42) \\
& =635.57 .
\end{aligned}
$$

g. Computes cost of oil used for preheating

If $T A V G<T D$

CBTUR $=$ BAR $\times \operatorname{RP} \times\left[(1+F C I F)^{t-1 /(1+R)^{t-1}}\right] / 1000000$

If $T A V G \geq T D$

CBTUR $=$ BAR $\times R P \times\left[(1+F C I F)^{\left.t-1+1 / 2 /(1+R)^{t-1+1 / 2}\right] / 1000000}\left(\begin{array}{l}(410) \\ \text { R }\end{array}\right.\right.$

(discounts to middle of year).

If $T T A V G \geq T D$

CBTUR $=0$

assumes that if preheating takes place for less than $1 / 4$ of a year that the cost is zero.

In our case

$$
\begin{aligned}
\text { CBTUR } & =635.57 \times 31.13 \times\left(1.03^{\left.17.5 / 1.0725^{17.5}\right) / 1000000}\right. \\
& =0.0098 .
\end{aligned}
$$

h. Process repeats for every year that preheating is used in the period and then yearly figures are summed. Using the steps outlined above gives us 
$\underline{\text { Step }}$

\begin{tabular}{|c|c|c|c|c|c|}
\hline Year & $T$ (beginning) & $T($ end $)$ & TAVG & TTAVG & CBTUR \\
\hline 18 & 76.58 & 71.91 & 74.25 & 73.08 & 0.0098 \\
\hline 19 & 71.91 & 71.67 & 71.79 & - & 0.0459 \\
\hline 20 & 71.67 & 71.45 & 71.56 & - & 0.0487 \\
\hline 21 & 71.45 & 71.25 & 71.35 & - & 0.0508 \\
\hline 22 & 71.25 & 77.06 & 71.16 & - & 0.0523 \\
\hline 23 & 71.06 & 70.88 & 70.97 & -- & 0.0535 \\
\hline 24. & 70.88 & 70.71 & 70.80 & -- & 0.0543 \\
\hline 25 & 70.71 & 70.56 & 70.64 & -- & 0.0548 \\
\hline 26 & 70.56 & 70.41 & 70.49 & -- & 0.0549 \\
\hline 27 & 70.41 & 70.27 & 70.34 & -- & 0.0550 \\
\hline 28 & 70.27 & 70.14 & 70.21 & -- & 0.0547 \\
\hline 29 & 70.14 & 70.02 & 70.08 & -- & 0.0543 \\
\hline 30 & 70.02 & 69.90 & 69.96 & -- & 0.0538 \\
\hline
\end{tabular}

Total cost for preheating is $\$ 0.6428$ million for the period year 18 through year 30 .

13 Compares total cost for preheat option to cost for redrilling (line 103). If preheating is more expensive than redrilling the program opts to redrill under the preheat option (1ines 106-108).

14 If redrilling occurs more than once during the time horizon, steps 9-13 are repeated (using RGIODD for odd numbered redrillings and RGIEVN for even numbered redrillings).

15 Total cost for redrilling to same depth using RGI cost figures is added to cost for initial drilling to give total reservoir costs under that option (1ine 139). Total preheat costs are added to initial drilling costs to give total reservoir costs for that option (line 140).

16 Program initializes values to be used in calculating redrilling to same depth using GEO cost data (1ines 148-151).

17 Calculates present value of redrilling in year 18 to same depth using GEO cost.

$$
\begin{aligned}
& \operatorname{GEORD}(18)=(0.5 \mathrm{GEOCT}+\mathrm{GFRAC}+0.35816) \\
& x\left[(1+D C I F)^{t-1} /(1+R)^{t-1}\right] \\
& =[0.5(10.81)+0.21+0.35816] \times(1.043417 / 1.072517) \\
& =3.7421 \text {. }
\end{aligned}
$$

Redrilling costs include plugging cost (0.35816), fracturing cost $(0.21)$ and half the cost of initial drilling, as only one well must be drilled in order to create a new reservoir system. 
Step

18 Preheat costs for the period (calculated in step 12 above) are compared to redrilling costs using GEO cost calculations (line 156). If preheat costs exceed redrilling costs, redrilling is undertaken using this option (line 159).

19 If redriling occurs more than once, steps 16-18 are repeated.

20 Total cost for redrilling to same depth using GEO cost figures is added to cost for initial drilling to give total reservoir costs (Line 164). Total preheat costs are added to initial costs to give total reservoir costs for that option (1ine 165).

21 Program initializes values to be used in calculating redrilling to deeper depths using both RGI and GEO cost data (1ines 170-180).

22 Redrilling depth is calculated

$D(K)=D O+H F \times K$

$D(1)=11557+(1181 \times 1)$

$=12738$.

23 The temperature obtained by creating the new reservoir via the deeper-drilling redrilling option is calculated:

$$
\begin{aligned}
\text { TTROCK } & =\text { TDB }+[D(1)-D B] \times G R \\
& =90+(12738-9000) \times 0.009144 \\
& =124.18 .
\end{aligned}
$$

24 Calculates cost associated with drilling one well to a deeper depth and fracturing to create a new reservoir.

a. $\operatorname{RGID}(1)=[\operatorname{RGICST}(5)+358.160]$

$$
\begin{aligned}
& x\left[(1+D C I F)^{t-1} /(1+R)^{t-1}\right] / 1000000 \\
= & (4839200+358.160) \\
& x\left(1.0434^{\left.17 / 1.0725^{17}\right) / 1000000}\right. \\
= & 3.256 .
\end{aligned}
$$

b. Calls subroutine GEOCOST to compute redrilling cost as

$$
\begin{aligned}
\text { GEORRD }= & 2\left\{1 2 1 . 9 6 2 7 9 4 3 \left[\mathrm{e}^{1.130093484[D(1) \times 0.3048 / 1000]}\right.\right. \\
& \left.-\mathrm{e}^{1.130093484(D B \times 0.3048 / 1000)}\right]+116.0894471 \\
& \times \mathrm{e}^{0.951723819(\mathrm{DB} \times 0.3048 / 1000)\} / 1000}
\end{aligned}
$$


Step

24

b. $\quad=17.369$.

Present value of redrilling is then given as

$$
\begin{aligned}
\operatorname{GEOD(1)=} & (0.5 \text { GEORRD }+ \text { GFRAC }+0.35816) \\
& x\left[(1+\text { DCIF })^{\left.t-1 /(1+R)^{t-1}\right]}\right. \\
= & {[0.5(17.369)+0.21+0.35816] } \\
& x(1.043417 / 1.072517) \\
= & 5.797 .
\end{aligned}
$$

Program calculates reservoir system flow rate and calls subroutine FLOW to calculate temperature drawdown. It then computes the temperature at the beginning of the next year. The process repeats until such time as reservoir temperature falls below design temperature or the end of the time horizon is reached (1ines 191-200). In our sample case, the temperature at the end of year 30 is $109.24^{\circ}$, which is above design temperature, so redrilling does not occur again, and we go to step 26. If temperature in any year (before the end of the time horizon) had fallen below design temperature, redrilling would have occurred again, and steps 21-25 would have been repeated.

26 Total cost for redrilling to deeper depths using RGI cost data is added to initial RGI drilling cost to give total reservoir costs.

$$
\begin{aligned}
\text { RGITDD } & =\text { RGIDD+RGICD } \\
& =3.198+8.268 \\
& =11.466 .
\end{aligned}
$$

Total cost for redrilling to deeper depths using GEO cost data is added to initial GEO drilling cost to give total reservoir costs.

$$
\begin{aligned}
\text { GEOTDD } & =\text { GEODD + GEOCD } \\
& =5.797+11.02 \\
& =16.817 .
\end{aligned}
$$

Al1 the steps given above are repeated for each combination of interest rates and for each initial drilling depth tested until (1) all depths are tested or (2) the initial drilling at a given depth results in a high enough temperature that the reservoir remains above design temperature throughout the time horizon. Should (2) occur, no further depths are tested. 
Step

29 The program then prints all total cost figures, net benefits, and the time path of reservoir temperature under each option at the terminal. 
HDR3 VARIABLE LIST

BARREL

BENF IT

BTUS

$D(L, N N N(L, K(L)))$

DB

DCIF (II)

DELT

DO(L)

$\operatorname{ERF}(L, J)$

FCIF (III)

G

GEOCD(L)

GEOCT

$\operatorname{GEOD}(L, I, I I, K(L))$

$\operatorname{GEODD}(L, I, I I)$

$\operatorname{GEOPH}(L, I, I I, I I I)$ the number of barrels of \#6 oil used to produce a given amount of Btus.

the present value of annual benefits attributable to HDR, defined as the avoided costs of using the conventional heat source (millions 1980\$).

the annual Btu requirement for space heating using the conventional system (steam heat generated by \#6 0i1).

the temperature depth to which a new well is drilled when redrilling to deeper depths (feet).

depth to basement rock (feet).

the IIth real rate of annual increase in drilling costs.

difference between entrance and exit temperatures in the surface system heat exchanger $\left(\mathrm{T}^{\circ} \mathrm{C}\right)$.

depth to temperature center reached as a result of initial drilling (feet).

the calculated error function used to compute temperature drawdown for initial drilling depth index $L$ in year $\mathrm{J}$.

the IIIrd real rate of annual increase in fuel costs.

geothermal gradient $\left({ }^{\circ} \mathrm{C} / \mathrm{km}\right)$.

the cost of creating the initial reservoir using GEOCOST for the initial depth index L (millions 1980\$).

the undiscounted cost of drilling a well pair to a given depth (millions of dollars).

the present value cost of redrilling to deeper depths for the $k$ th redrilling using GEOCOST and initial drilling depth index $L$ and interest rate indexes $I$ and II (millions 1980\$).

the sum of the present value costs for all redrillings to deeper depths using GEOCOST, initial drilling depth index $\mathrm{L}$, and interest rate indexes $\mathrm{I}$ and II (millions 1980\$).

the present value of total reservoir costs using the preheat option and GEOCOST for initial drilling depth $L$ and interest rate indexes I, II, and III (millions 1980\$). 
GEORD (L, I, II,NN(L,NRD(L))) the present value cost of redrilling to same depth in year NN with initial depth index $L$ and interest rate indexes I and II using GEOCOST (millions 1980\$).

GEORRD

$\operatorname{GEOSD}(L, I, I I)$

$\operatorname{GEOTDD}(L, I, I I)$

$\operatorname{GEOTSD}(L, I, I I)$

GFRAC

GR

HDRBTU

HF

$\operatorname{HTCST}(\operatorname{NRD}(L))$

I, II , II I

ITH

$K(L)$

L

$\operatorname{MDOT}(L, J)$

MM

NDCIF same as GEOCT, used for deeper drilling option (millions of dollars).

the sum of the present value costs of all redrillings to same depth using GEOCOST (mil1ions 1980\$).

the present value of total reservoir costs under the deeper depth redrilling option using GEOCOST, initial depth index $L$ and interest rate indexes $I$ and II (millions $1980 \$)$.

the present value of total reservoir drilling costs under the same depth redrilling option using GEOCOST with initial depth index $L$ and interest rate indexes $I$ and II (millions 1980\$).

the undiscounted cost of fracturing (millions of dollars).

geothermal gradient $\left({ }^{\circ} \mathrm{C} / \mathrm{ft}\right)$.

the annual Btu requirement for space heating using the HDR, hot water system.

the height of fractures (feet).

the present value cost of using the preheat option for the period associated with the NRDth redrilling (millions $1980 \$)$.

indexes for the discount rate, rate of drilling cost increase factor, and rate of fuel cost increase factor, respectively.

the time horizon over which the system will operate (years).

the number of redrillings that have occurred under the deeper depth redrilling option for an initial depth index L.

initial drilling depth index.

the reservoir system flow rate in year $J$ for the initial depth index $\mathrm{L}(\mathrm{kg} / \mathrm{s})$.

a counter for years since any drilling occurred, used to compute temperature drawdown.

the number of drilling cost increase factors to be tested. 
NFCIF

NFRAC

$N N(L, N R D(L))$

$N N N(L, K(L))$

NR

$\operatorname{NRD}(L)$

$R(I)$

$\operatorname{RGICD}(L)$

$\operatorname{RGICST}(L, N)$

$\operatorname{RGID}(L, I, I I, K(L))$

$\operatorname{RGIDD}(L, I, I I)$ the number of fuel cost increase factors to be tested.

the number of fractures in the reservoir system.

the year in which the NRDth redrilling occurs under the same depth redrilling option, for initial depth index $L$.

the year in which the $K$ th redrilling occurs under the deeper depths redrilling option, for initial depth index $L$.

the number of real discount rates to be tested.

the number of redrillings that have occurred under the same depth redrilling option for an initial depth index $L$.

the Ith real rate of social discount.

the cost of creating the initial reservoir using RGICOST, for the initial depth index $L$ (millions 1980\$)

matrix of cost data contained in the file WICST , where L is the row and $\mathrm{N}$ is the column.

the present value cost of redrilling to deeper depths for the Kth redrilling using RGICOST, for initial depth index $L$ and interest rate indexes $I$ and II (millions 1980\$).

the sum of the present value costs for all redrillings to deeper depths using RGICOST, initial depth index $L$, and interest rate indexes I and II (millions 1980\$).

$\operatorname{RGIEVN}(L, I, I I, N N(L, N R D(L)))$ the present value of redrilling to same depth in year NN when a new production well is created using RGICOST, initial depth index $L$, and interest rate indexes I and II (millions 1980\$).

$\operatorname{RGIODD}(L, I, I I, N N(L, N R D(L)))$ the present value of redrilling to same depth in year NN when a new injection well is created using RGICOST, initial depth index $L$, and interest rate indexes I and II (millions 1980\$).

RGIPH(L, I, I I , I I I)

$\operatorname{RGISD}(L, I, I I)$

$\operatorname{RGITDD}(L, I, I I)$ the present value of total reservoir costs using the preheat option and RGICOST for initial depth index $L$ and interest rate indexes I, II, and III (millions 1980\$).

the sum of the present value costs of all redrillings to same depth using RGICOST for initial depth index $L$ and interest rate indexes I and II (millions 1980\$).

the present value of total reservoir costs under the deeper depths redrilling option using RGICOST, initial depth index $L$ and interest rate indexes $I$ and II (millions $1980 \$$ ). 
$\operatorname{RGITSD}(L, I, I I)$

$\mathrm{RP}$

SMDOT

$T(L, J)$

TD

TDB

THTCST

TINJ

TONE

TOTBEN ( I , I I I)

$\operatorname{TROCK}(L)$

$T T(L, J)$

TTHREE

TTROCK

$\operatorname{TTT}(L, J)$

TTWO

$\operatorname{TT}(L)$ the present value of total reservoir costs under the same depth redrilling option using RGICOST, initial depth index $L$, and interest rate indexes I and II (millions 1980\$).

the retail price of alternative fuel source (\#6 0i1) (1980\$/barrel).

the surface system flow rate $(\mathrm{kg} / \mathrm{s})$.

temperature at the beginning of year $J$ resulting from initial drilling and redrilling to same depth for initial depth index $L\left({ }^{\circ} \mathrm{C}\right)$.

design temperature or minimum temperature requirement for the surface system $\left({ }^{\circ} \mathrm{C}\right)$.

the temperature of the rock at a depth equal to the depth of basement $\left({ }^{\circ} \mathrm{C}\right)$.

the present value of total reservoir costs using the preheat option (millions 1980\$).

the temperature of water that is reinjected into the HDR reservoir from the surface $\left({ }^{\circ} \mathrm{C}\right)$.

the first year of the period for which preheat option costs are calculated.

the present value of total benefits (avoided costs) attributable to the use of HDR for interest rate indexes I and III (millions 1980\$).

the temperature resulting from initial drilling to the depth $D O$ for the initial depth index $L\left({ }^{\circ} \mathrm{C}\right)$.

temperature at the beginning of year $J$ resulting from redrilling to deeper depths for initial depth index $L$ $\left({ }^{\circ} \mathrm{C}\right)$.

the last year of the period for which preheat option costs are calculated when the first year of the period is TTWO.

the temperature resulting from redrilling to deeper depths $\left({ }^{\circ} \mathrm{C}\right)$.

temperature at the beginning of year $\mathrm{J}$ resulting from the use of the preheat option for initial depth index $L\left({ }^{\circ} \mathrm{C}\right)$.

the last year of the period for which preheat option costs are calculated, also the first year of the next period.

the temperature that would have resulted at the beginning of the year had redrilling to the same depth not occurred in that year $\left({ }^{\circ} \mathrm{C}\right)$. 
$\operatorname{TTXX}(L, K(L))$

the temperature that would have resulted at the beginning of the year had redrilling to deeper depths not occurred in that year $\left({ }^{\circ} \mathrm{C}\right)$.

$\operatorname{TX}(L)$

the temperature that would have resulted at the end of the year had redrilling to the same depth not occurred in that year $\left({ }^{\circ} \mathrm{C}\right)$.

$\operatorname{TXX}(L, K(L))$

the temperature that would have resulted at the end of the year had redrilling to deeper depths not occurred in that year $\left({ }^{\circ} \mathrm{C}\right)$.

$Z(L, J)$

the calculated value used to compute the error function in year $\mathrm{J}$ for initial drilling depth index $\mathrm{L}$. 


\section{REFERENCES}

1. "Industrial Assessment of Drilling Completion and Workover Costs of the Well and Fracture Subsystems of Hot Dry Rock Geothermal Systems," prepared for Los Alamos National Laboratory by Republic Geothermal, Inc., Santa Fe Springs, California (March 17, 1979).

2. R. G. Cummings, C. J. Arundale, R. L. Bivins, H. S. Burness, R. H. Drake, and R. D. Norton, "The Use of Hot, Dry Rock Geothermal Resources for Space Heating: A Case Study," LoS Alamos National Laboratory report (in preparation). 
APPENDIX A

FILE WRITEPP

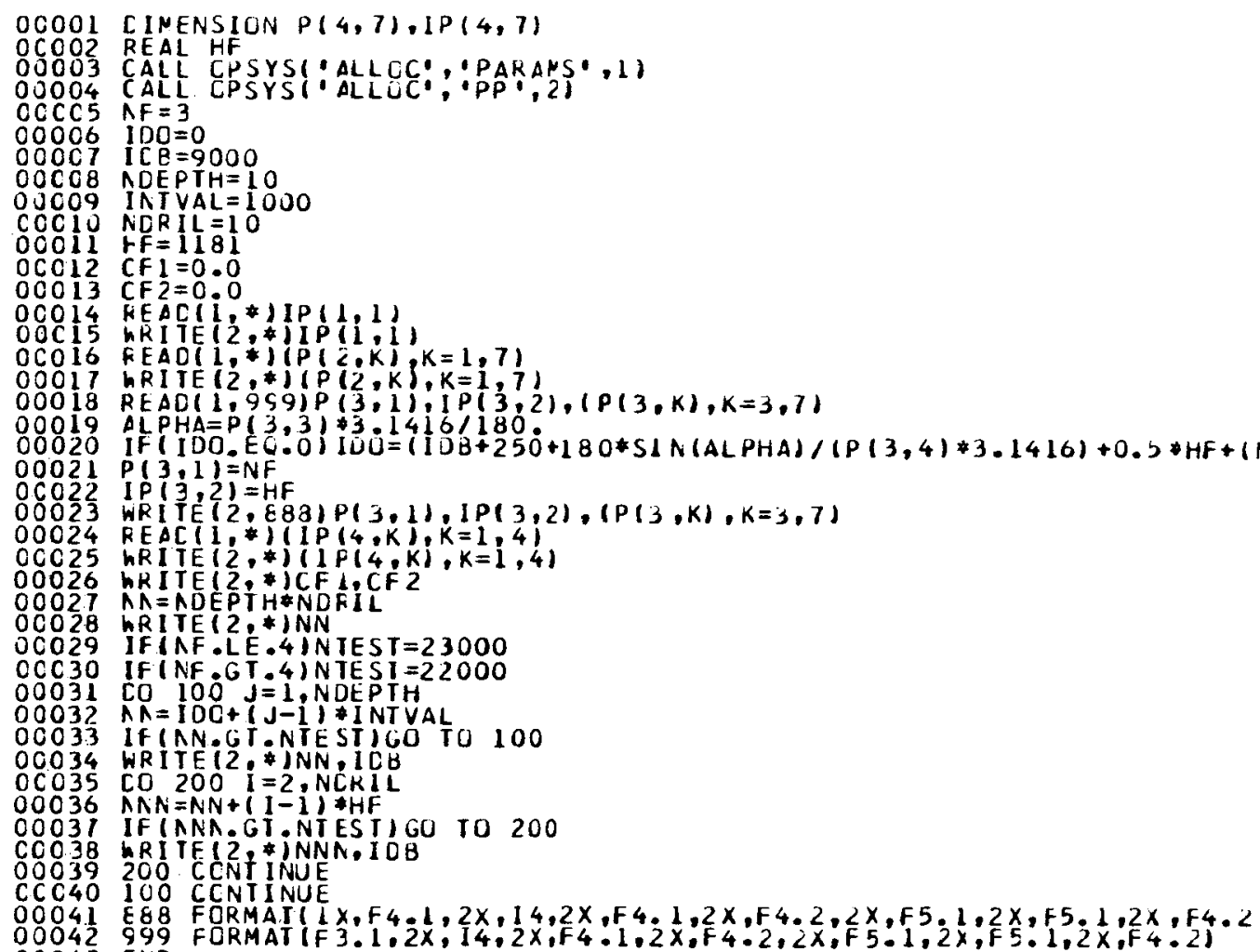




\section{APPENDIX B}

F ILE IT

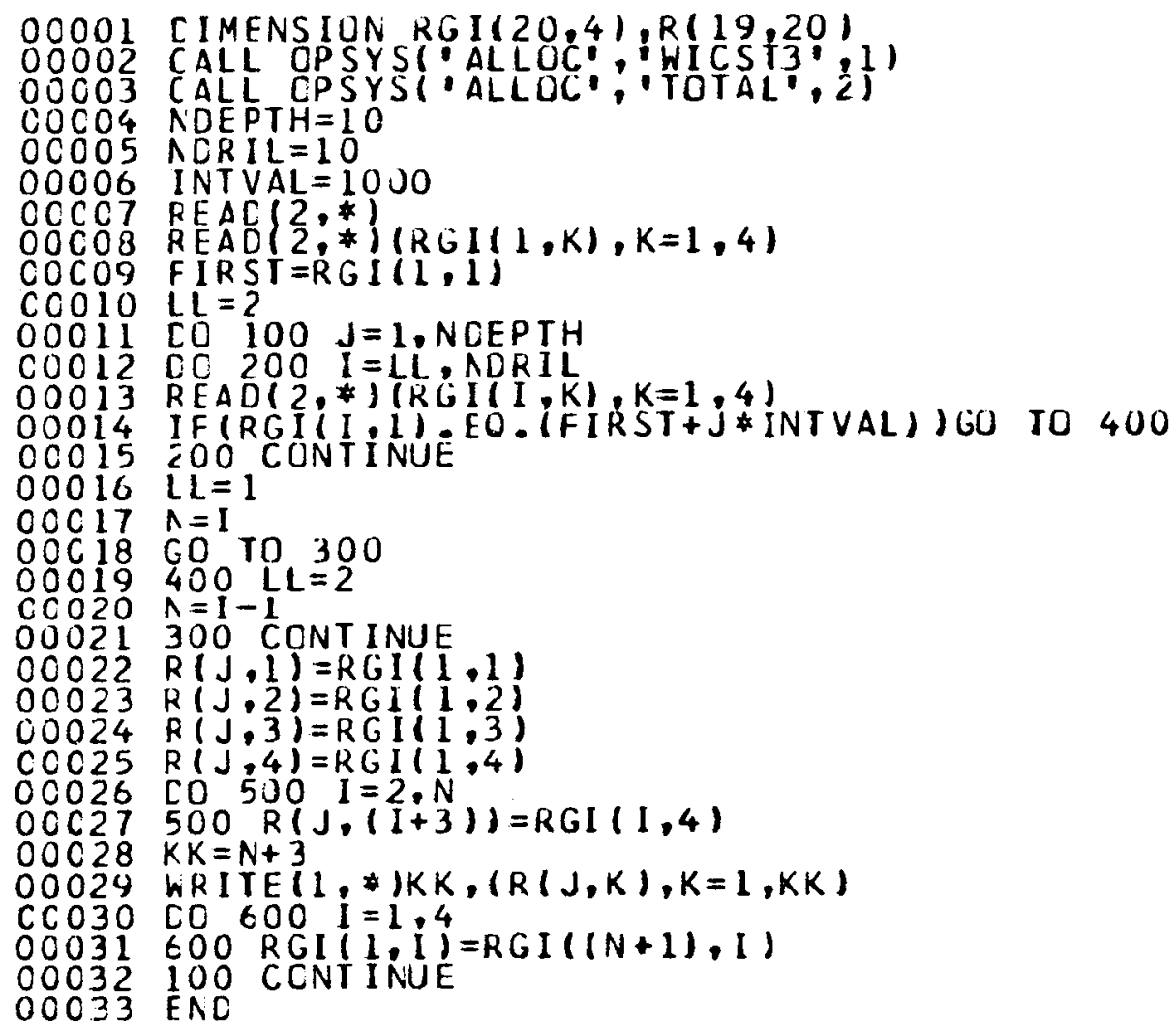




\section{APPENDIX C}

\section{RGICOST}

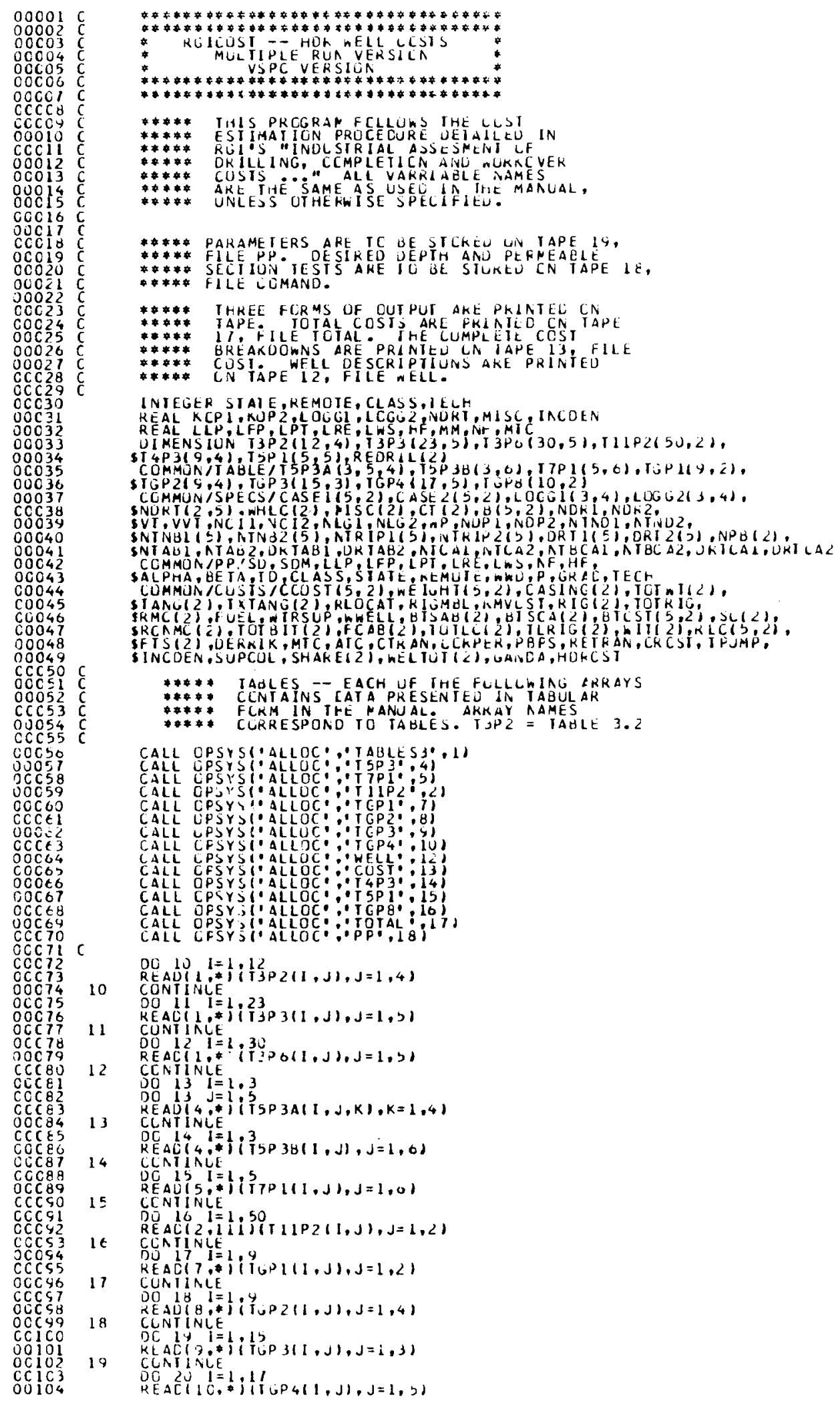




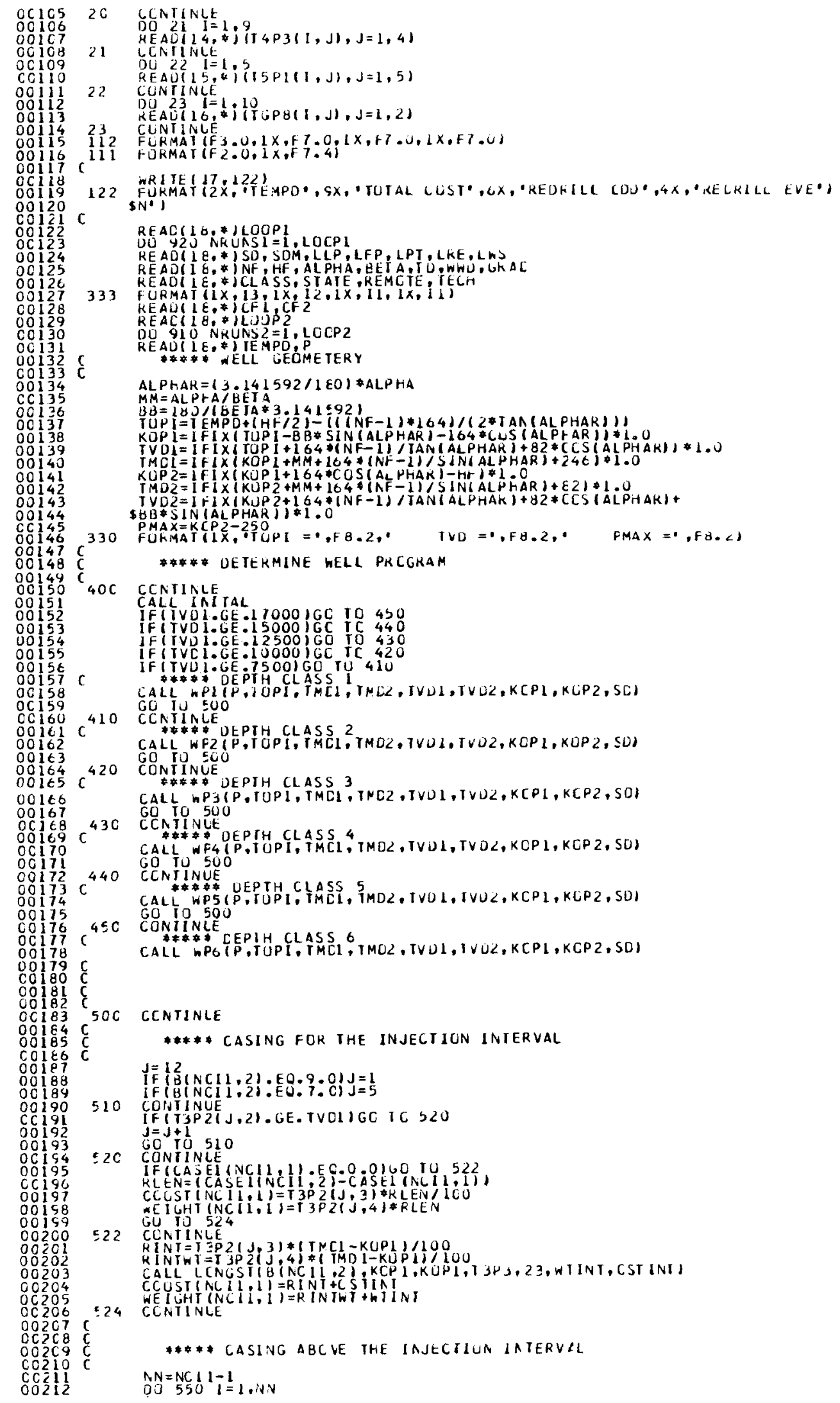




\section{RGICOST (cont)}

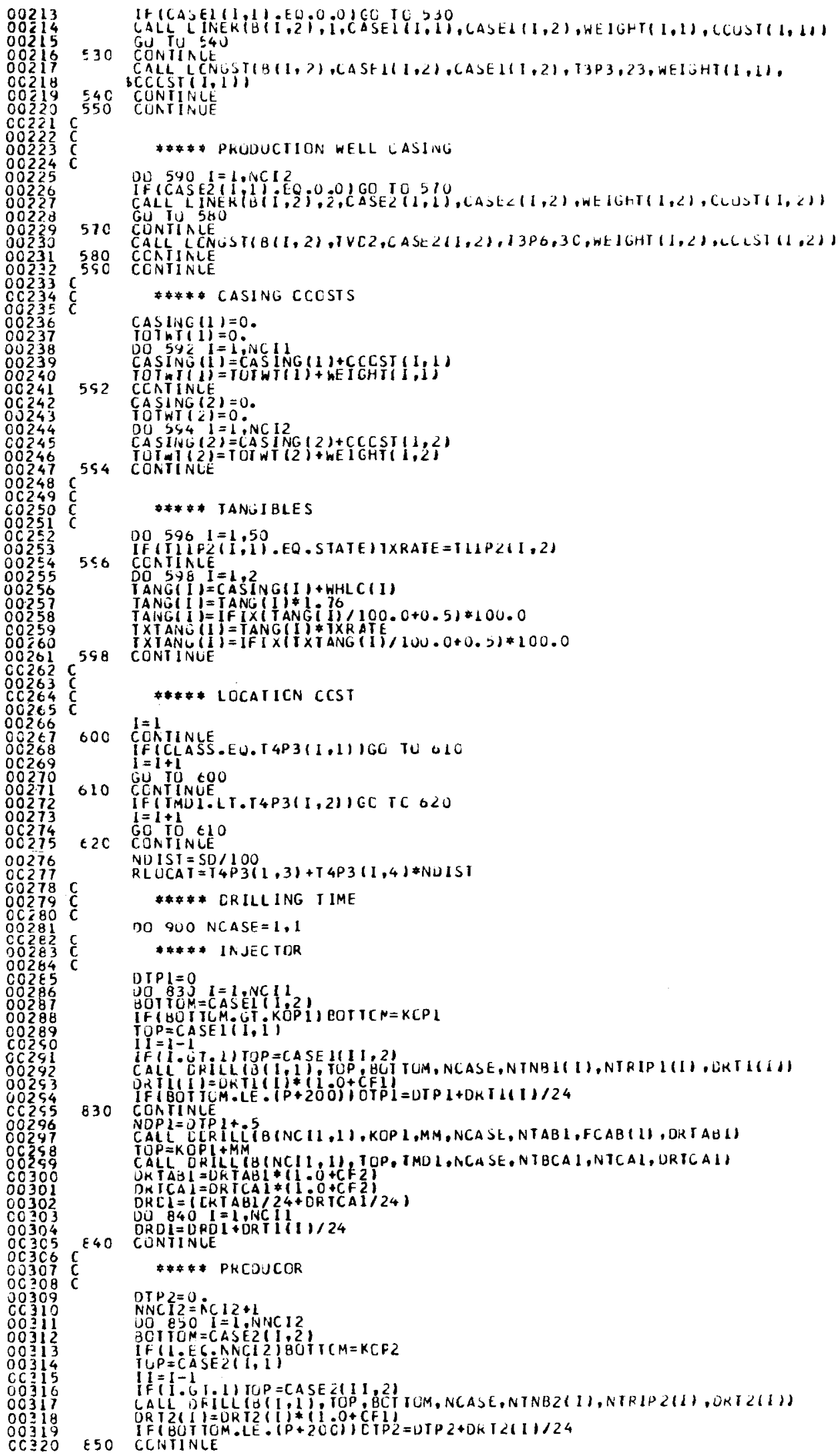




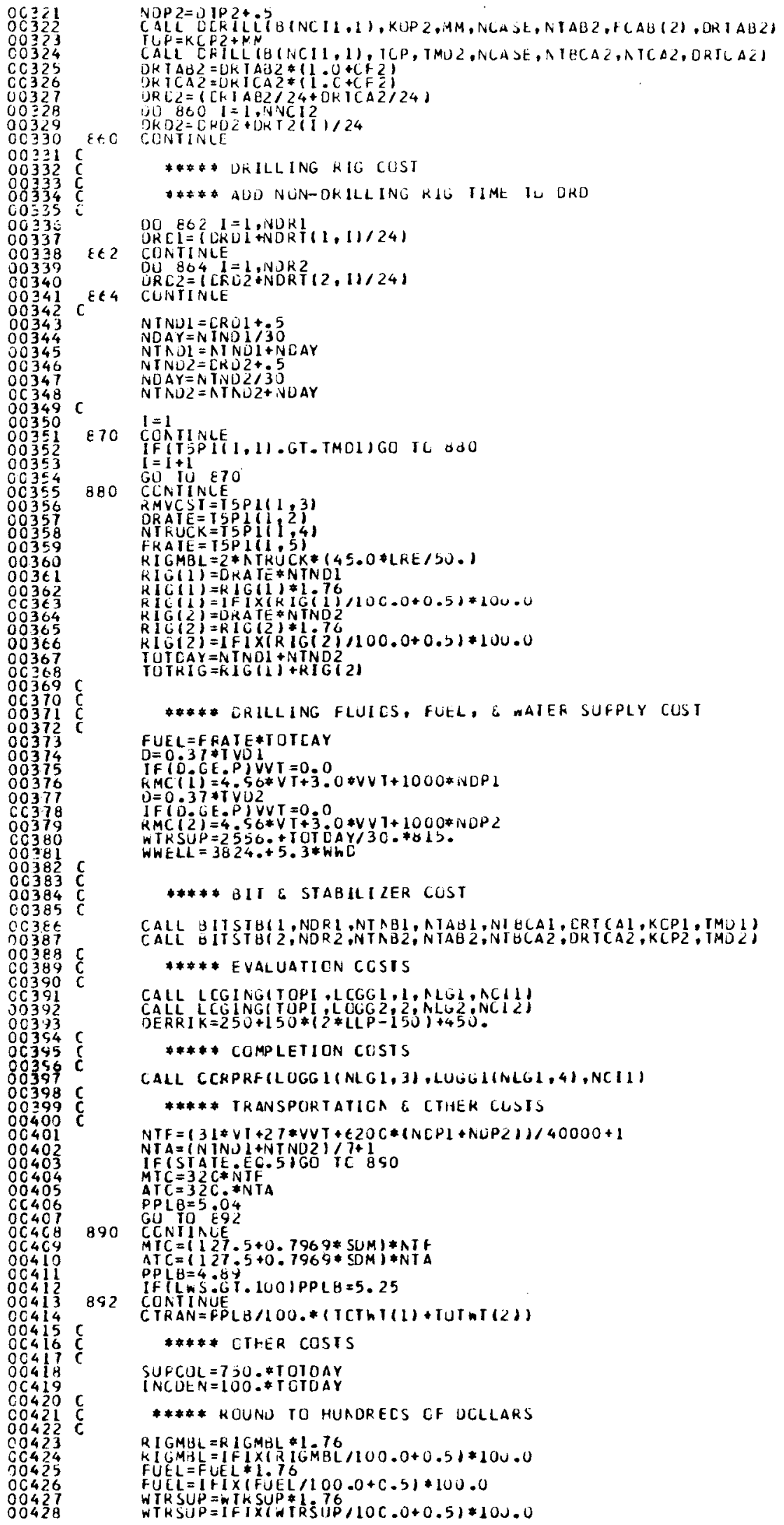




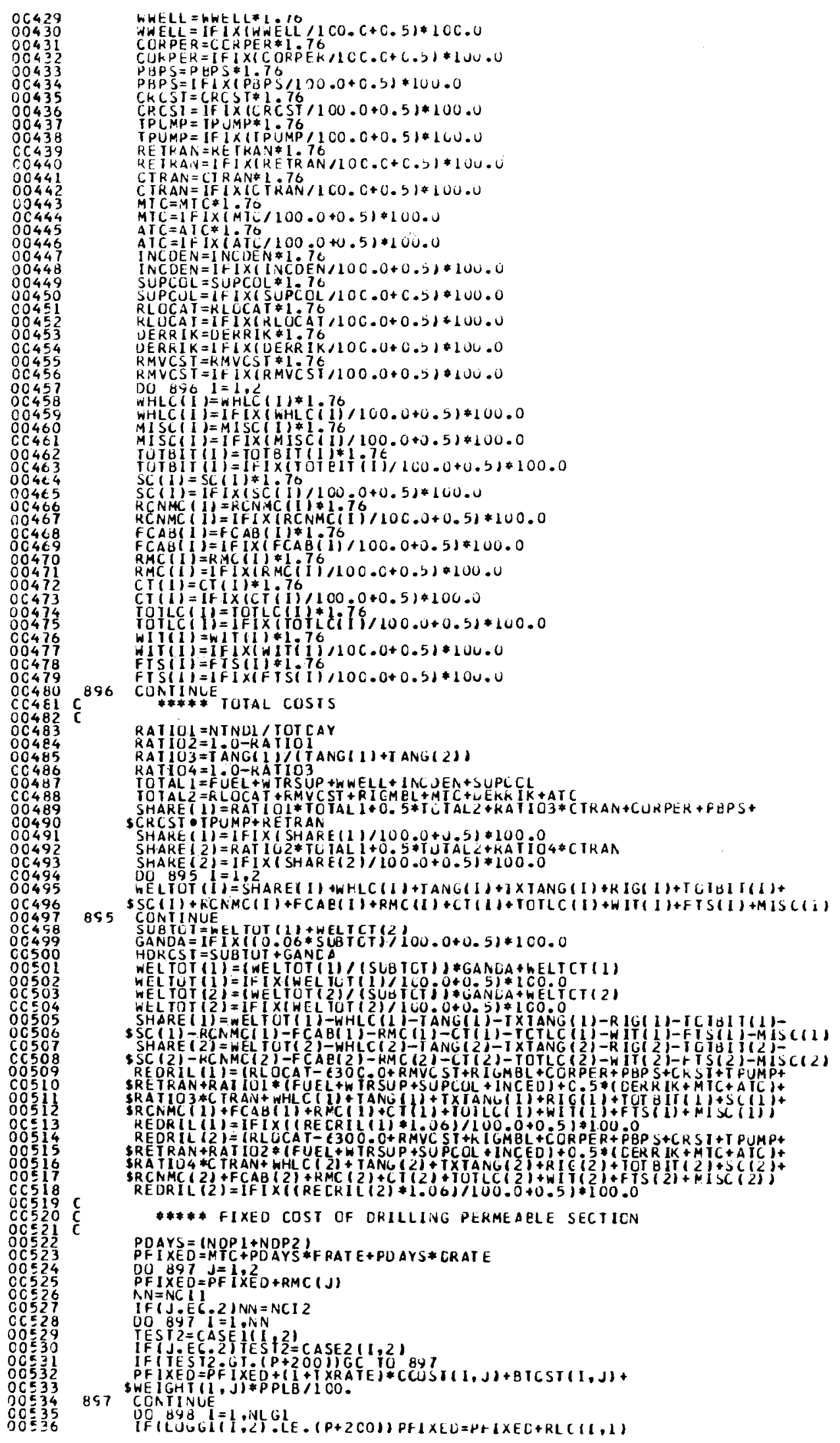




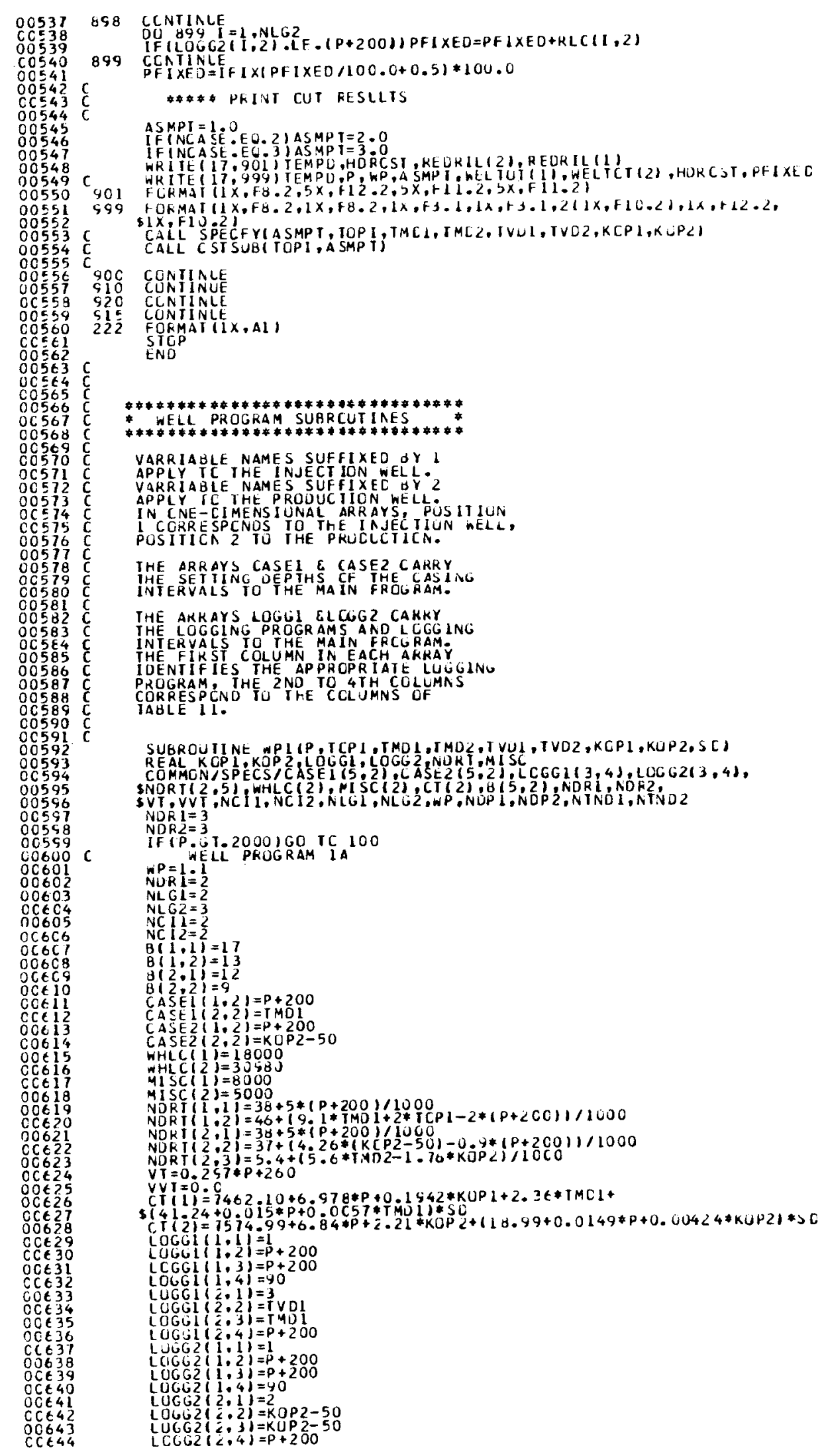


RGICOST (cont)

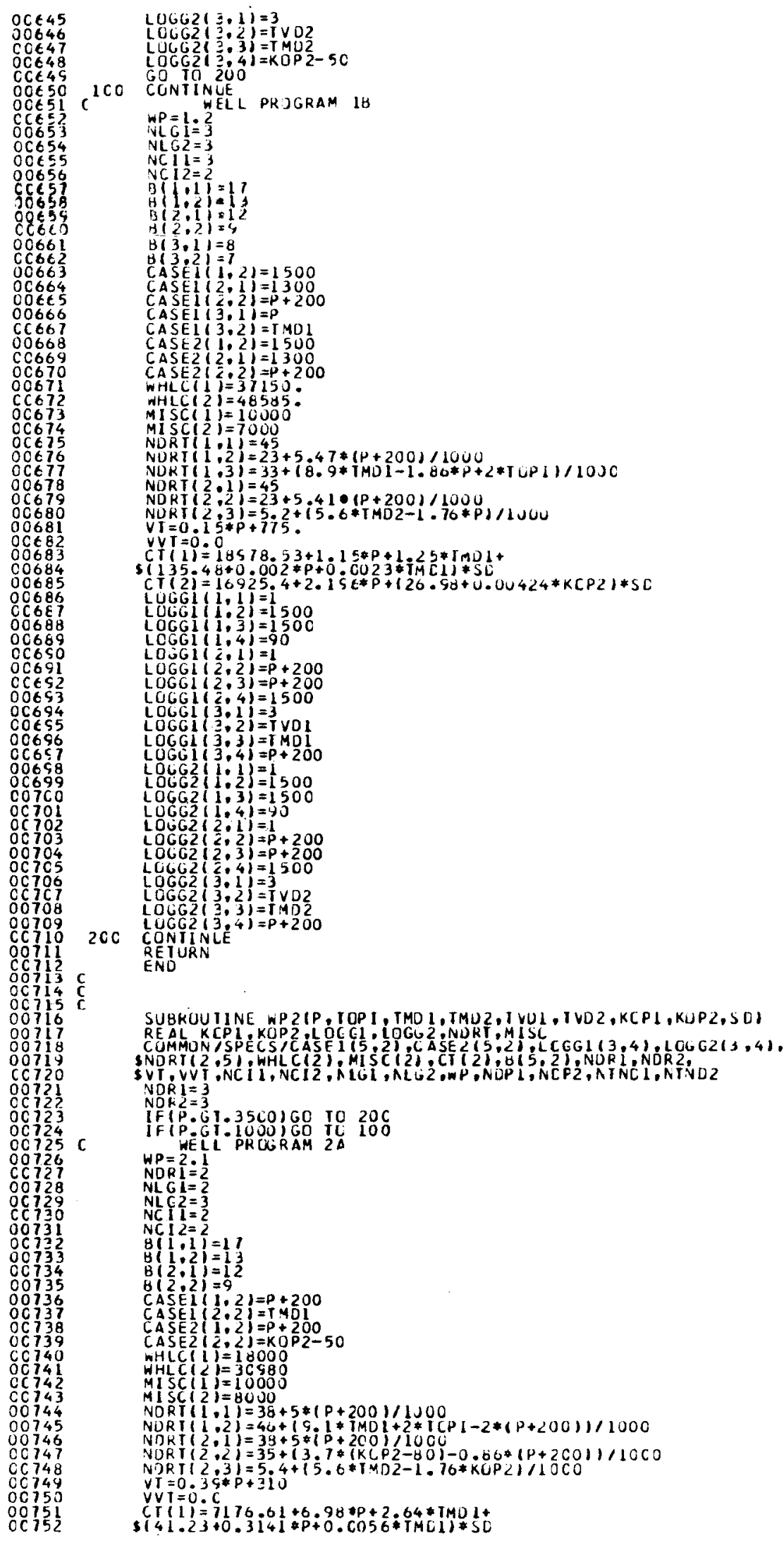


RGICOST (cont)

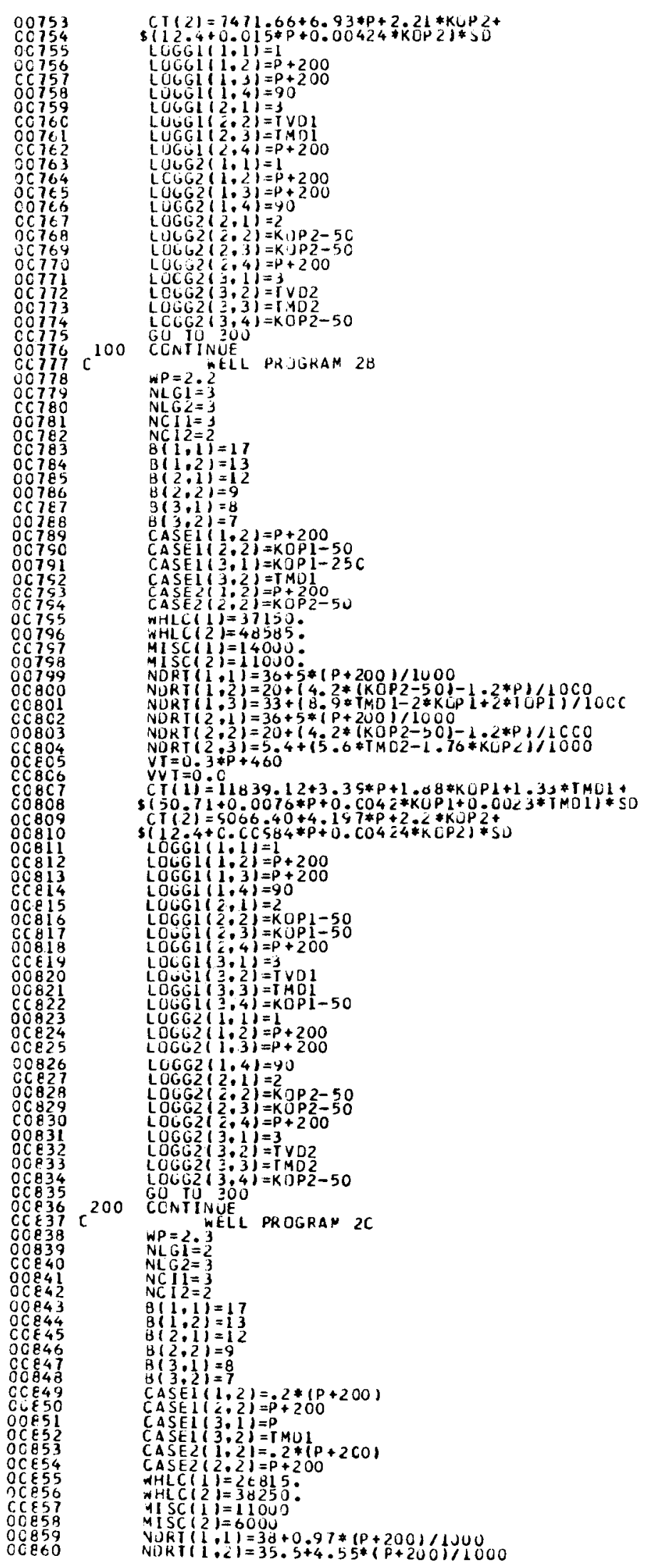




\section{RGICOST (cont)}

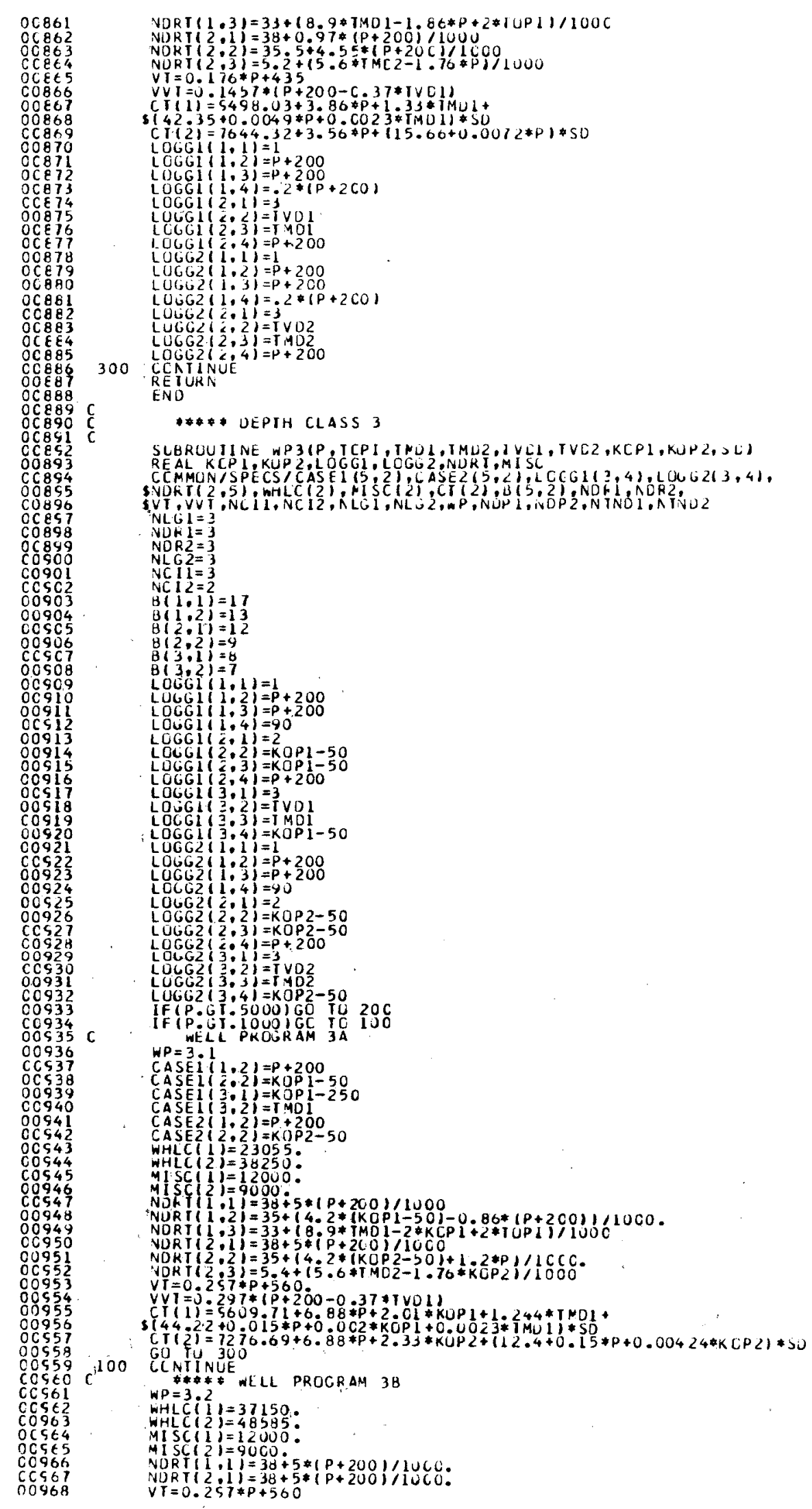




\section{RGICOST (cont)}

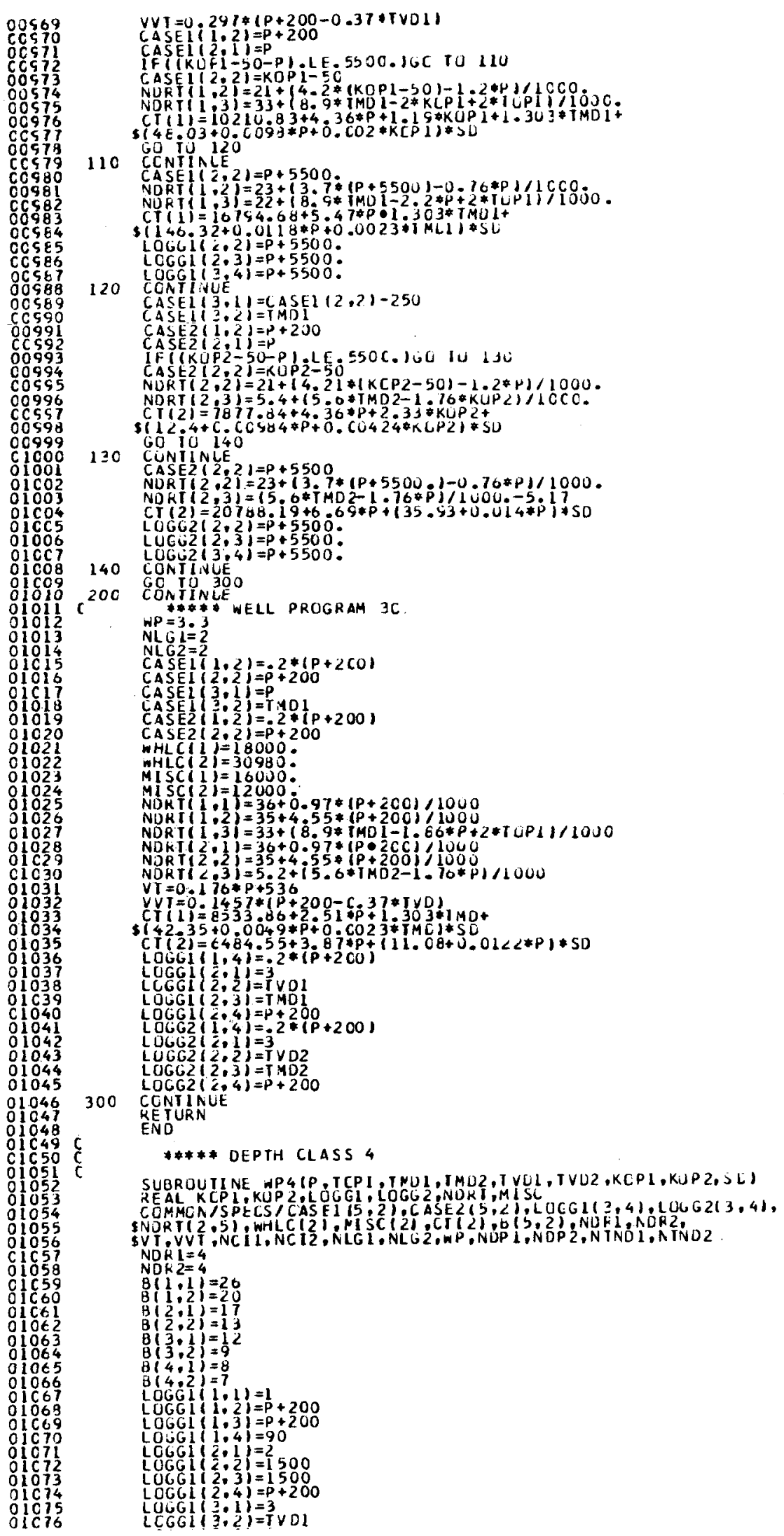




\section{RGICOST (cont)}

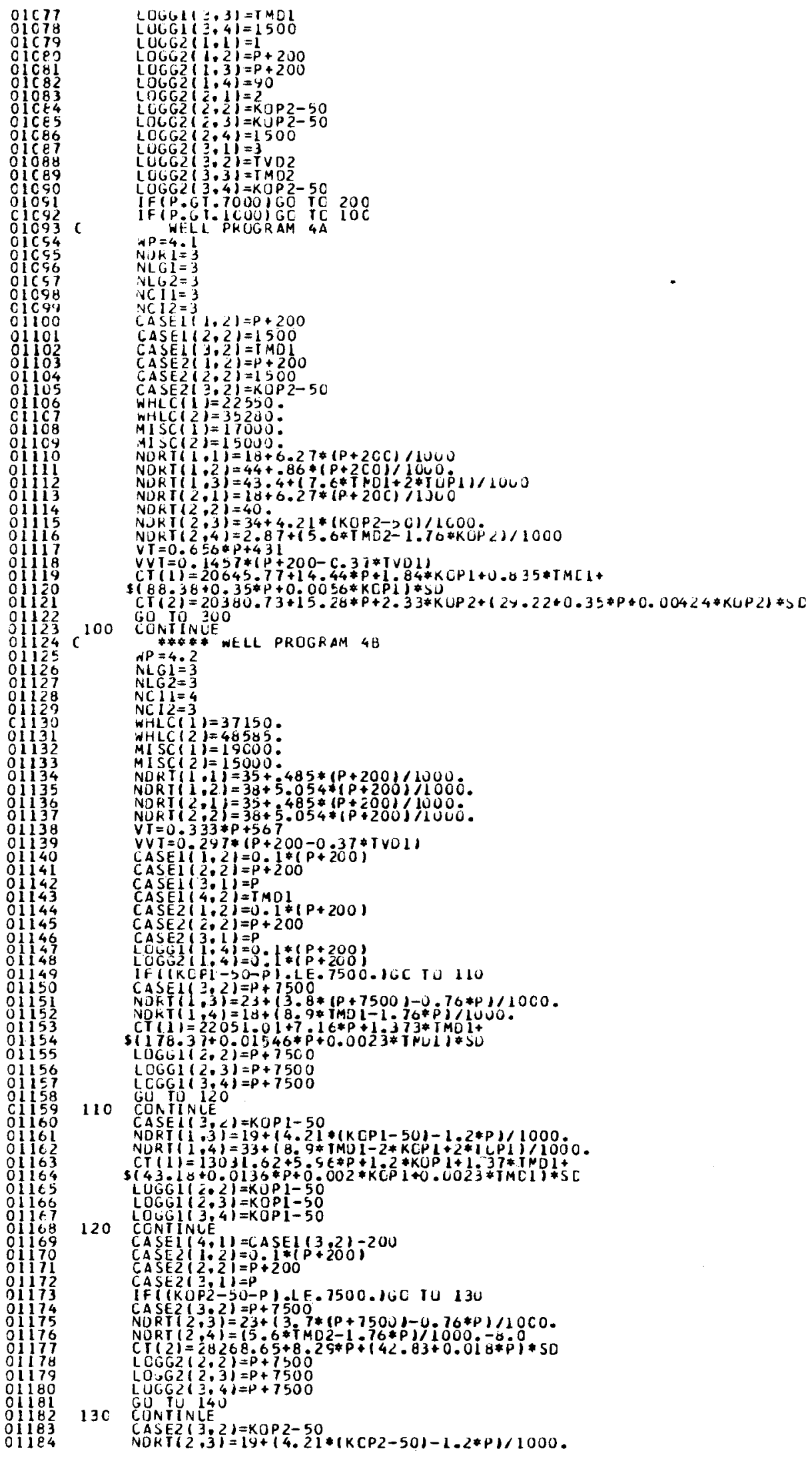




\section{RGICOST (cont)}

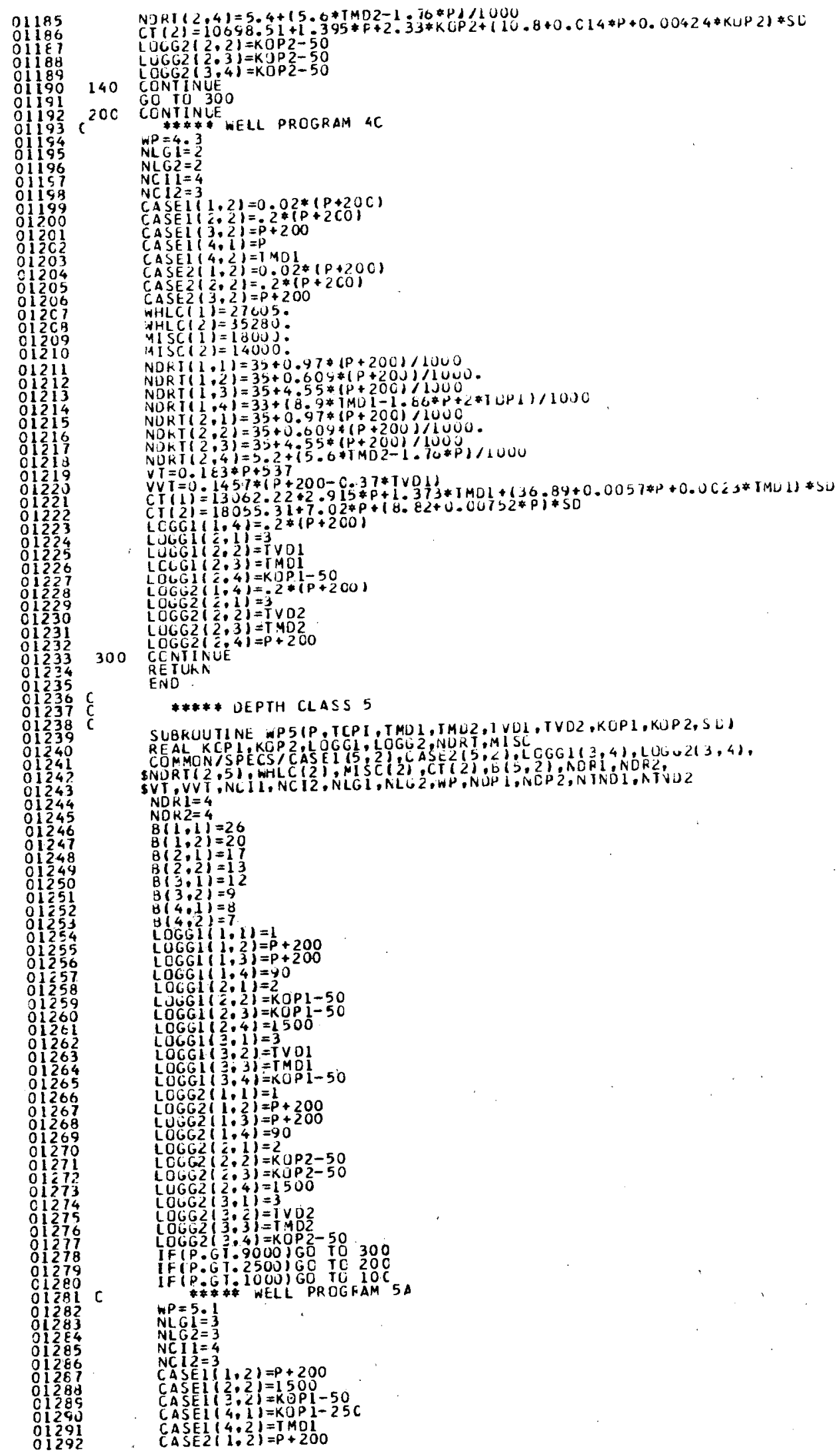


RGICOST (cont)

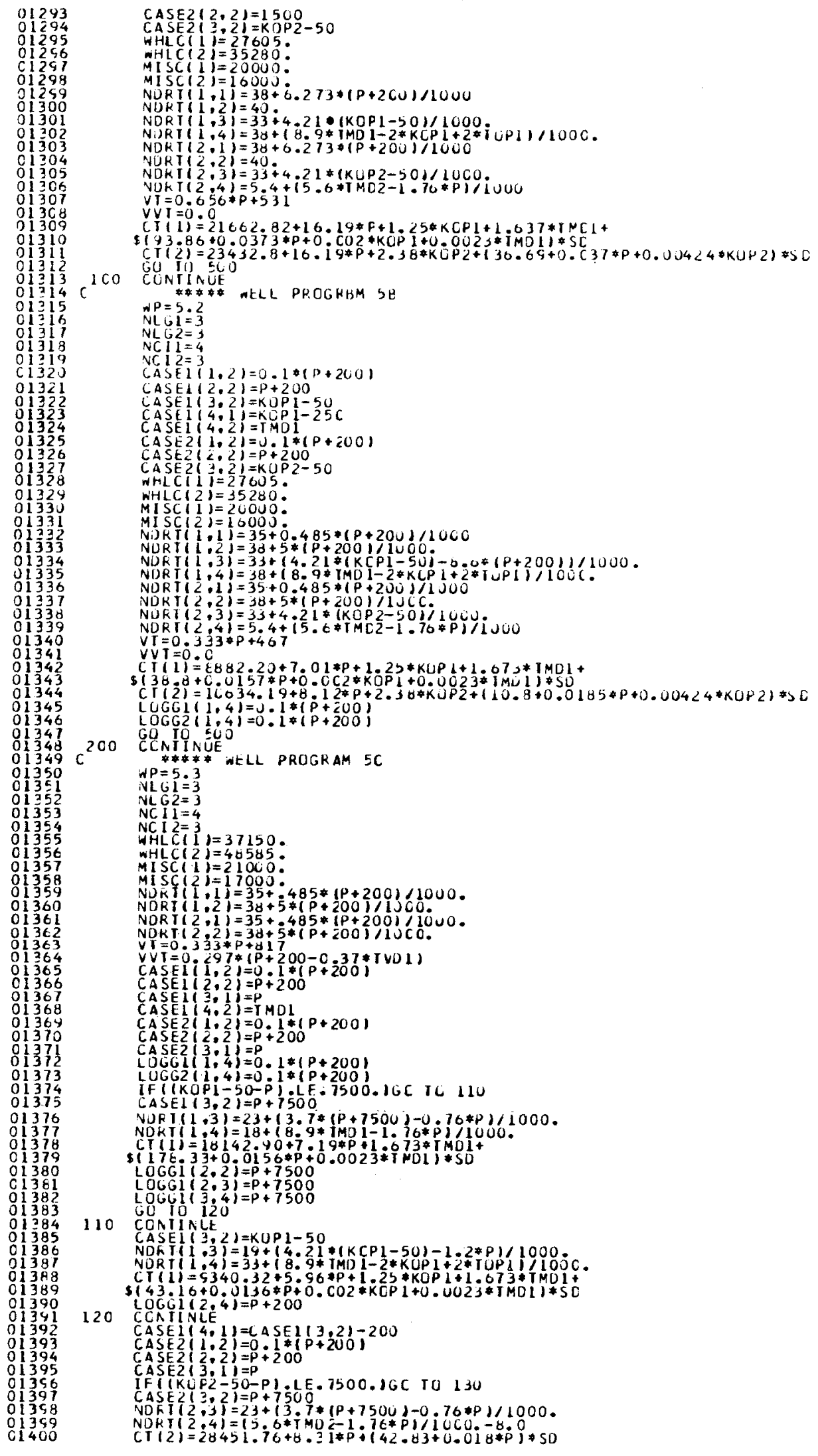




\section{RGICOST (cont)}

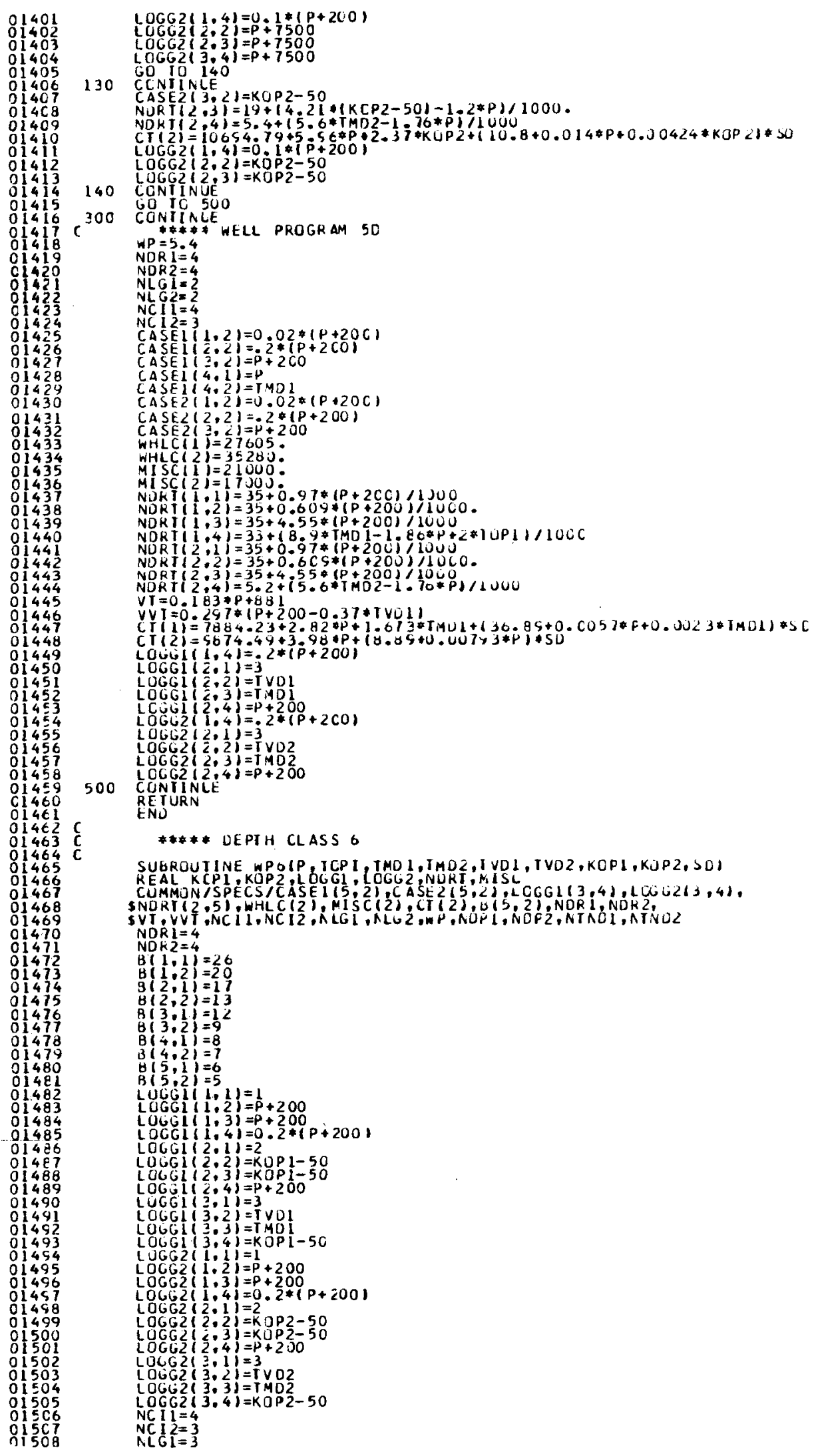




\section{RGICOST (cont)}

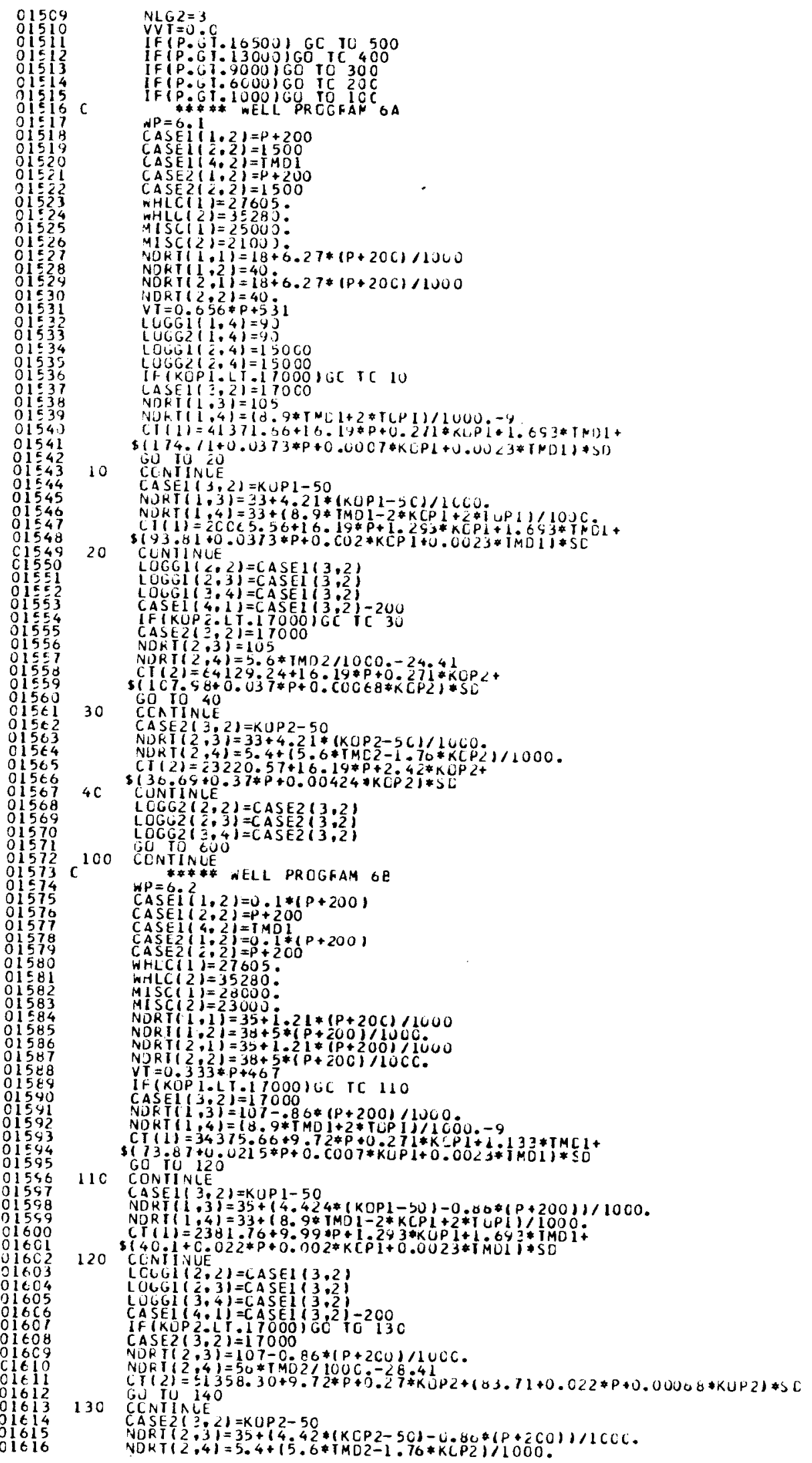




\section{RGICOST (cont)}

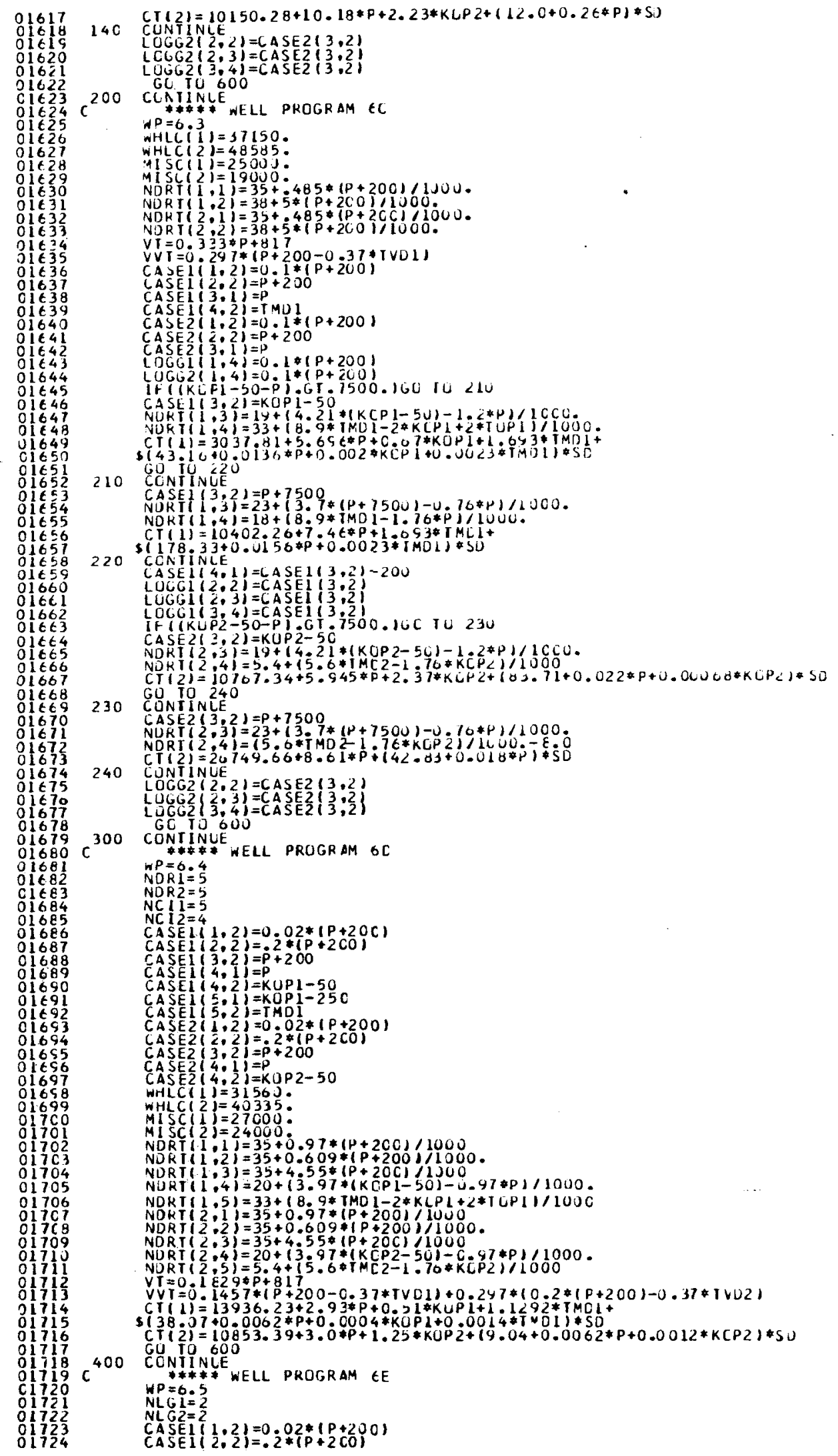


RGICOST (cont)

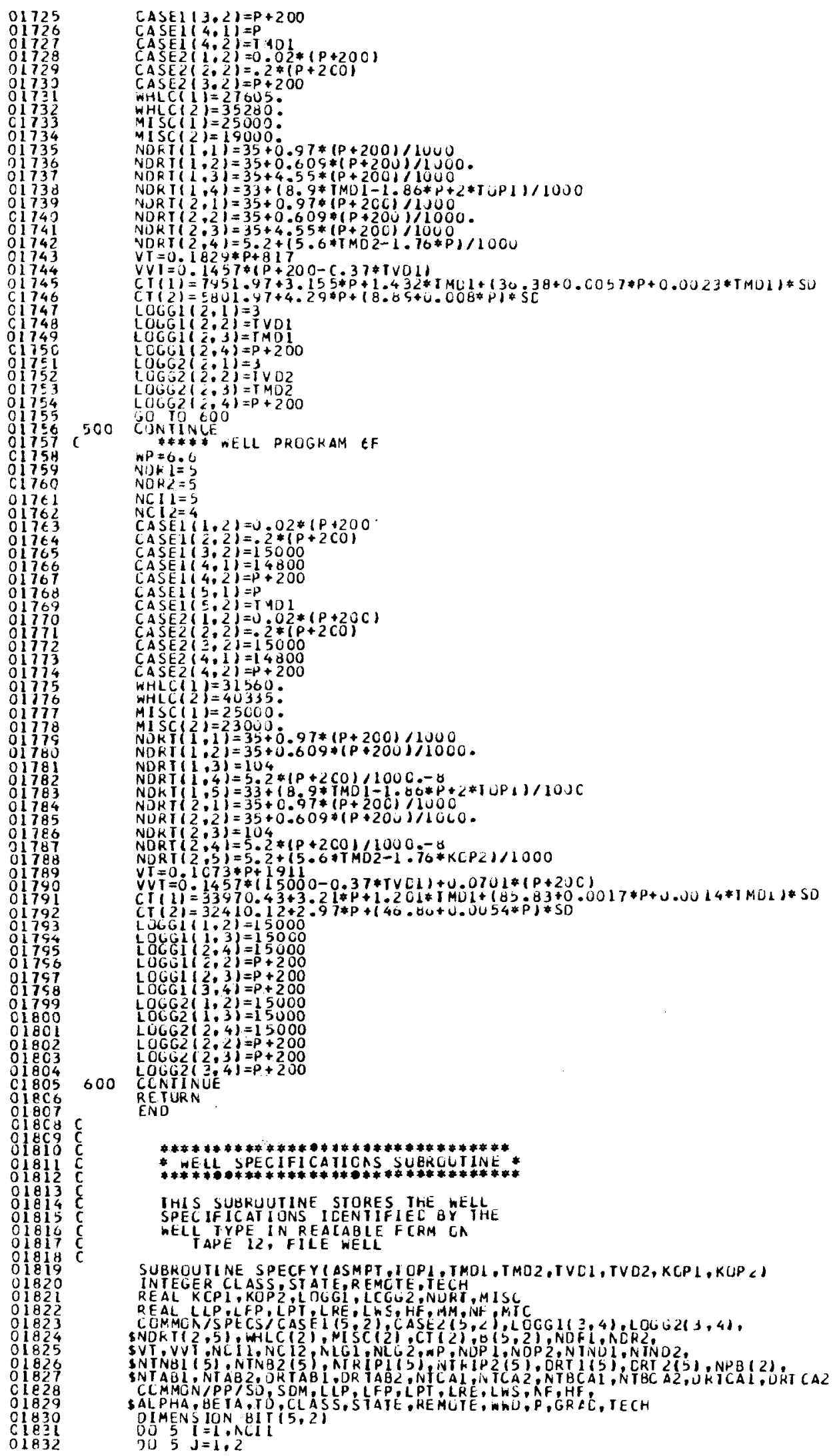




\section{RGICOST (cont)}

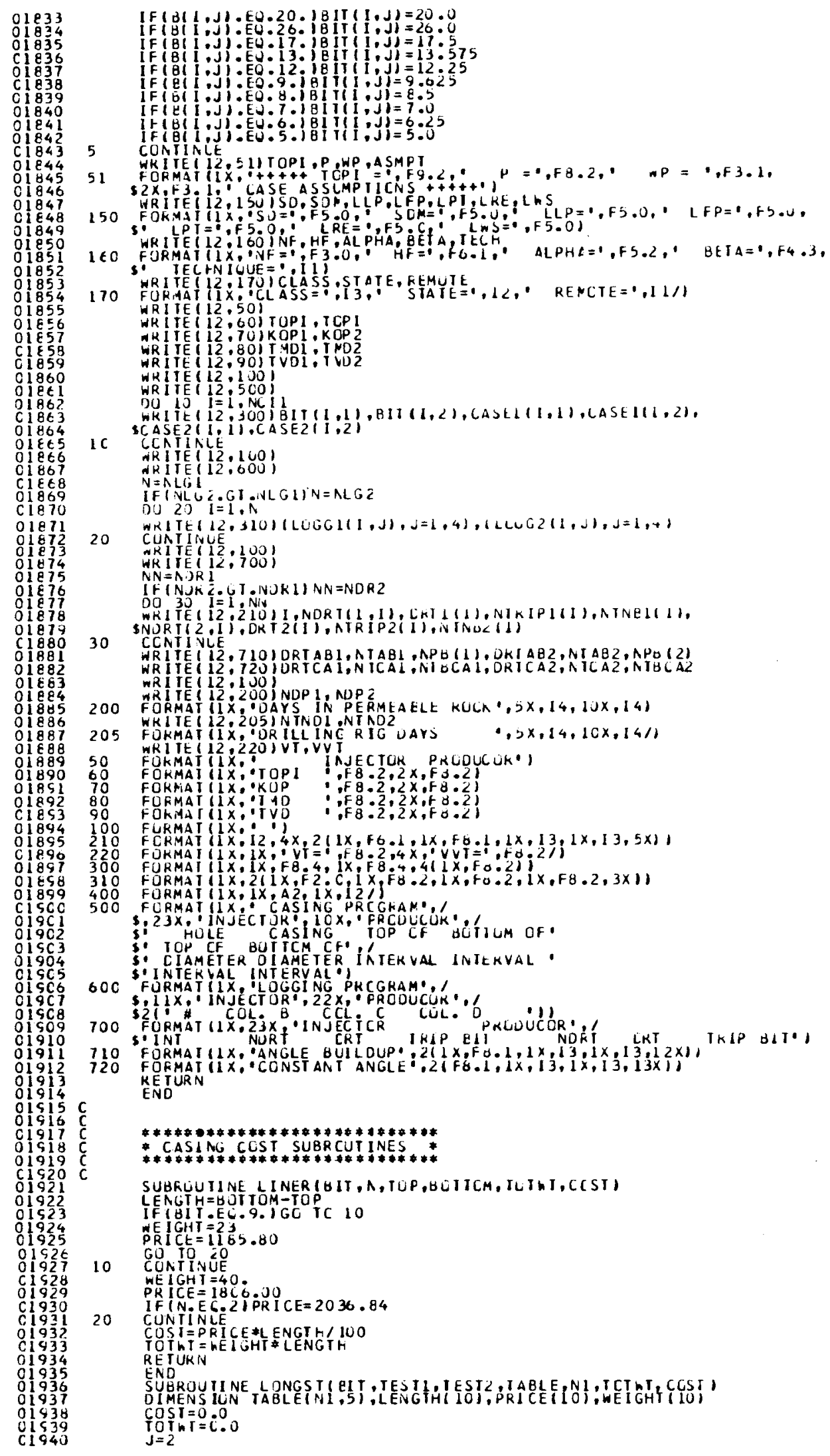




\section{RGI COST (cont)}

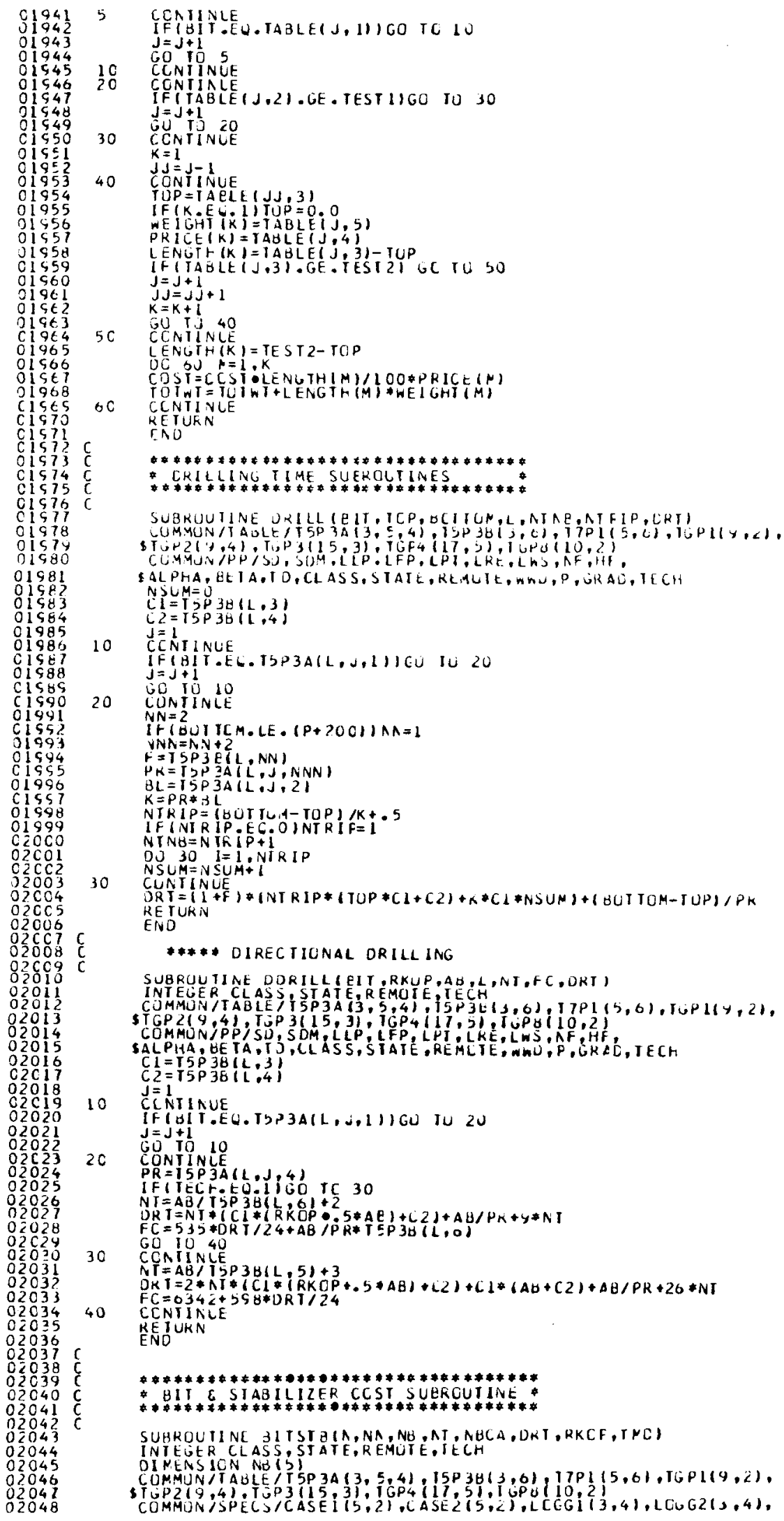




\section{RGICOST (cont)}

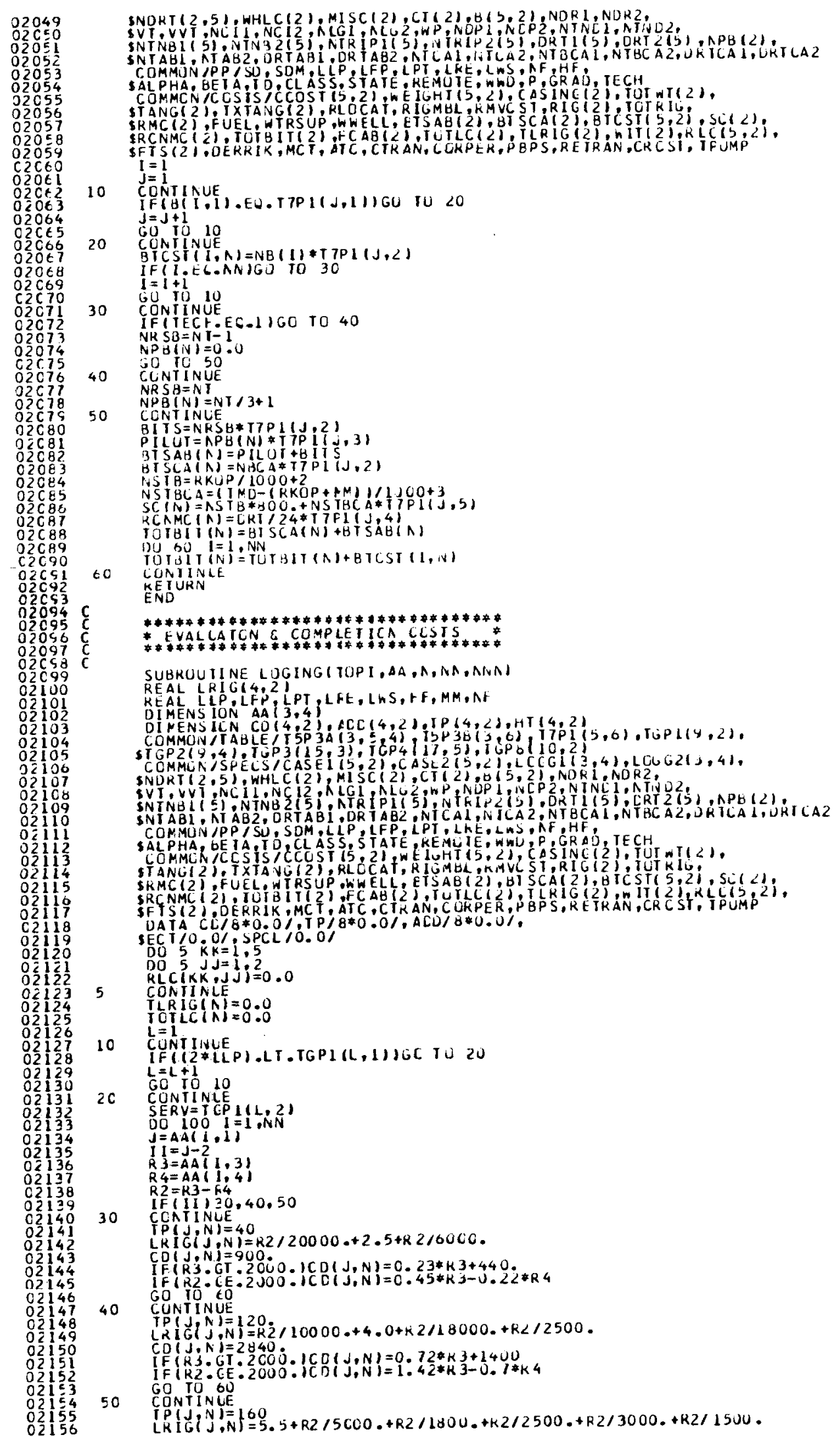




\section{RGICOST (cont)}

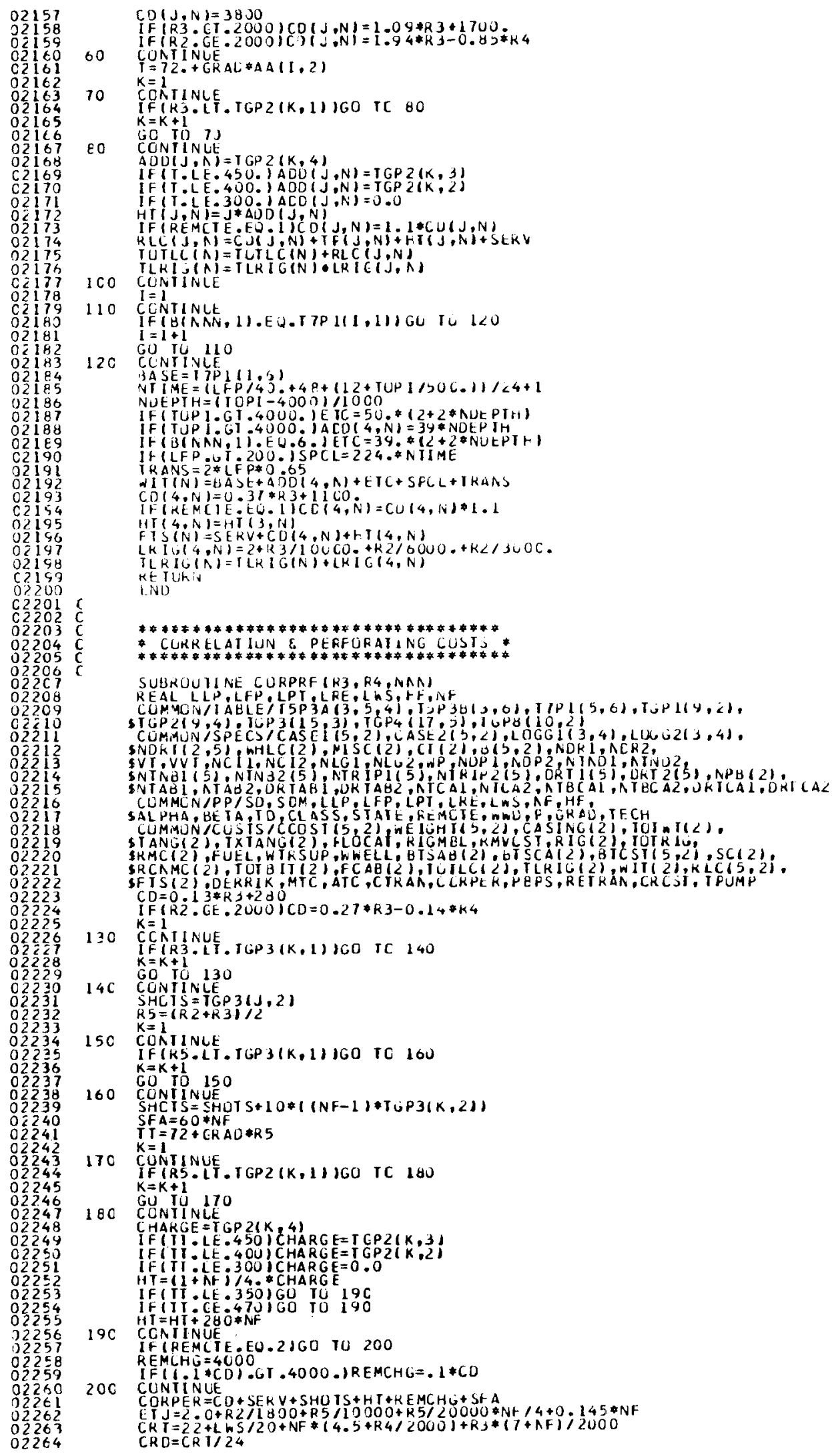




\section{RGICOST (cont)}

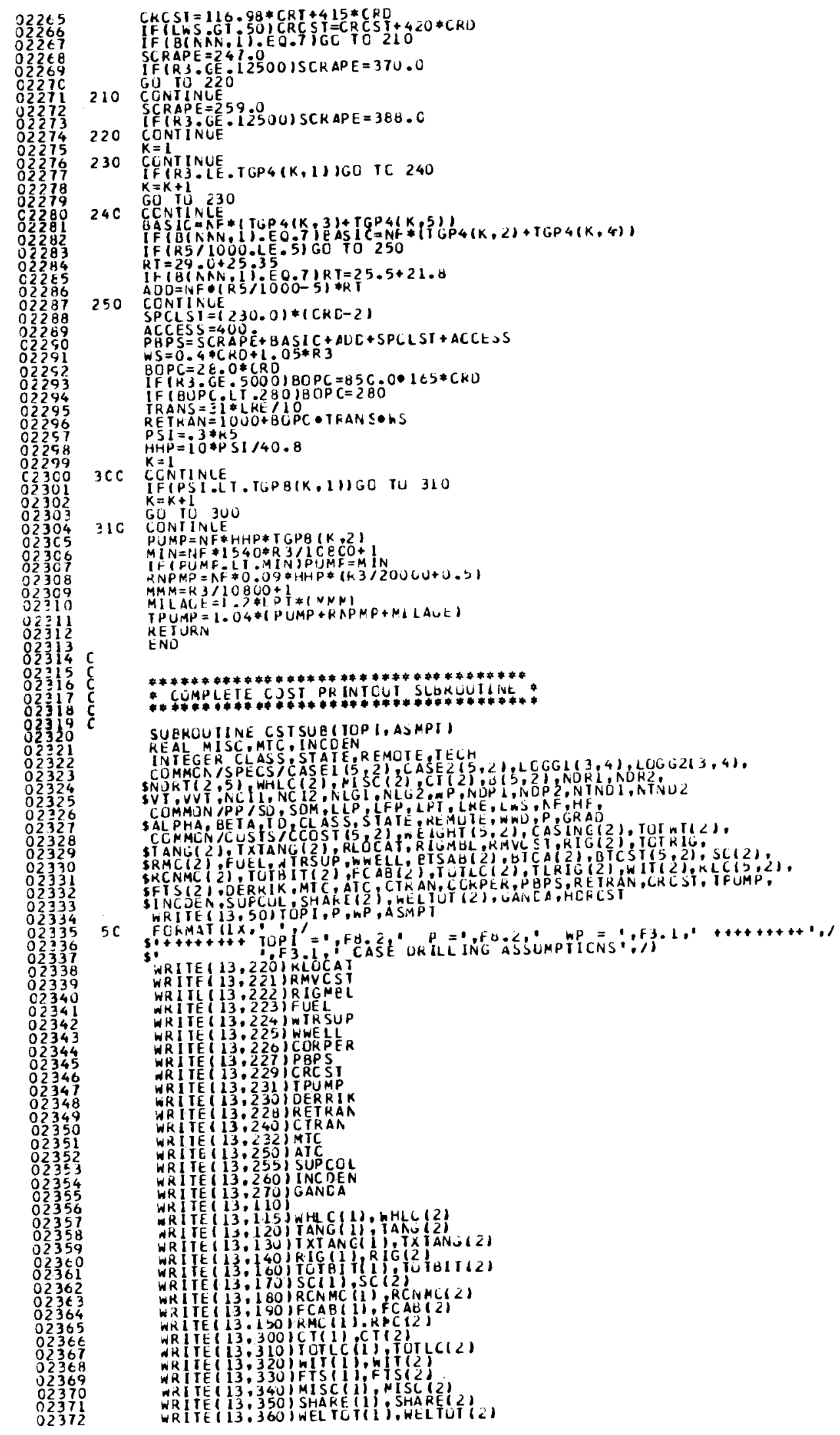


RGICOST (cont)

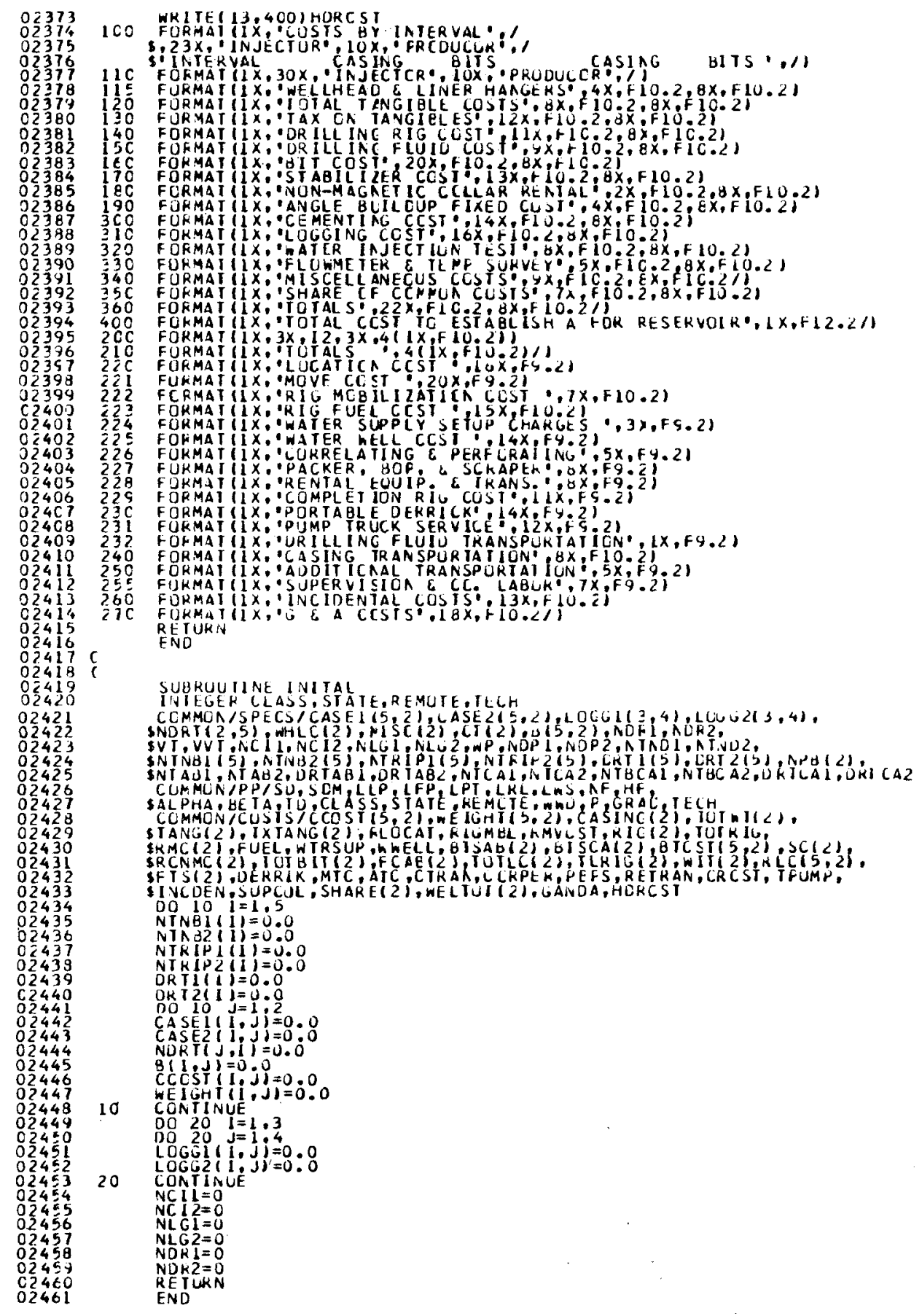




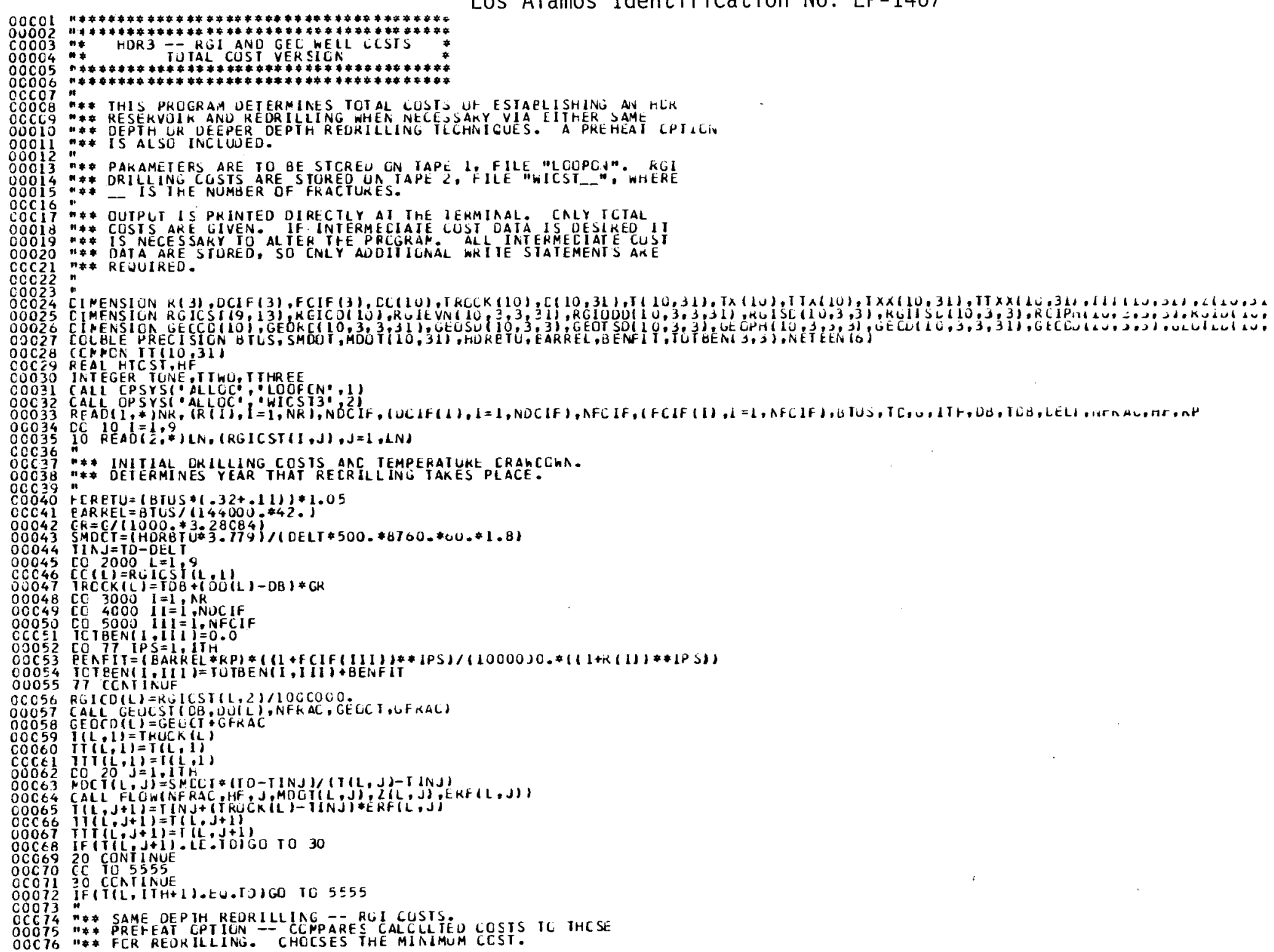

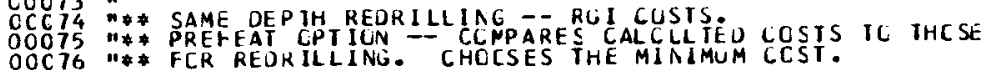




\section{HDR3 (cont)}

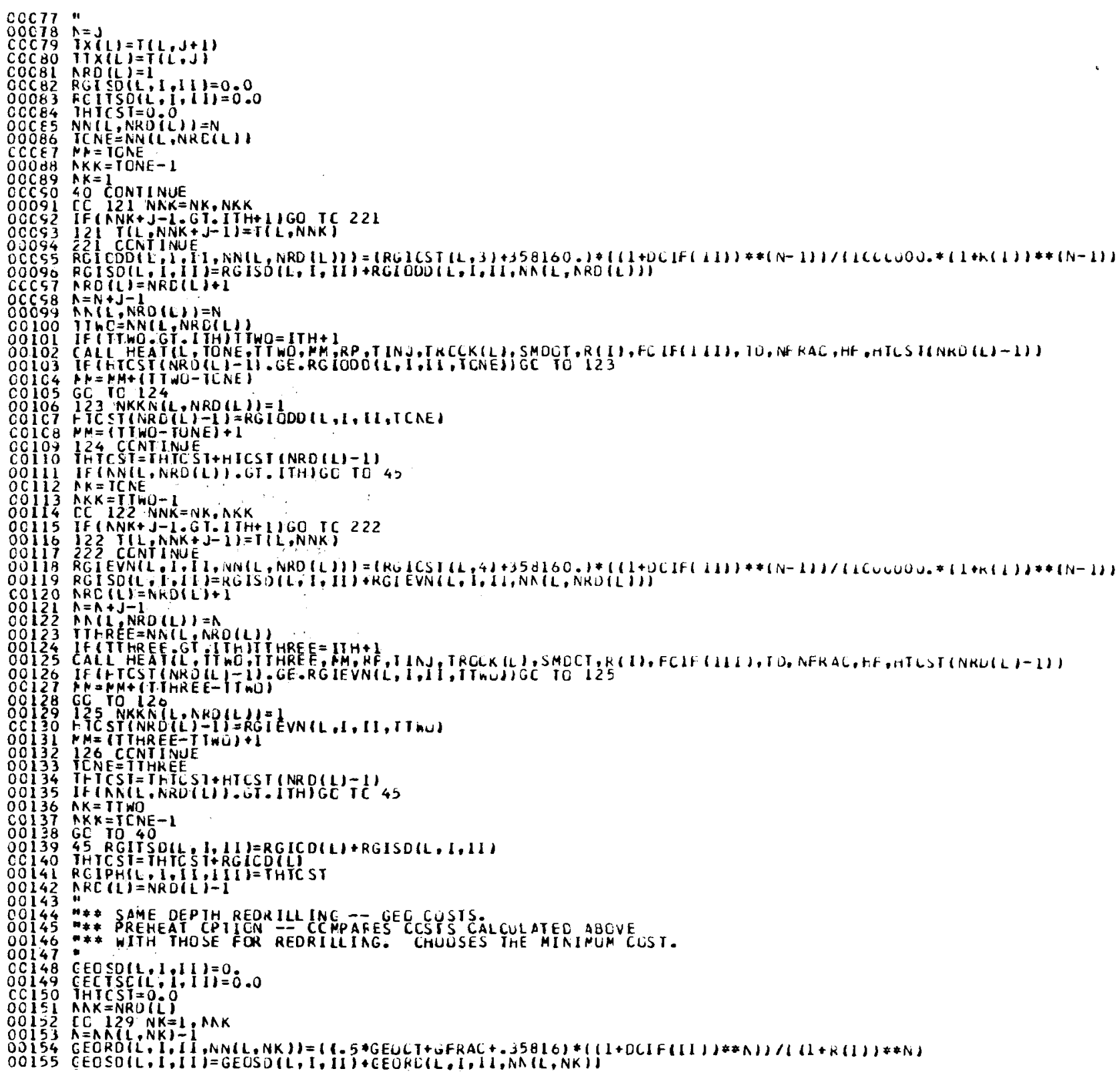




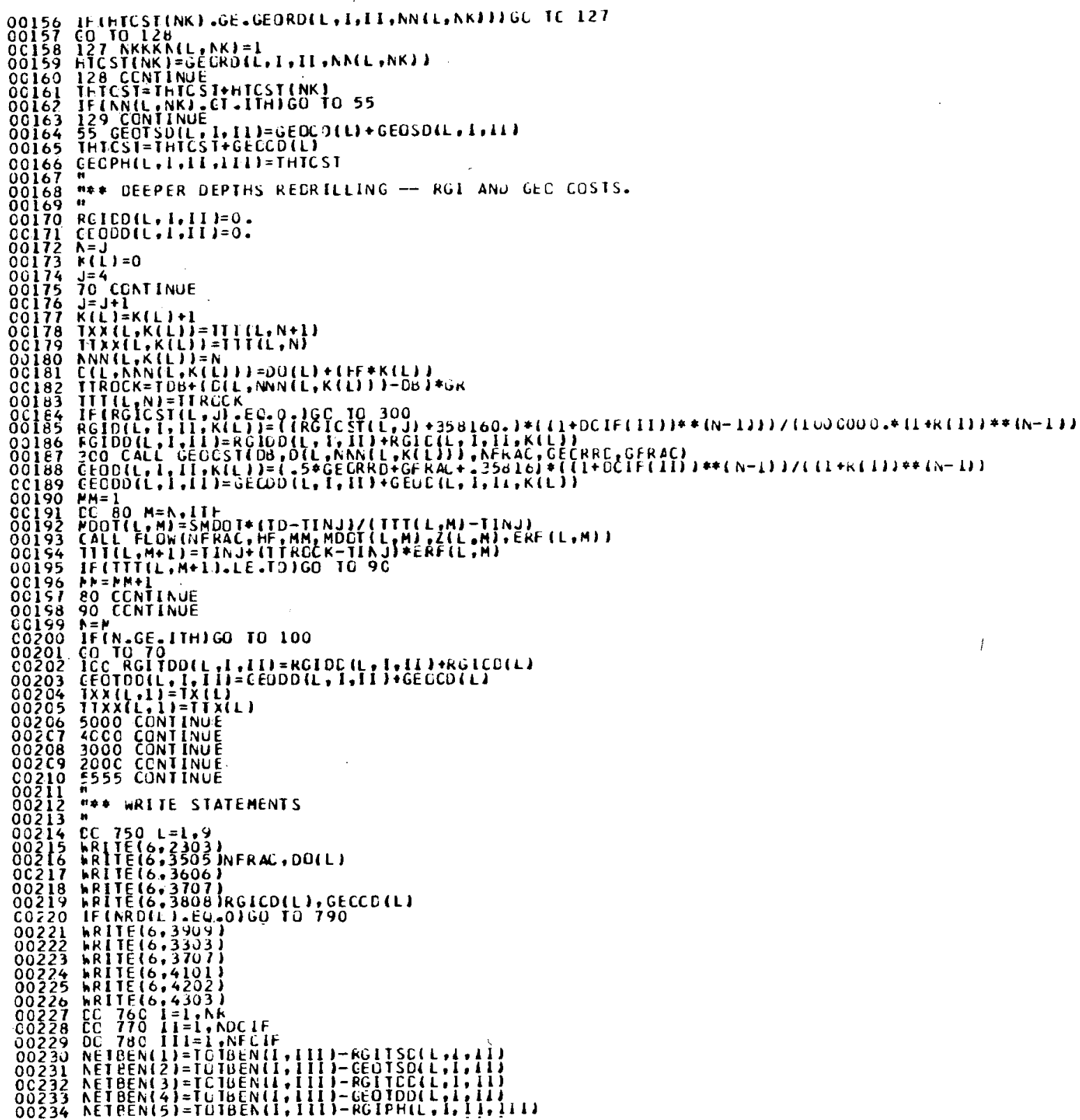




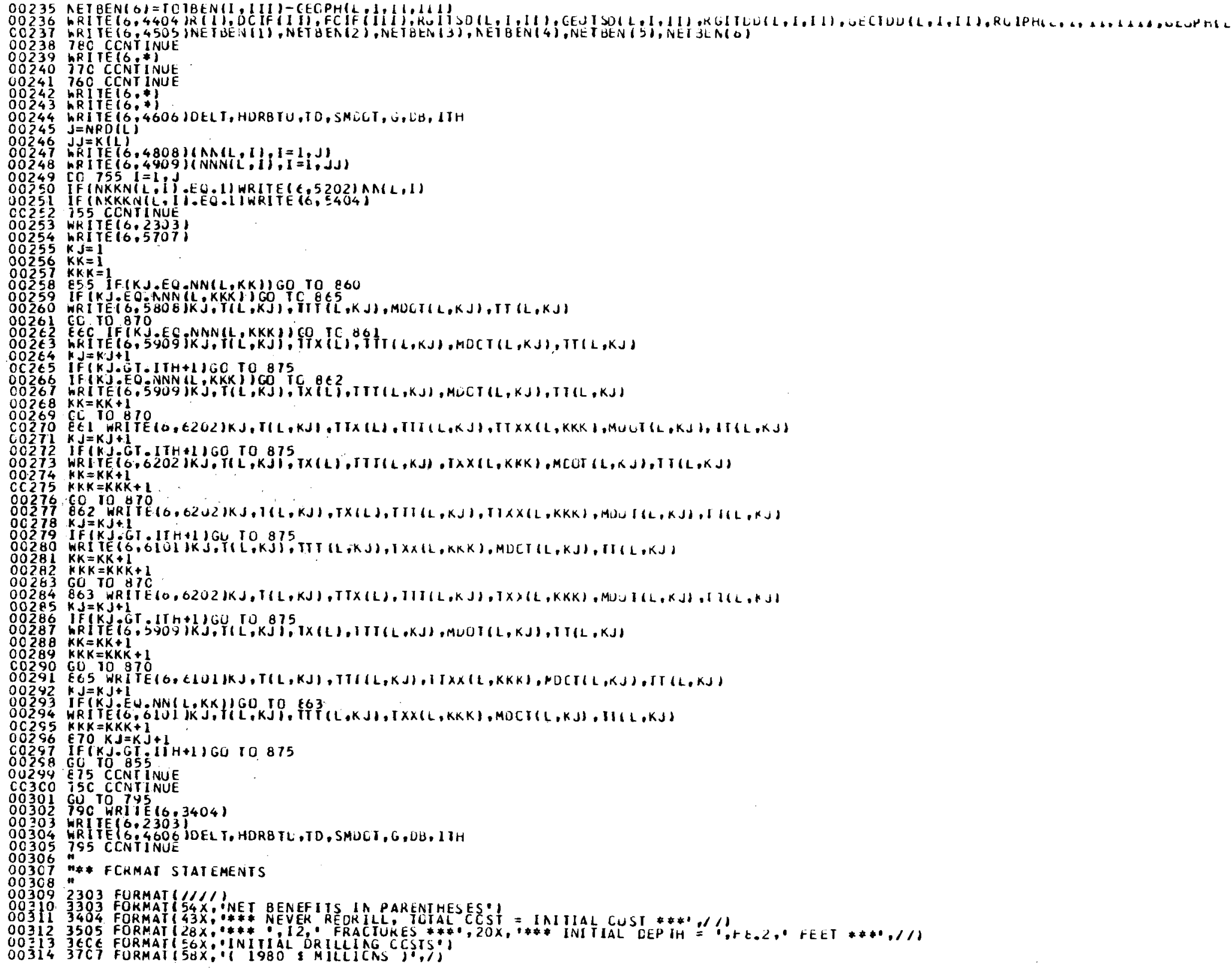

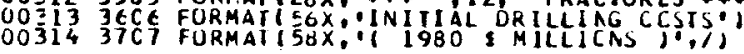




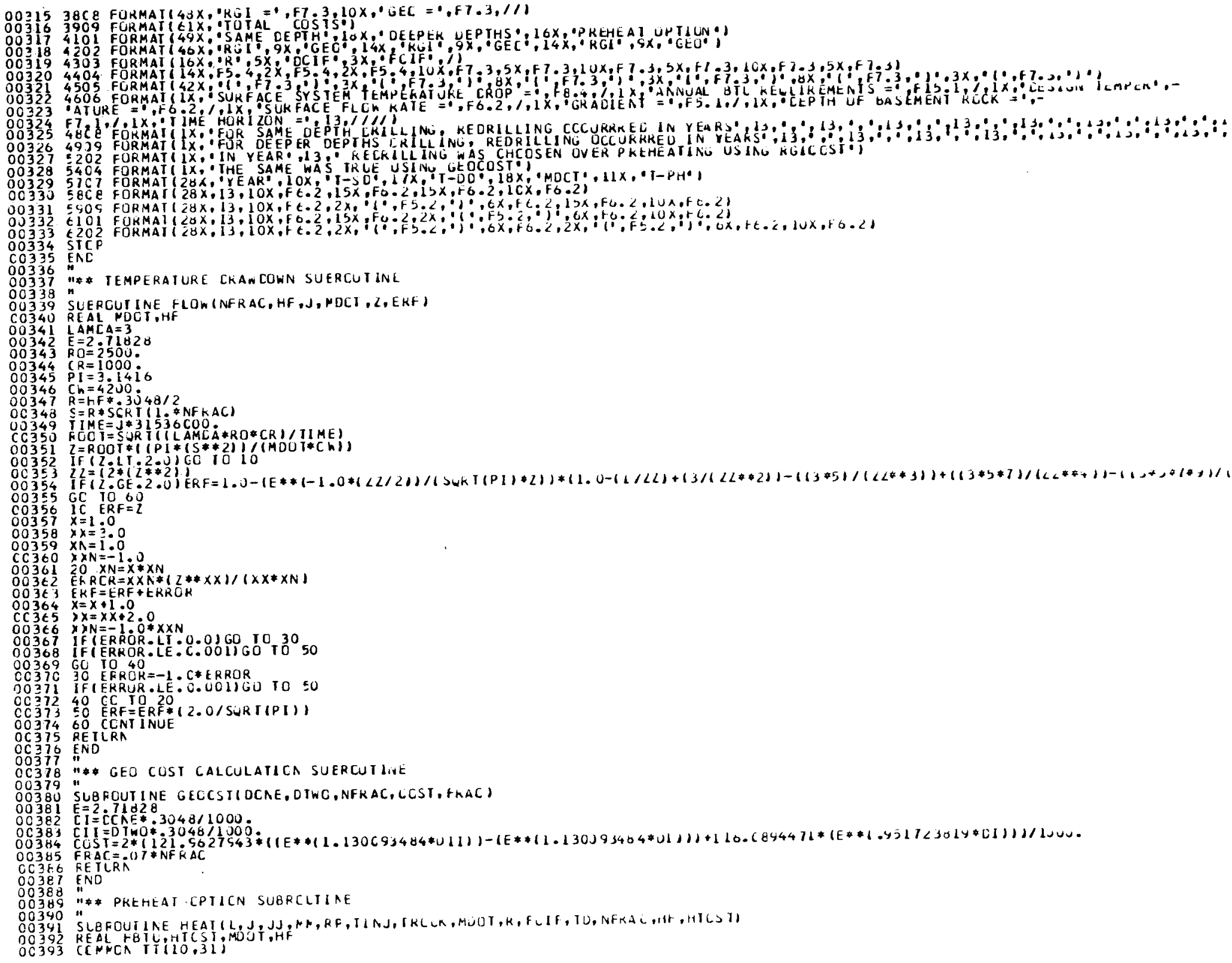


HDR3 (cont)

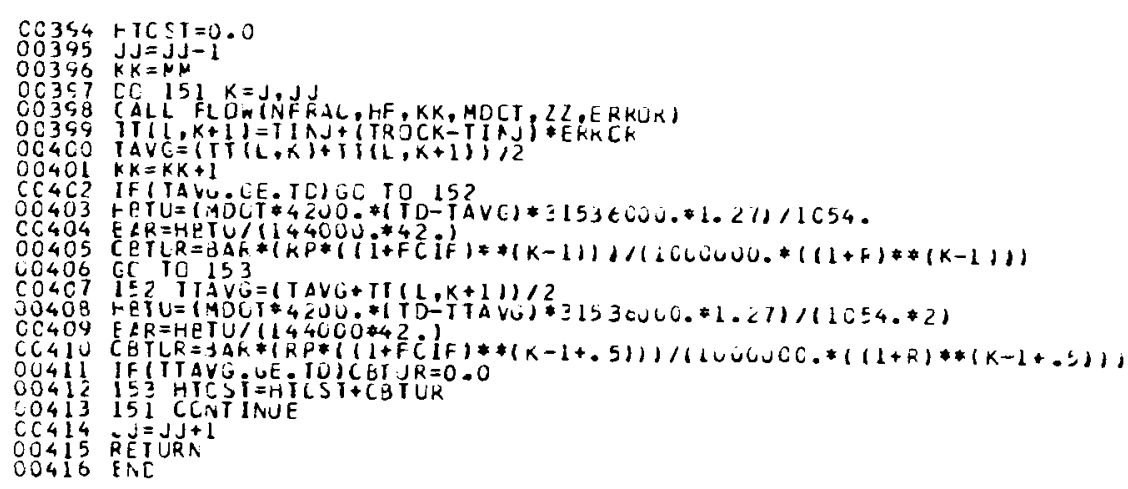




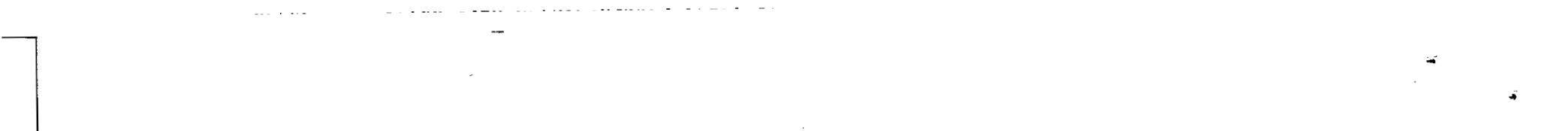

7 